\title{
Securinega alkaloids of Securinega suffruticosa and their biological activities
}

Kyoung Jin Park, ${ }^{\dagger}$ Chung Sub Kim, ${ }^{\dagger}$ Zahra Khan, ${ }^{\ddagger}, \S$ Joonseok Oh, ${ }^{\perp}, \|$ Sun Yeou Kim, ${ }^{\ddagger}, \S$ Sang Un Choi,, Kang Ro Lee ${ }^{*}, \dagger$

†Natural Products Laboratory, School of Pharmacy, Sungkyunkwan University, Suwon 16419, Republic of Korea

${ }^{\ddagger}$ Gachon Institute of Pharmaceutical Science, Gachon University, Incheon 21936, Republic of Korea

${ }^{\S}$ College of Pharmacy, Gachon University, \#191, Hambakmoero, Yeonsu-gu, Incheon 21936, Republic of Korea

${ }^{\perp}$ Department of Chemistry, Yale University, New Haven, Connecticut 06520, United States $\|_{\text {Chemical Biology Institute, Yale University, West Haven, Connecticut 06516, United States }}$ ${ }^{\nabla}$ Korea Research Institute of Chemical Technology, Daejeon 34114, Republic of Korea 


\section{Contents}

Figure S1. The HRESIMS spectrum of $\mathbf{1}$.

Figure S2. The ${ }^{1} \mathrm{H}$ NMR spectrum of 1 in DMSO- $d_{6}$.

Figure S3. The ${ }^{13} \mathrm{C}$ NMR spectrum of 1 in DMSO- $d_{6}$.

Figure S4. The COSY spectrum of 1 in DMSO- $d_{6}$.

Figure S5. The HSQC spectrum of 1 in DMSO- $d_{6}$.

Figure S6. The HMBC spectrum of 1 in DMSO- $d_{6}$.

Figure S7. The NOESY spectrum of 1 in DMSO- $d_{6}$.

Figure S8. The ${ }^{1} \mathrm{H}$ NMR spectrum of 1 in chloroform- $d$.

Figure S9. The ${ }^{13} \mathrm{C}$ NMR spectrum of 1 in chloroform- $d$.

Figure S10. The HRESIMS spectrum of 2.

Figure S11. The ${ }^{1} \mathrm{H}$ NMR spectrum of $\mathbf{2}$ in chloroform- $d$.

Figure S12. The ${ }^{13} \mathrm{C}$ NMR spectrum of $\mathbf{2}$ in chloroform- $d$.

Figure S13. The COSY spectrum of $\mathbf{2}$ in chloroform- $d$.

Figure S14. The HSQC spectrum of $\mathbf{2}$ in chloroform- $d$.

Figure S15. The HMBC spectrum of $\mathbf{2}$ in chloroform- $d$.

Figure S16. The NOESY spectrum of 2 in chloroform- $d$.

Figure S17. The HRESIMS spectrum of $\mathbf{3}$.

Figure S18. The ${ }^{1} \mathrm{H}$ NMR spectrum of $\mathbf{3}$ in chloroform- $d$.

Figure S19. The ${ }^{13} \mathrm{C}$ NMR spectrum of $\mathbf{3}$ in chloroform- $d$.

Figure S20. The COSY spectrum of $\mathbf{3}$ in chloroform- $d$.

Figure S21. The HSQC spectrum of $\mathbf{3}$ in chloroform- $d$.

Figure S22. The HMBC spectrum of $\mathbf{3}$ in chloroform- $d$.

Figure S23. The NOESY spectrum of $\mathbf{3}$ in chloroform- $d$.

Figure S24. The HRESIMS spectrum of 4.

Figure S25. The ${ }^{1} \mathrm{H}$ NMR spectrum of $\mathbf{4}$ in chloroform- $d$.

Figure S26. The ${ }^{13} \mathrm{C}$ NMR spectrum of $\mathbf{4}$ in chloroform- $d$.

Figure S27. The COSY spectrum of $\mathbf{4}$ in chloroform- $d$.

Figure S28. The HSQC spectrum of $\mathbf{4}$ in chloroform- $d$.

Figure S29. The HMBC spectrum of $\mathbf{4}$ in chloroform- $d$.

Figure S30. The ${ }^{1} \mathrm{H}$ NMR spectrum of 4 in DMSO- $d_{6}$.

Figure S31. The NOESY spectrum of 4 in DMSO- $d_{6}$.

Figure S32. The HRESIMS spectrum of $\mathbf{5}$.

Figure S33. The ${ }^{1} \mathrm{H}$ NMR spectrum of 5 in chloroform- $d$.

Figure S34. The ${ }^{13} \mathrm{C}$ NMR spectrum of 5 in chloroform- $d$.

Figure S35. The COSY spectrum of 5 in chloroform- $d$.

Figure S36. The HSQC spectrum of 5 in chloroform- $d$.

Figure S37. The HMBC spectrum of 5 in chloroform- $d$.

Figure S38. The NOESY spectrum of 5 in chloroform- $d$.

Figure S39. The HRESIMS spectrum of $\mathbf{6}$.

Figure S40. The ${ }^{1} \mathrm{H}$ NMR spectrum of 6 in chloroform- $d$.

Figure S41. The ${ }^{13} \mathrm{C}$ NMR spectrum of 6 in chloroform- $d$.

Figure S42. The COSY spectrum of 6 in chloroform- $d$.

Figure S43. The HSQC spectrum of 6 in chloroform- $d$.

Figure S44. The HMBC spectrum of 6 in chloroform- $d$.

Figure S45. The NOESY spectrum of 6 in chloroform- $d$.

Figure S46. The experimental ECD spectrum of $\mathbf{6}$.

Figure S47. The HRESIMS spectrum of 7.

Figure S48. The ${ }^{1} \mathrm{H}$ NMR spectrum of 7 in chloroform- $d$. 
Figure S49. The ${ }^{13} \mathrm{C}$ NMR spectrum of 7 in chloroform- $d$.

Figure S50. The COSY spectrum of 7 in chloroform- $d$.

Figure S51. The HSQC spectrum of 7 in chloroform- $d$.

Figure S52. The HMBC spectrum of 7 in chloroform- $d$.

Figure S53. The ${ }^{1} \mathrm{H}$ NMR spectrum of 8 in chloroform- $d$.

Figure S54. The ${ }^{13} \mathrm{C}$ NMR spectrum of 8 in chloroform- $d$.

Figure S55. The COSY spectrum of $\mathbf{8}$ in chloroform- $d$.

Figure S56. The HSQC spectrum of 8 in chloroform- $d$.

Figure S57. The HMBC spectrum of 8 in chloroform- $d$.

Figure S58. Experimental and calculated ECD spectra of 8.

Figure S59. The chemical structures of 1a-1d.

Figure S60. The 3D structures of the conformers of 1a-1d.

Table S1. Experimental (Exp.) and calculated (Cal.) ${ }^{1} \mathrm{H}$ and ${ }^{13} \mathrm{C}$ chemical shift values of 1 and its possible isomers $\mathbf{1 a - 1 d}$ used for DP4+ analysis.

Figure S61. Results of DP4+ analysis of 1.

Table S2. Experimental (Exp.) and calculated (Cal.) ${ }^{1} \mathrm{H}$ and ${ }^{13} \mathrm{C}$ chemical shift values of 7 and its possible isomers $\mathbf{7 a}$ and $\mathbf{7 b}$ used for DP4+ analysis.

Figure S62. Results of DP4+ analysis of 7.

Table S3. Boltzmann populations of the identified conformers of $\mathbf{7 a}$ and $\mathbf{7 b}$. 
Figure S1. The HRESIMS spectrum of $\mathbf{1}$.

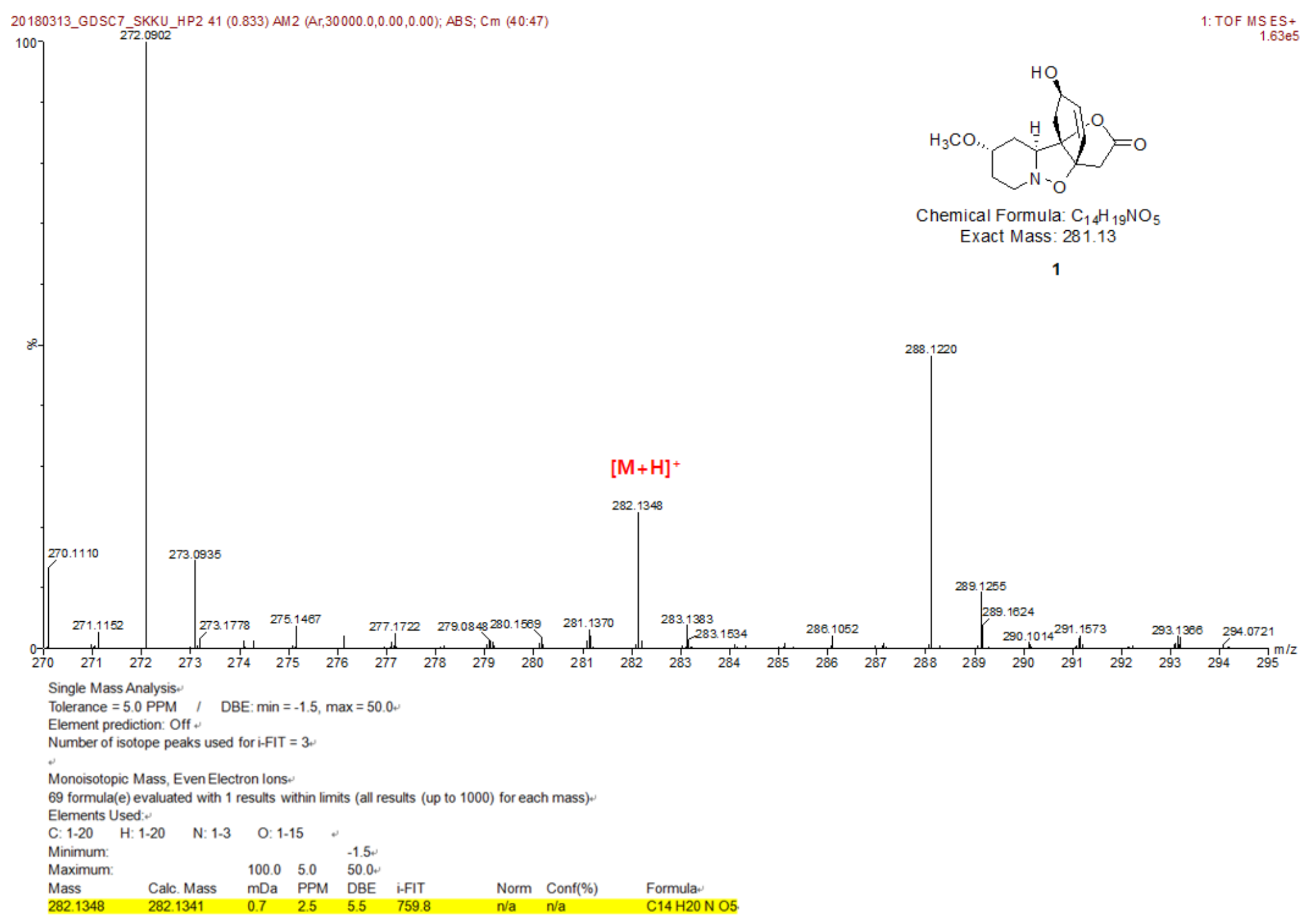


Figure S2. The ${ }^{1} \mathrm{H}$ NMR spectrum of $\mathbf{1}$ in DMSO- $d_{6}$.

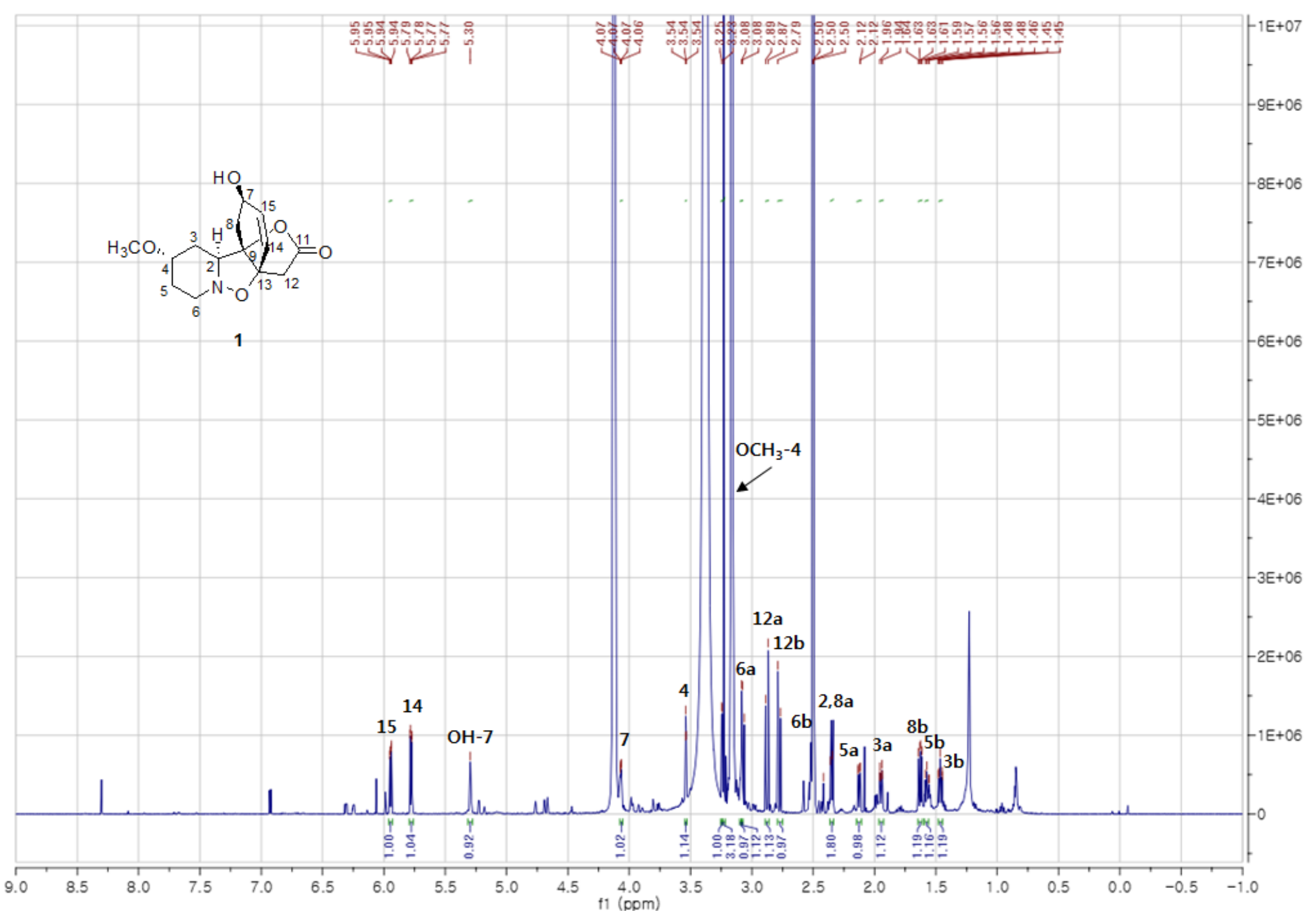


Figure S3. The ${ }^{13} \mathrm{C}$ NMR spectrum of $\mathbf{1}$ in DMSO- $d_{6}$.

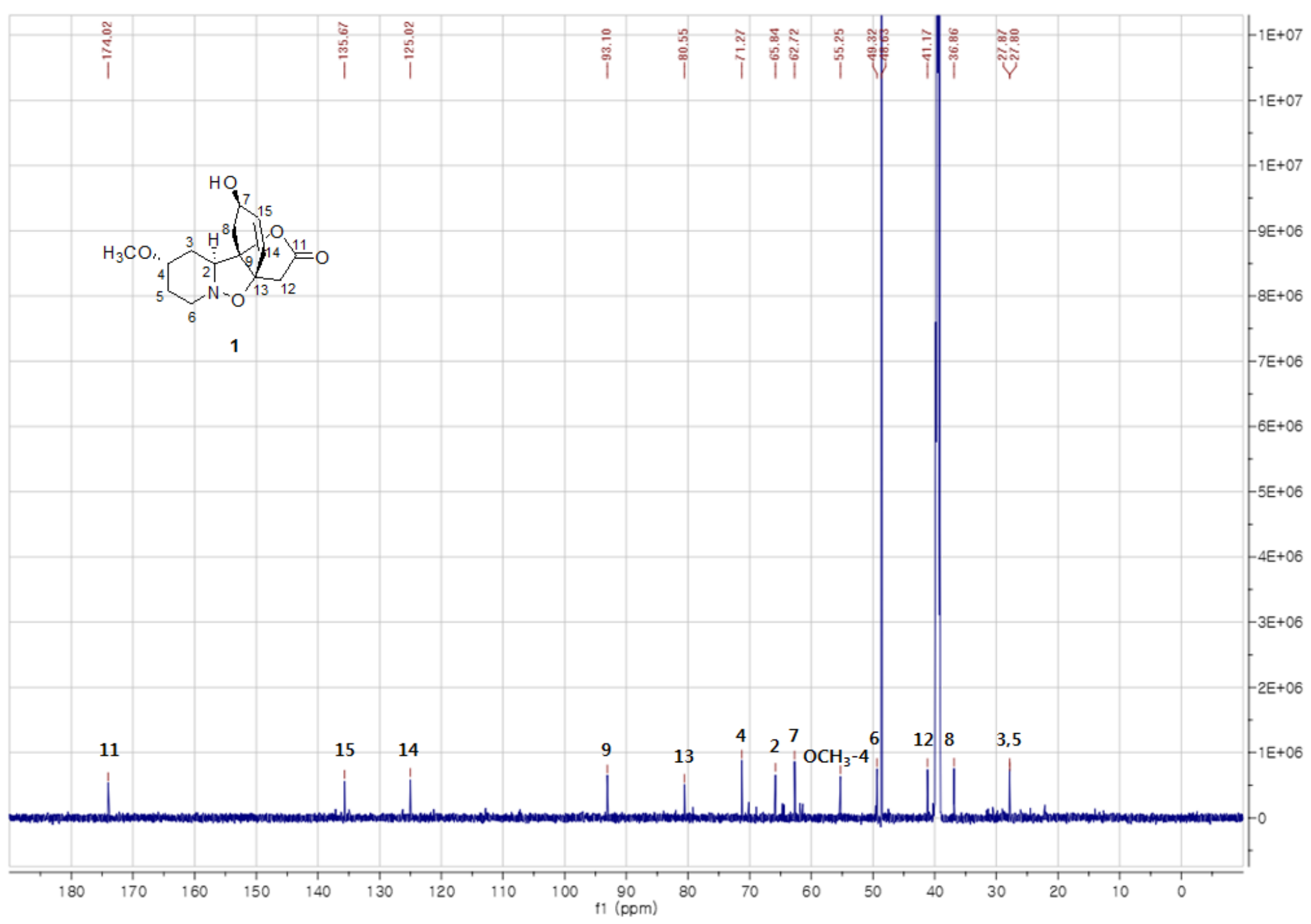


Figure S4. The COSY spectrum of 1 in DMSO- $d_{6}$.

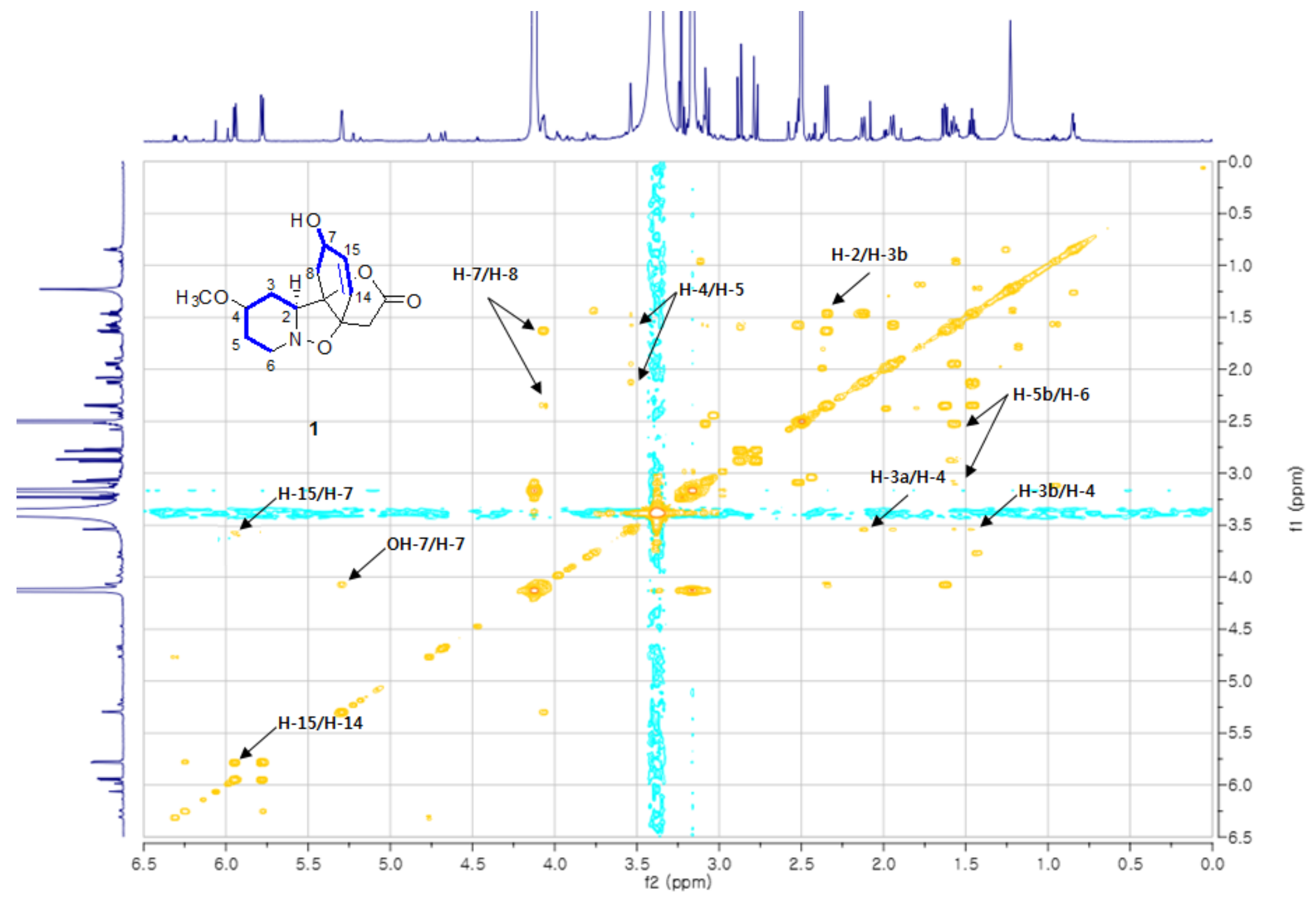


Figure S5. The HSQC spectrum of 1 in DMSO- $d_{6}$.

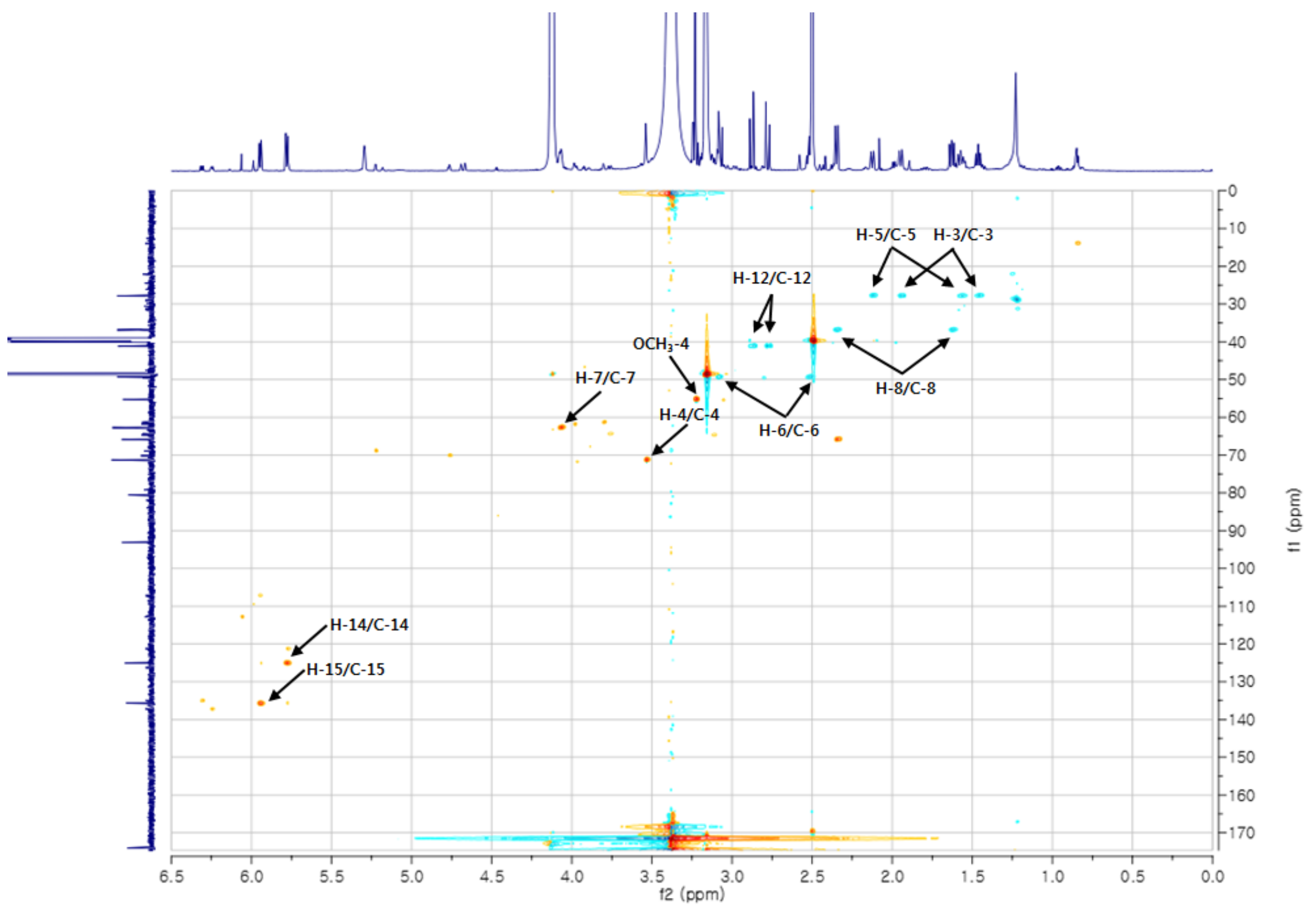


Figure S6. The HMBC spectrum of 1 in DMSO- $d_{6}$.

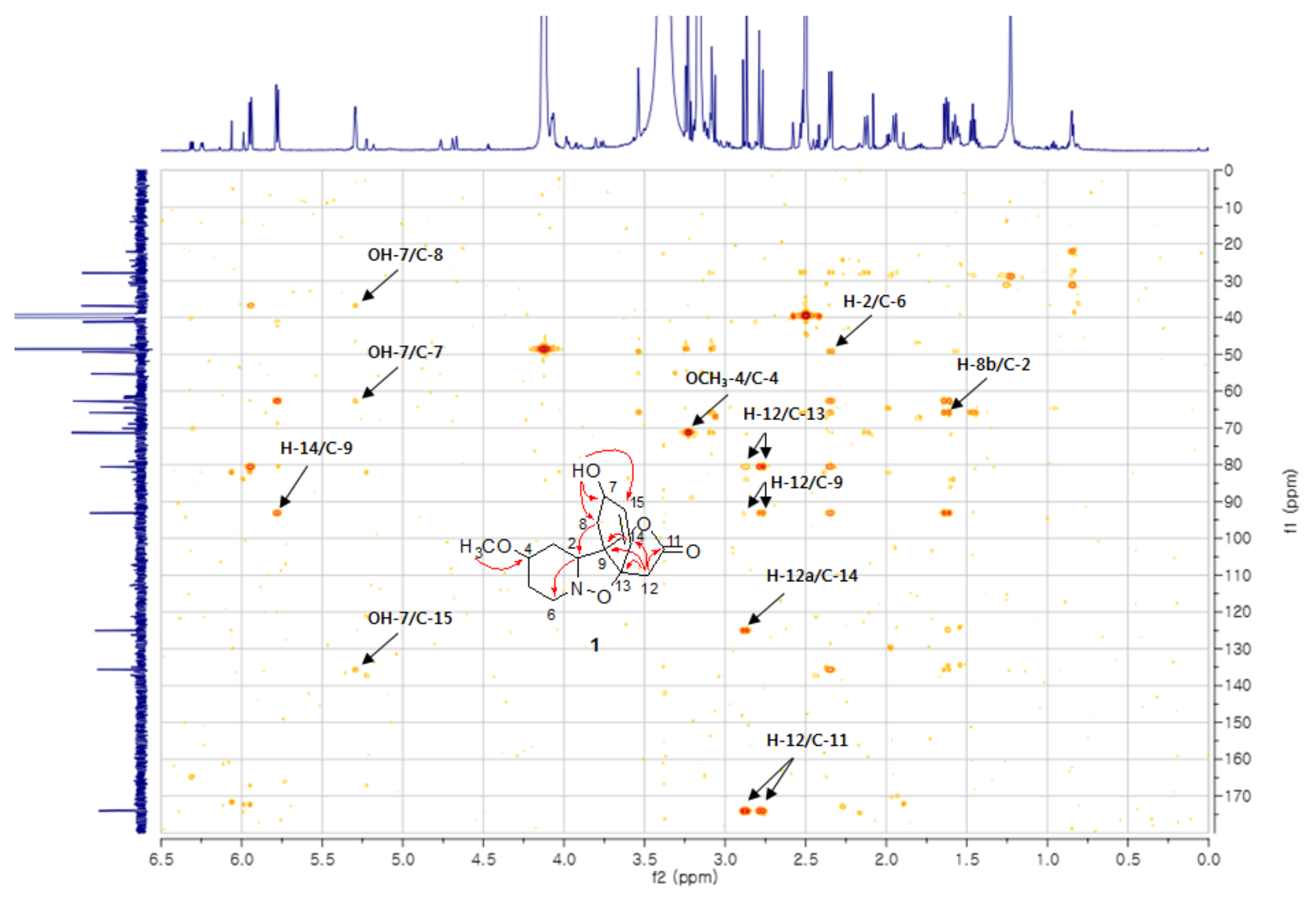


Figure S7. The NOESY spectrum of $\mathbf{1}$ in DMSO- $d_{6}$.

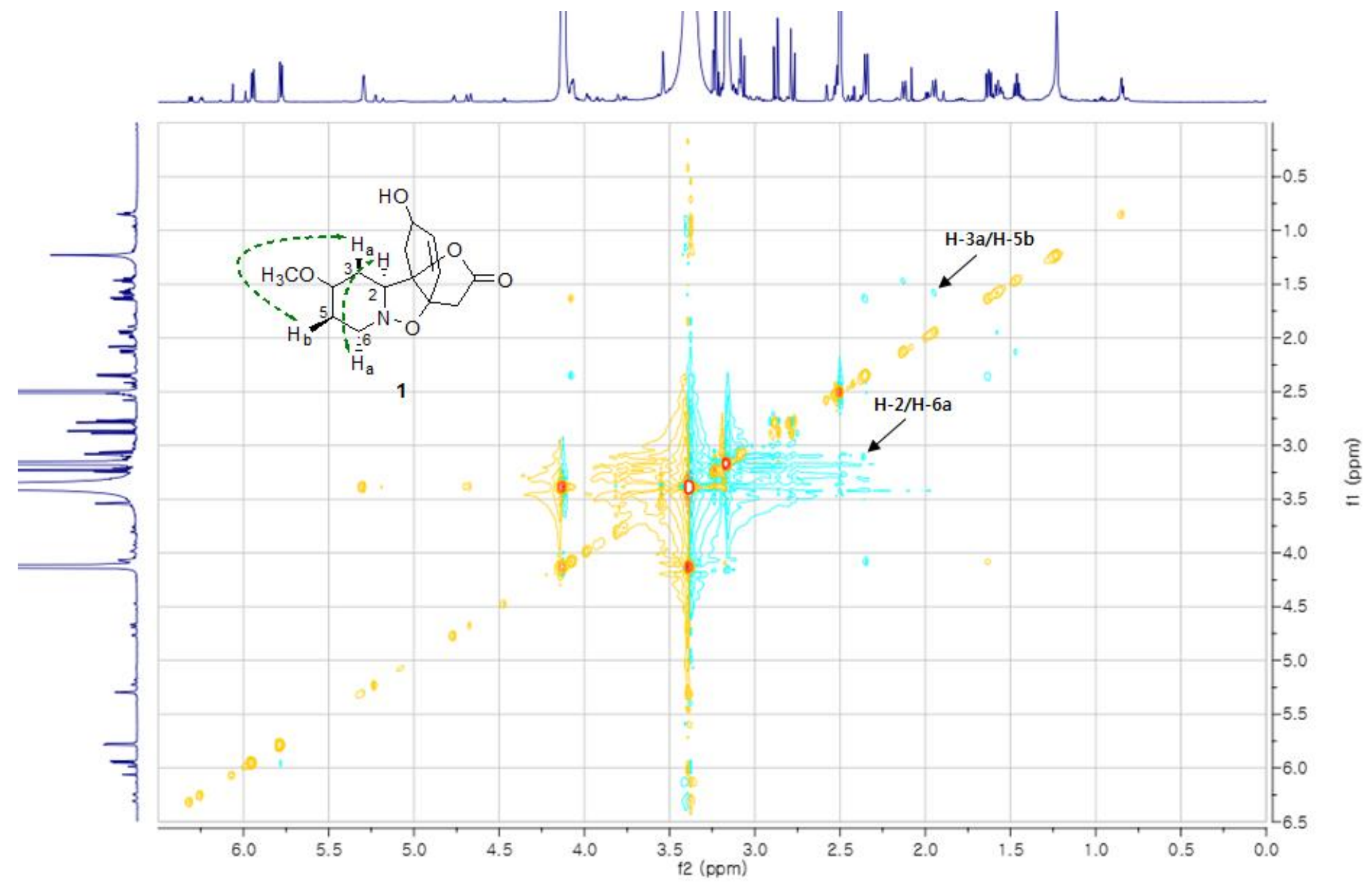


Figure S8. The ${ }^{1} \mathrm{H}$ NMR spectrum of $\mathbf{1}$ in chloroform- $d$.

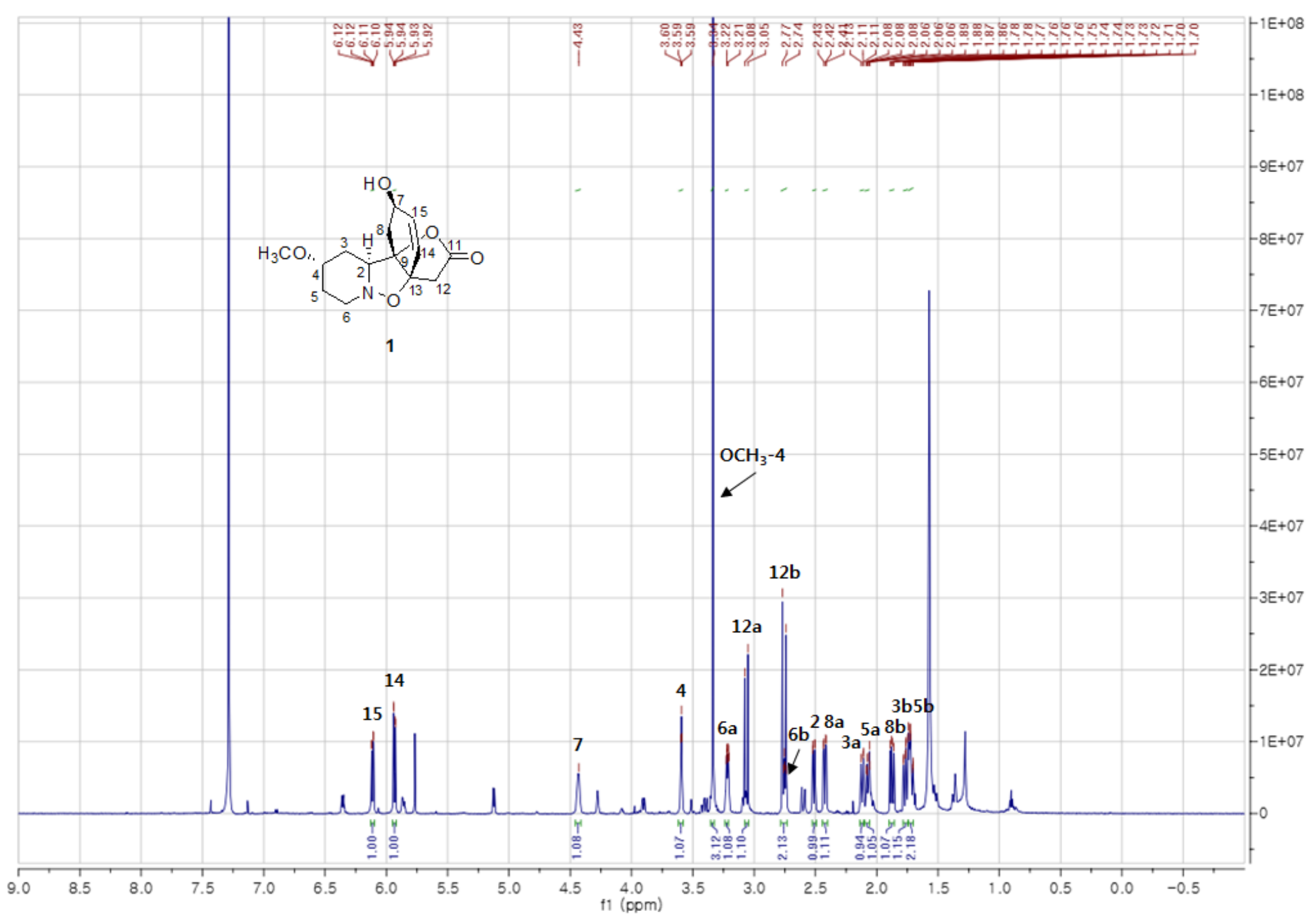


Figure S9. The ${ }^{13} \mathrm{C}$ NMR spectrum of $\mathbf{1}$ in chloroform- $d$.

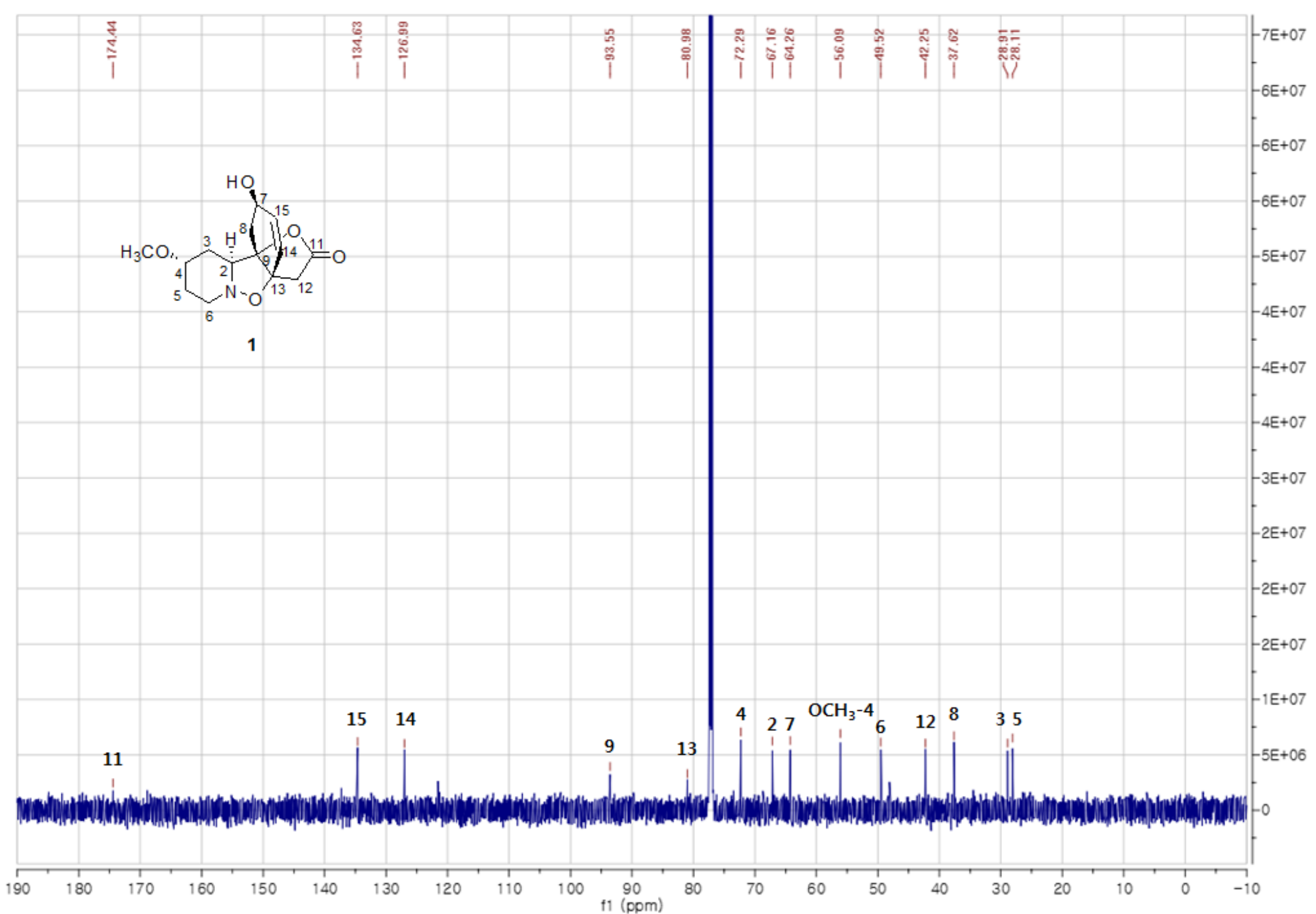


Figure S10. The HRESIMS spectrum of 2.

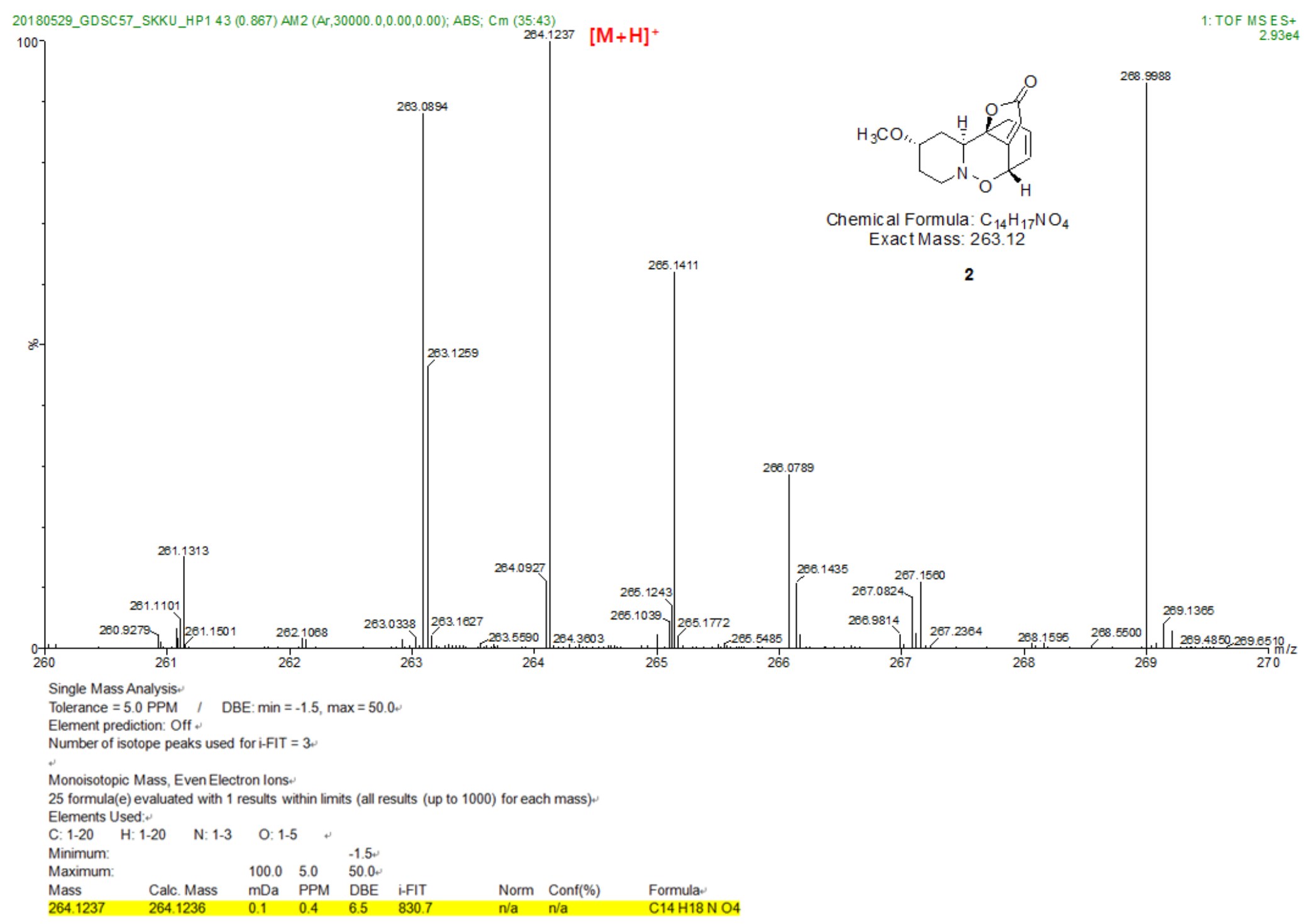


Figure S11. The ${ }^{1} \mathrm{H}$ NMR spectrum of $\mathbf{2}$ in chloroform- $d$.

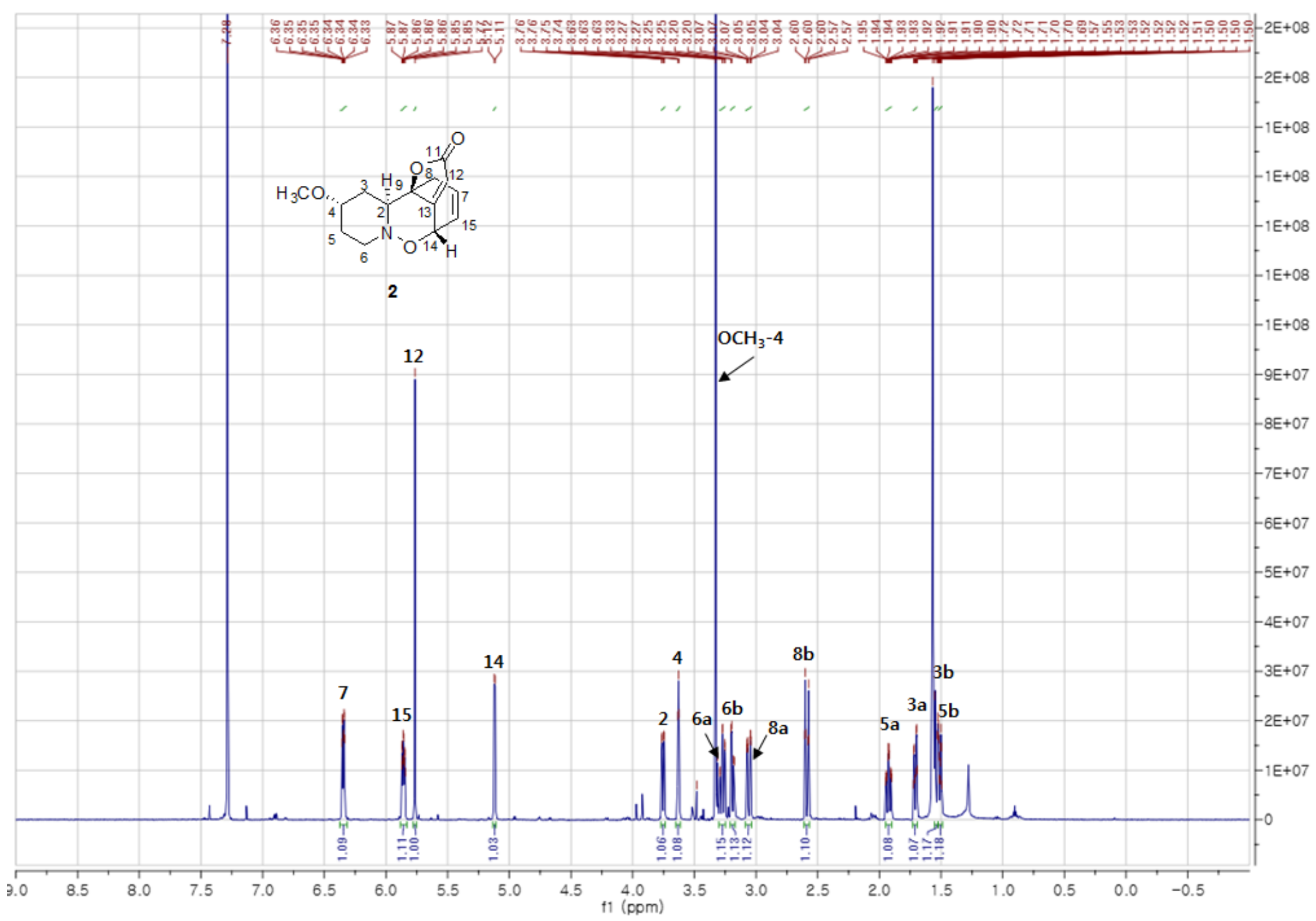


Figure S12. The ${ }^{13} \mathrm{C}$ NMR spectrum of $\mathbf{2}$ in chloroform- $d$.

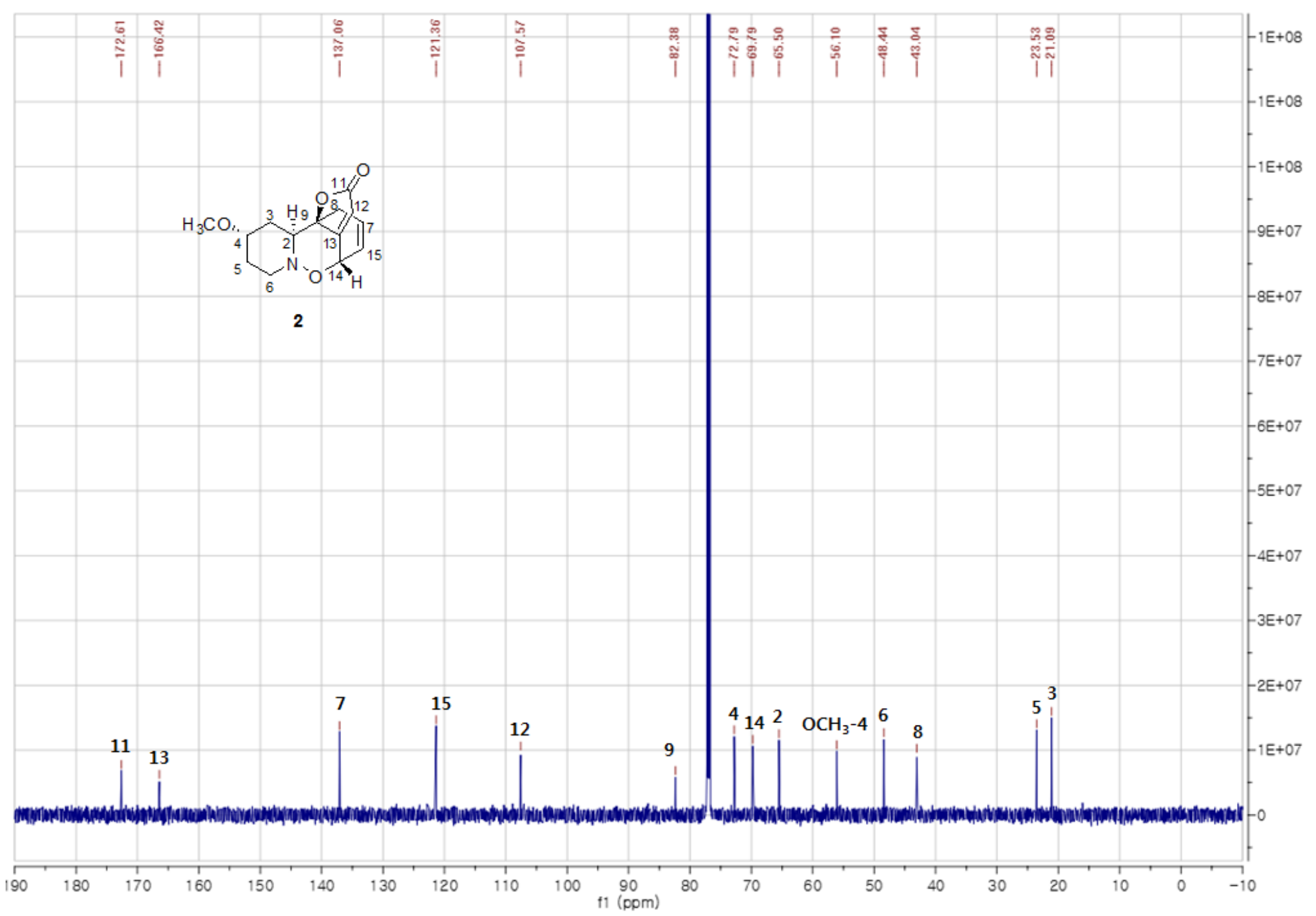


Figure S13. The COSY spectrum of $\mathbf{2}$ in chloroform- $d$.

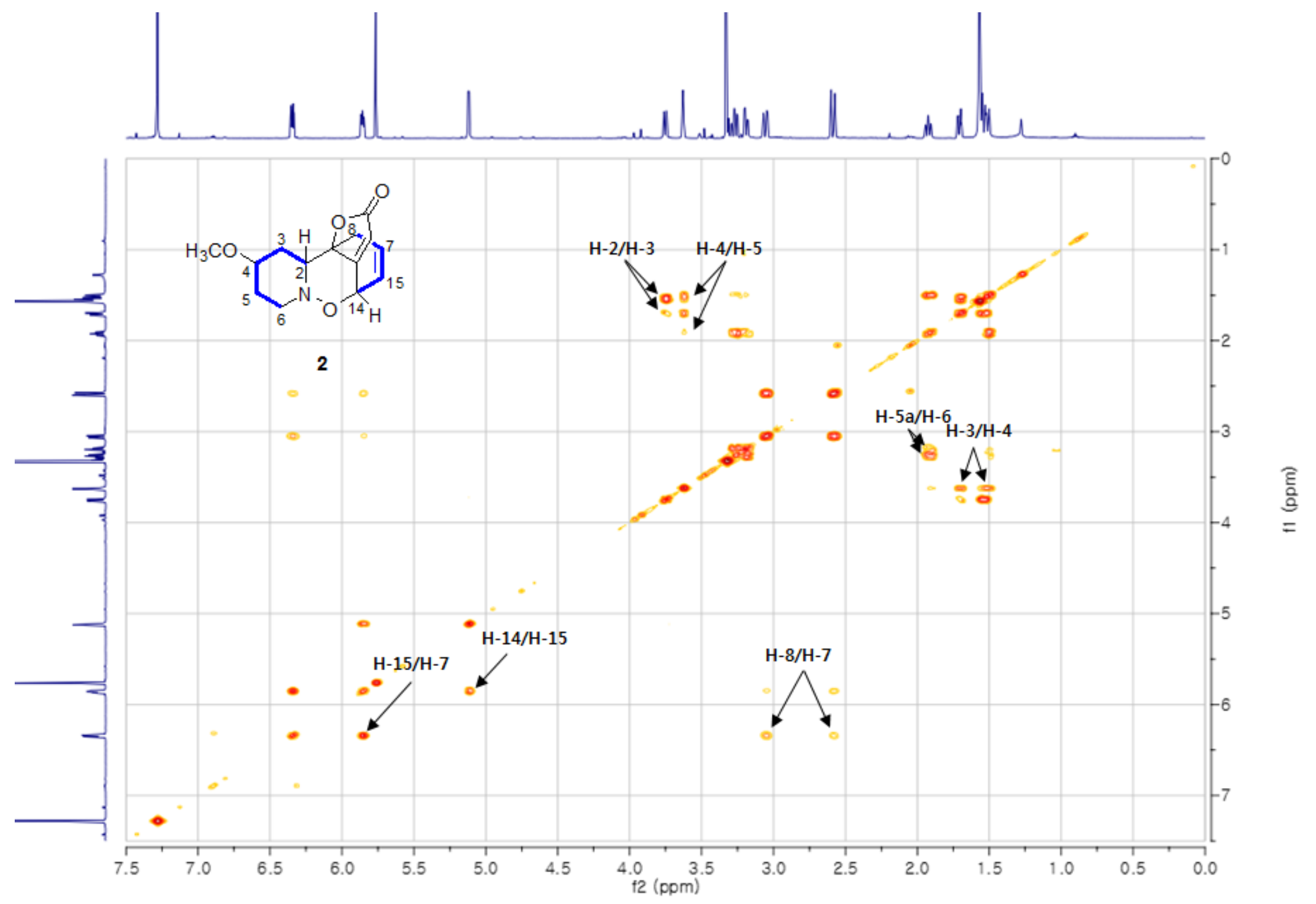


Figure S14. The HSQC spectrum of 2 in chloroform- $d$.

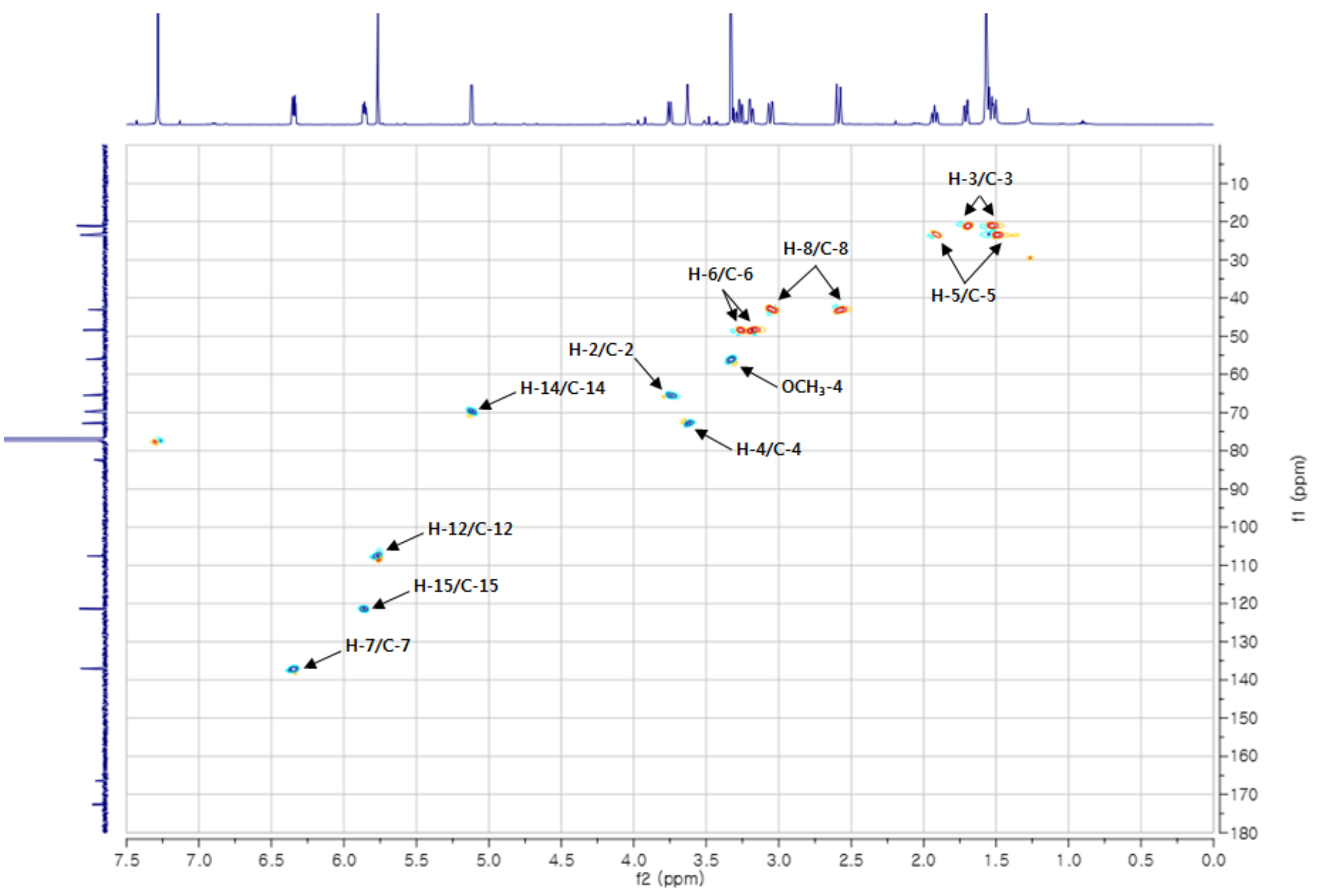


Figure S15. The HMBC spectrum of $\mathbf{2}$ in chloroform- $d$.

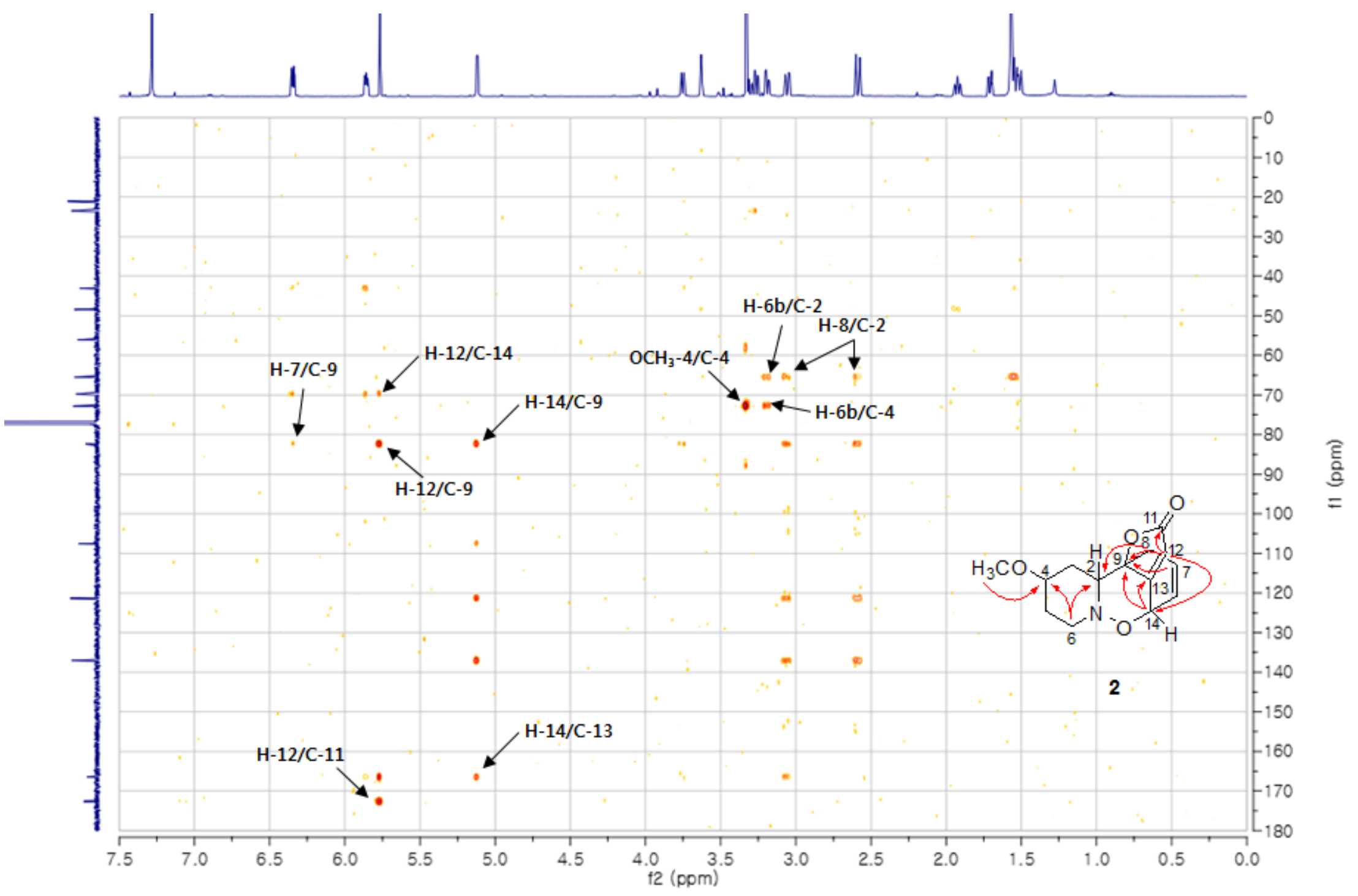


Figure S16. The NOESY spectrum of $\mathbf{2}$ in chloroform- $d$.

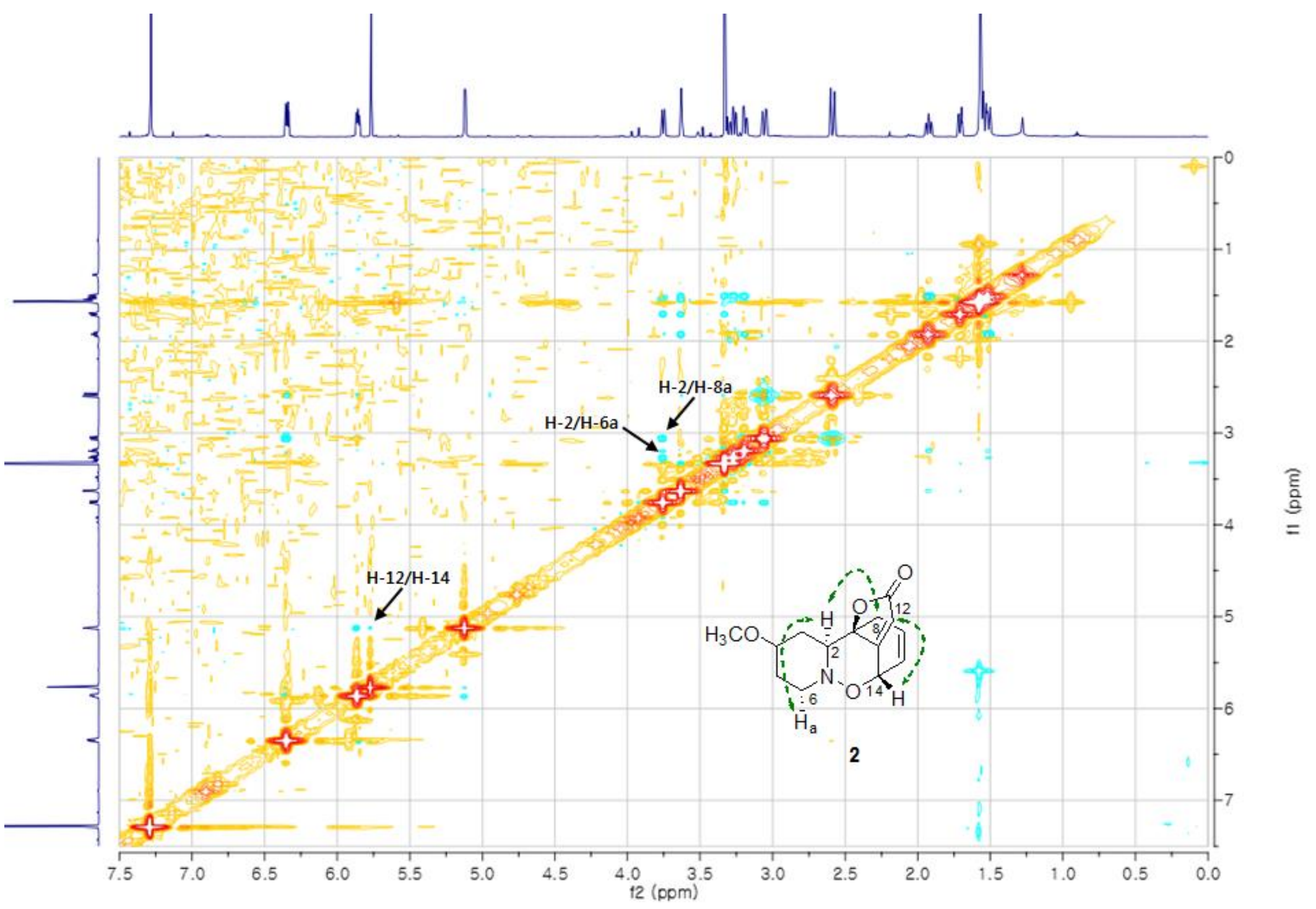


Figure S17. The HRESIMS spectrum of 3.

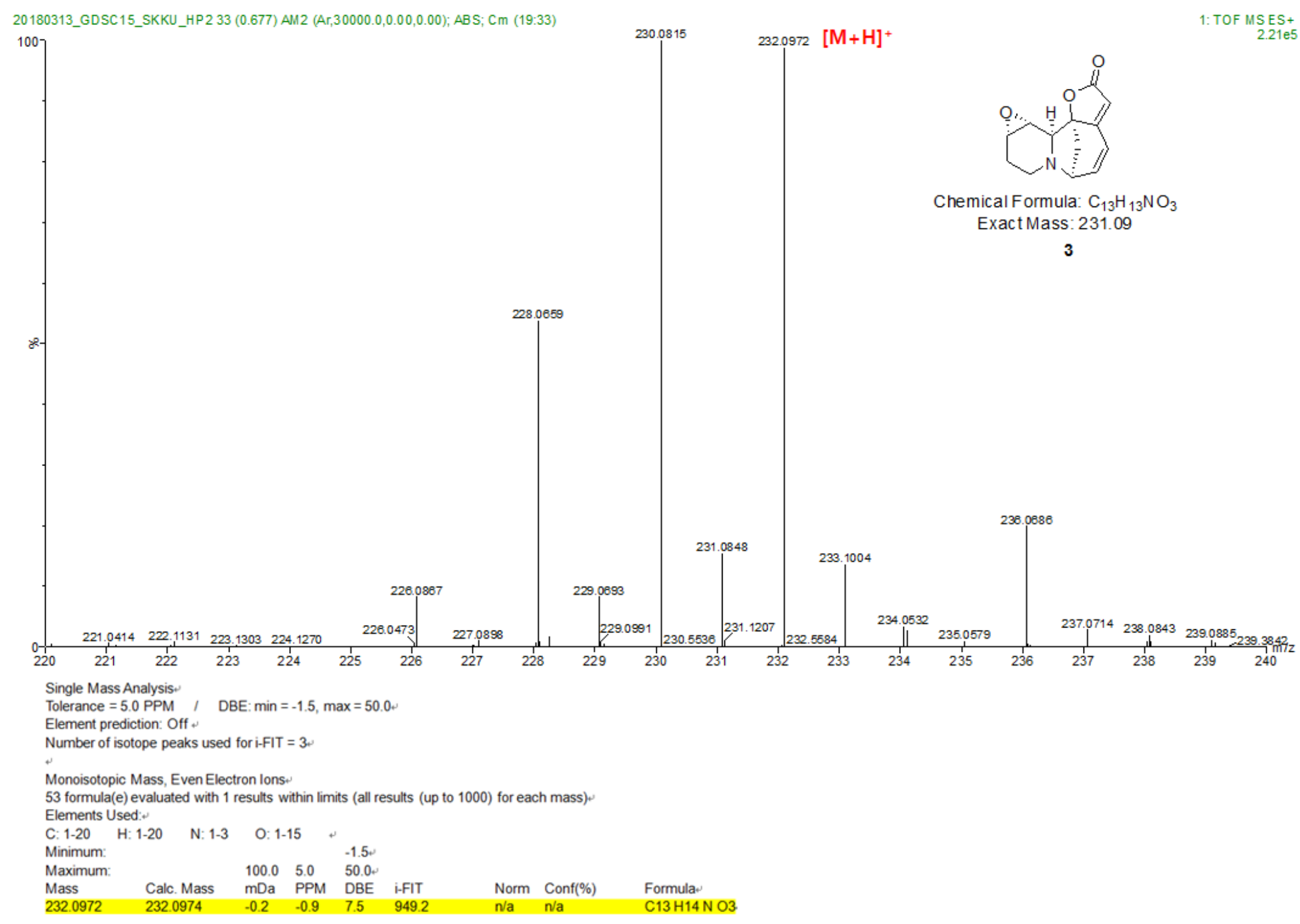


Figure S18. The ${ }^{1} \mathrm{H}$ NMR spectrum of $\mathbf{3}$ in chloroform- $d$.

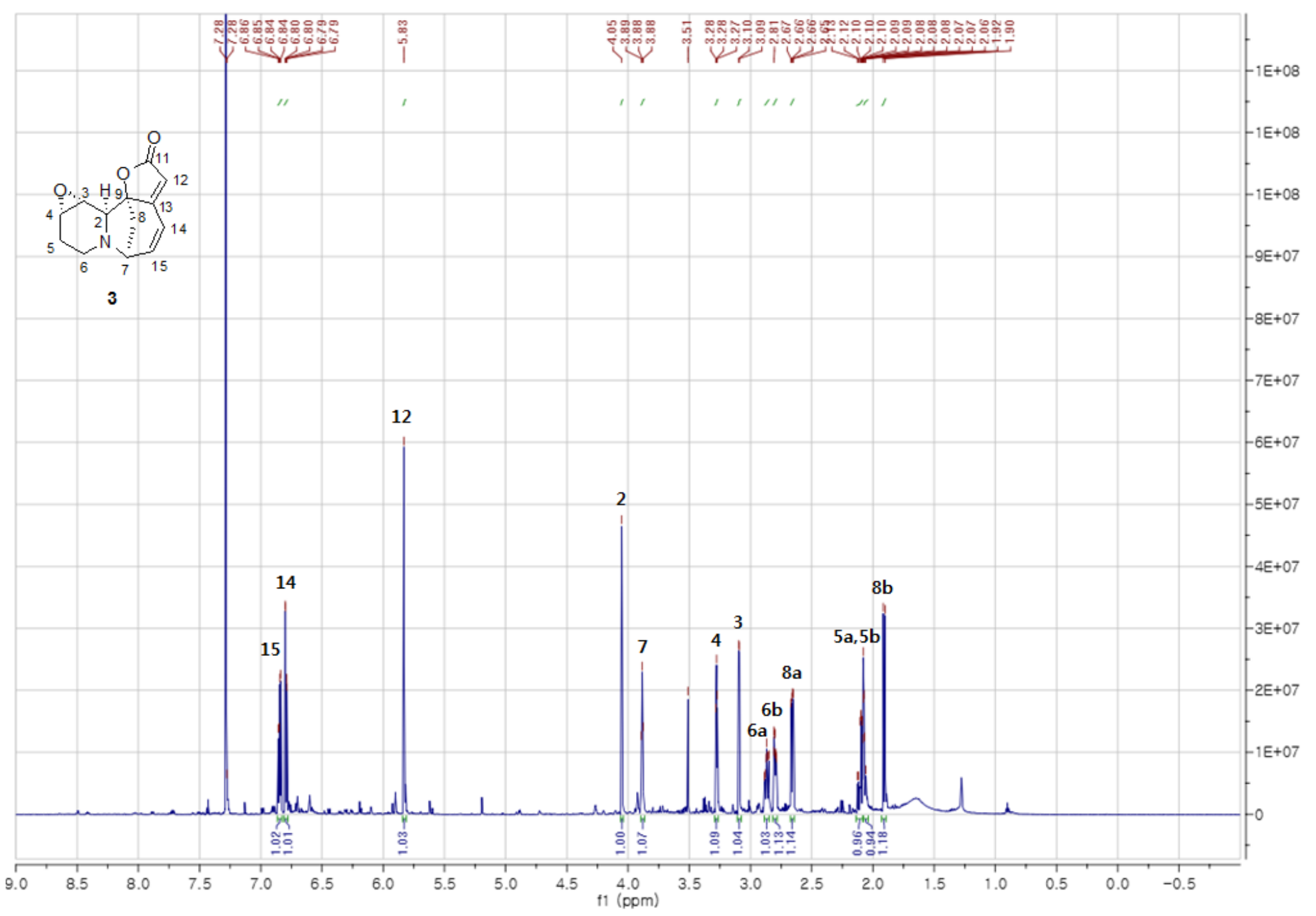


Figure S19. The ${ }^{13} \mathrm{C}$ NMR spectrum of $\mathbf{3}$ in chloroform- $d$.

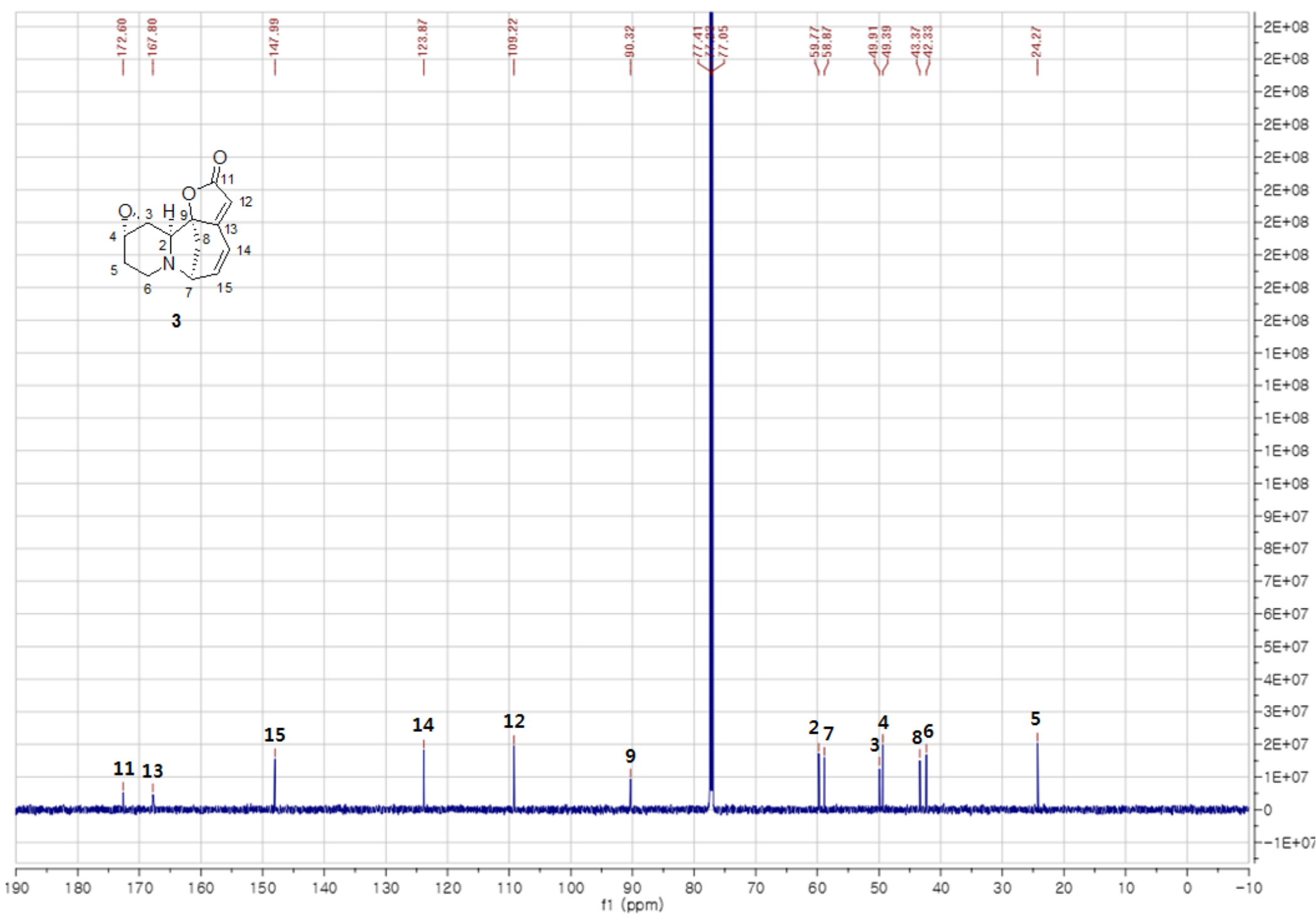


Figure S20. The COSY spectrum of $\mathbf{3}$ in chloroform- $d$.

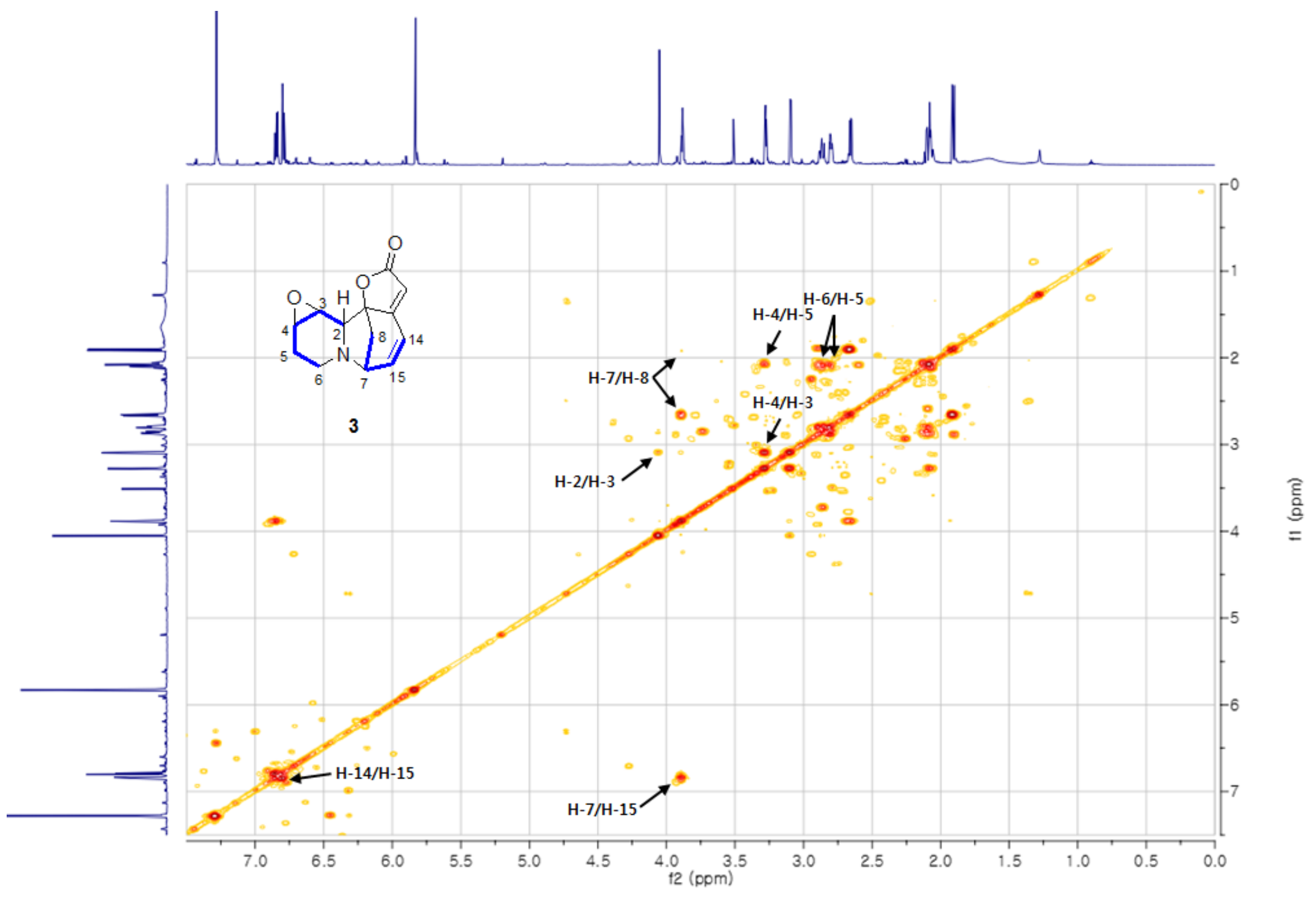


Figure S21. The HSQC spectrum of $\mathbf{3}$ in chloroform- $d$.

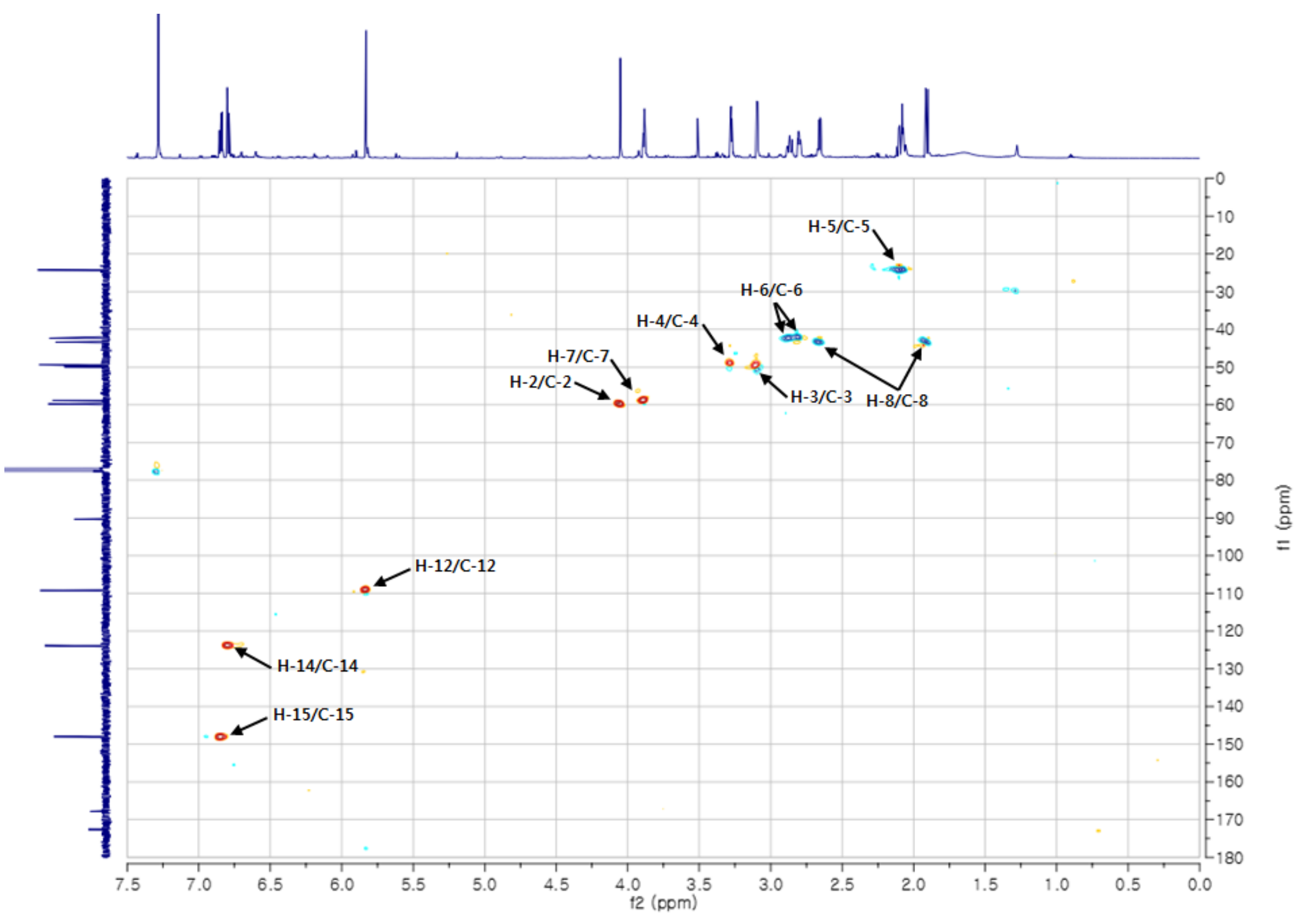


Figure S22. The HMBC spectrum of $\mathbf{3}$ in chloroform- $d$.

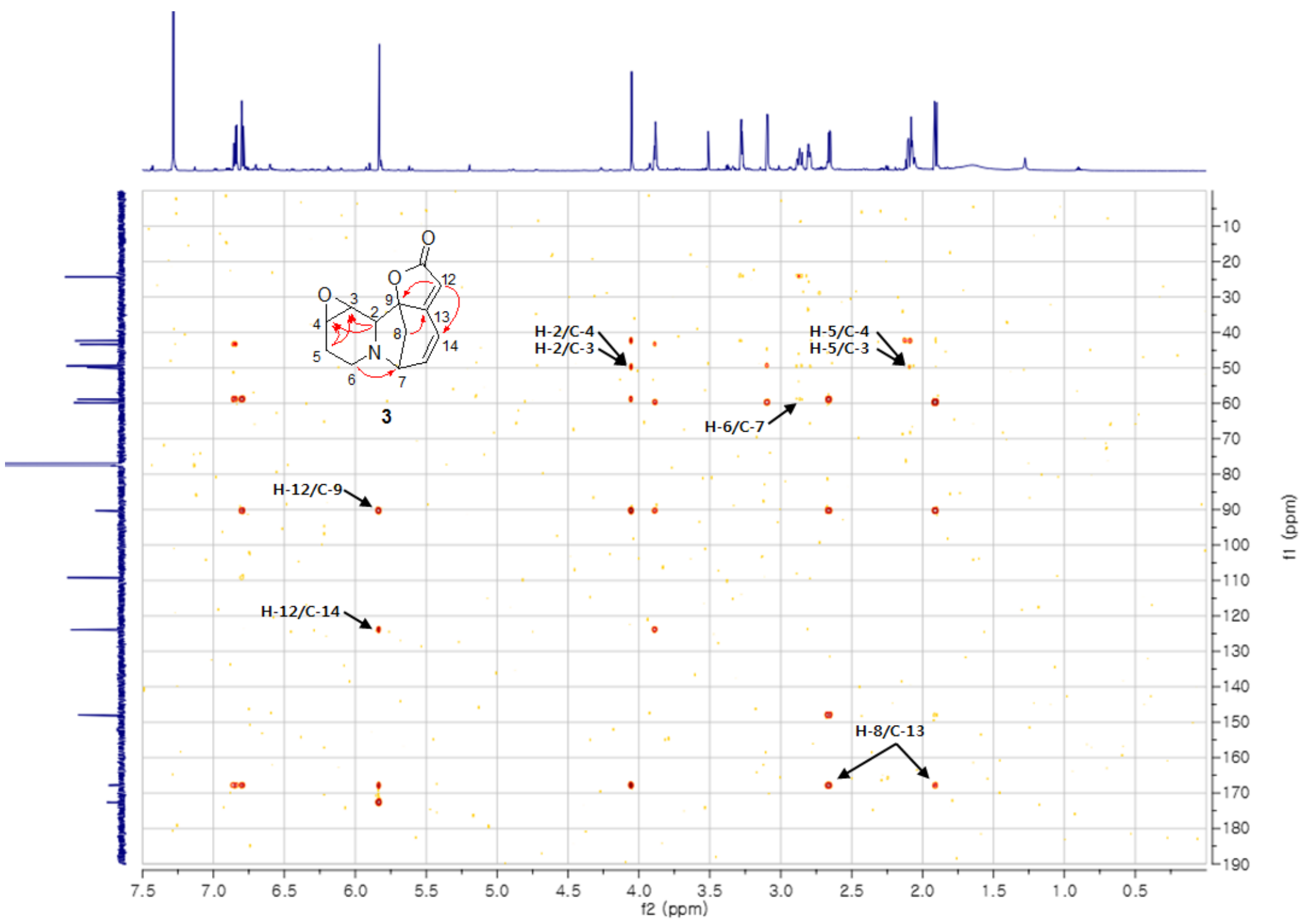


Figure S23. The NOESY spectrum of $\mathbf{3}$ in chloroform- $d$.

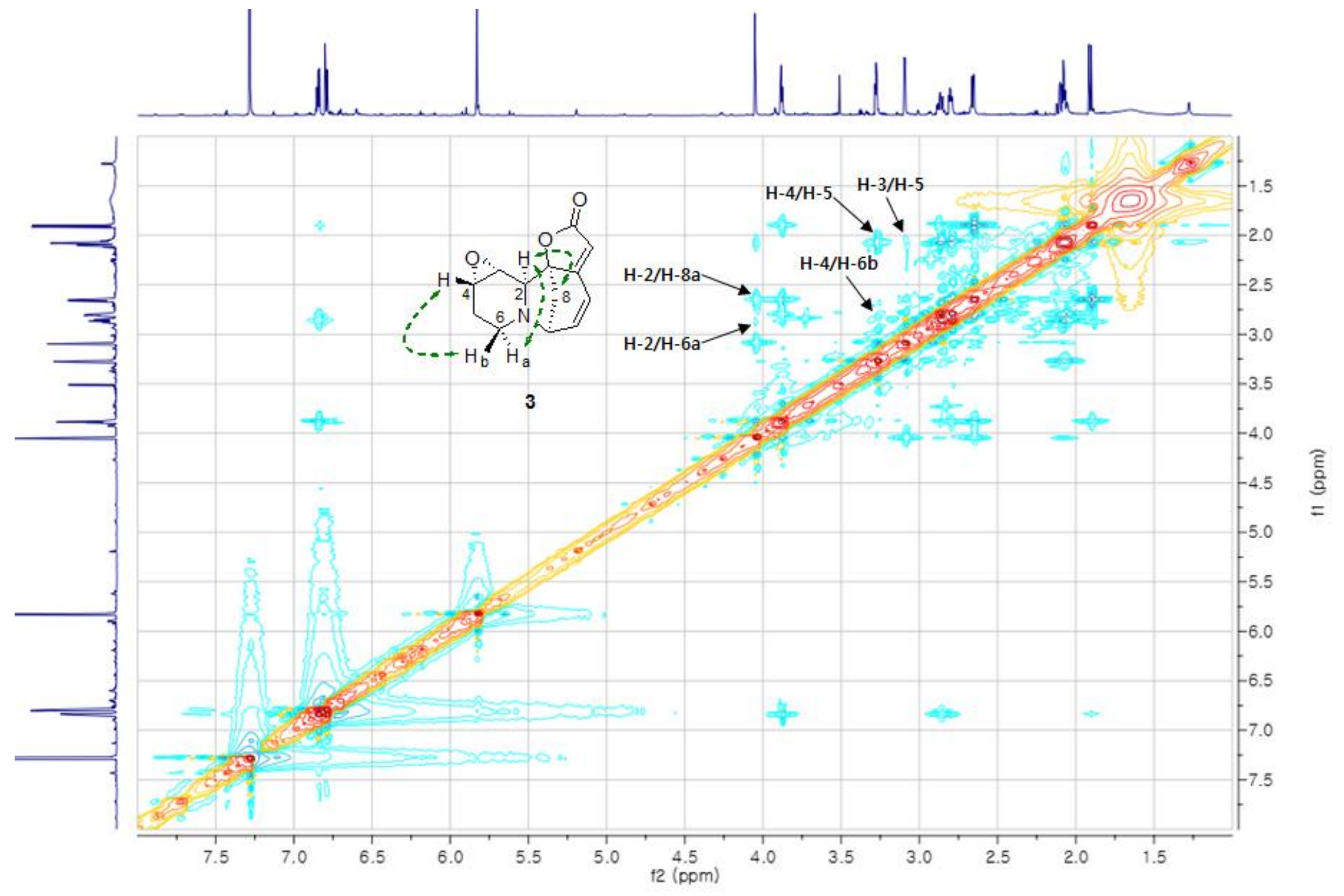


Figure S24. The HRESIMS spectrum of 4.

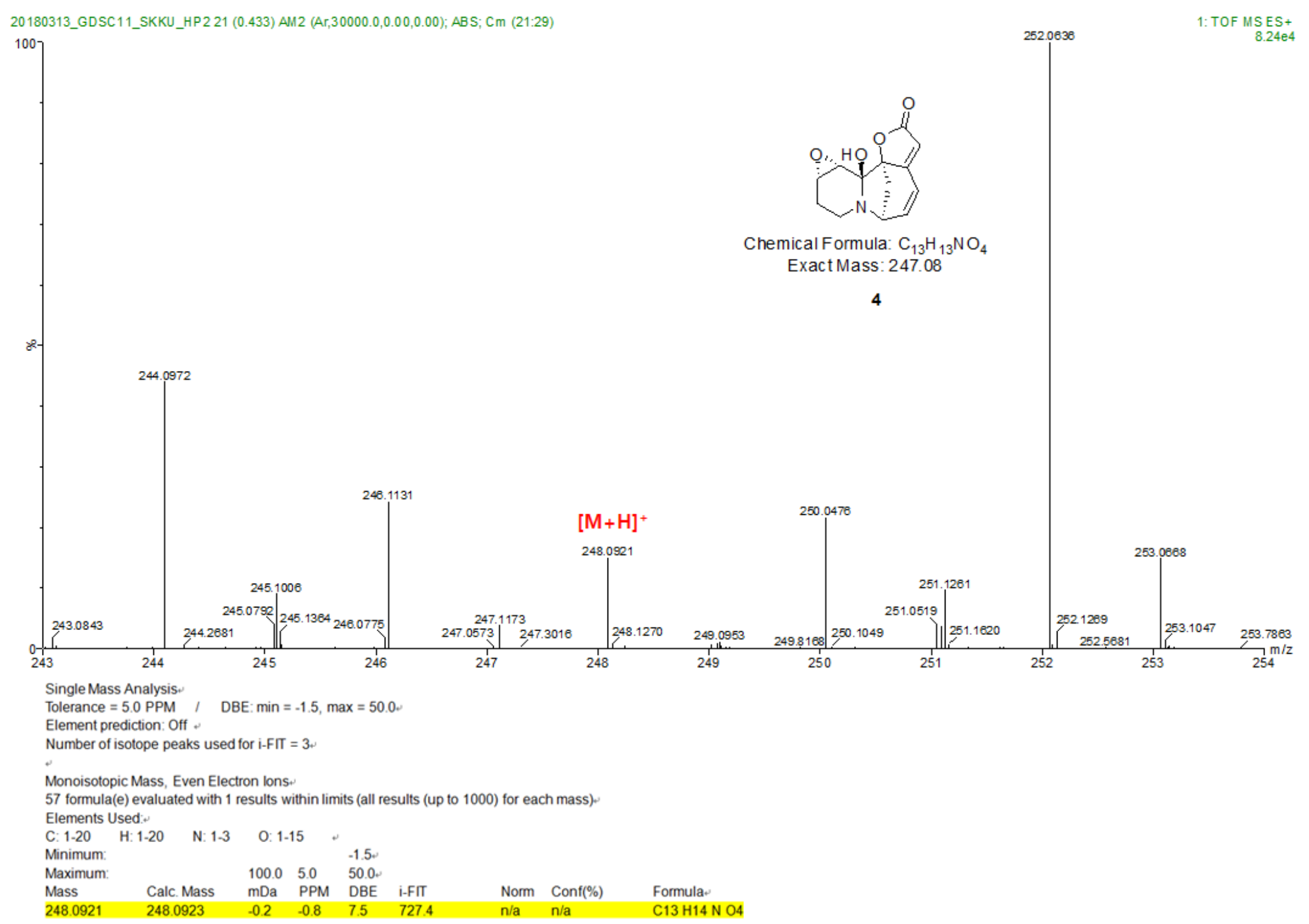


Figure S25. The ${ }^{1} \mathrm{H}$ NMR spectrum of $\mathbf{4}$ in chloroform- $d$.

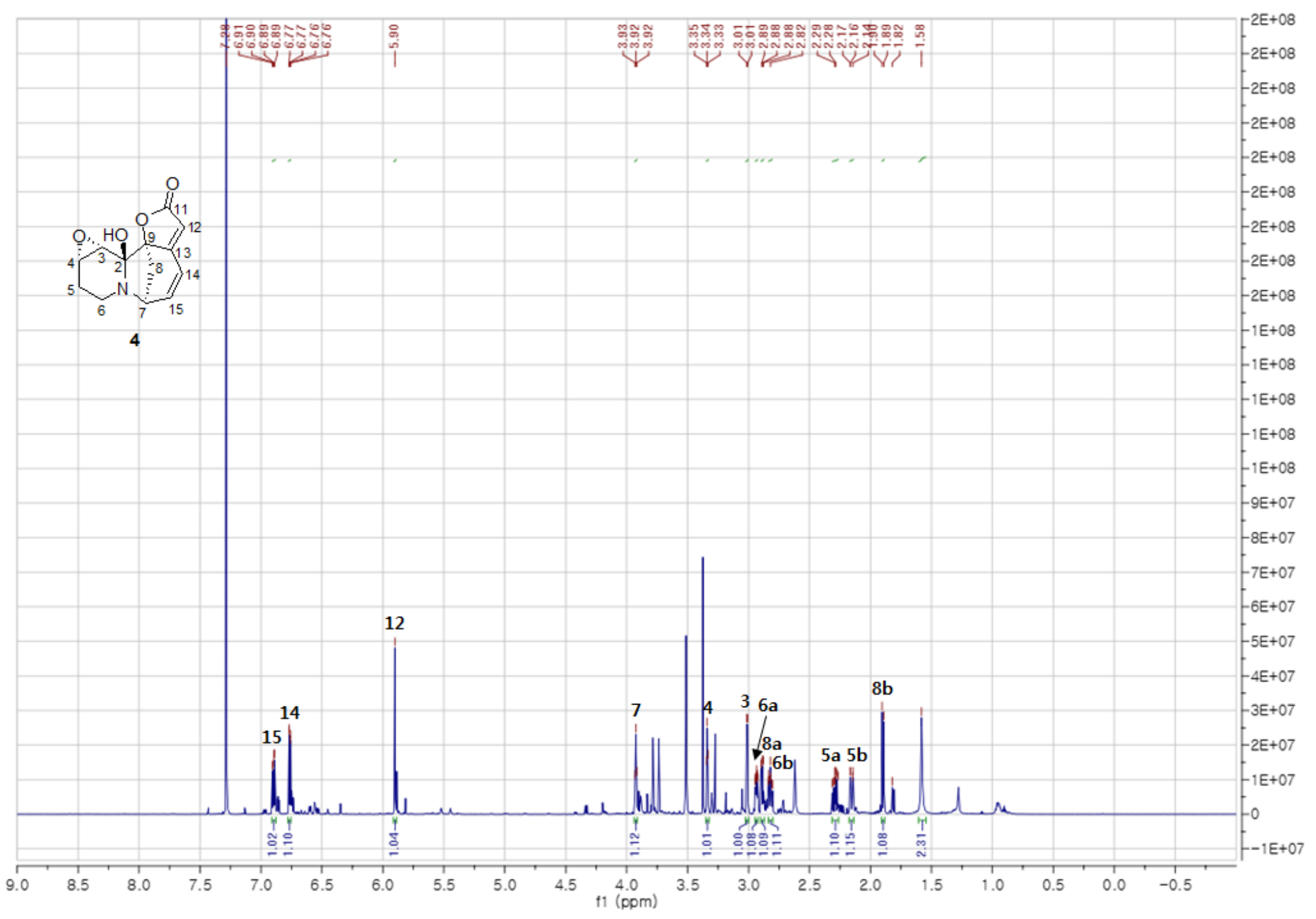


Figure S26. The ${ }^{13} \mathrm{C}$ NMR spectrum of 4 in chloroform- $d$.

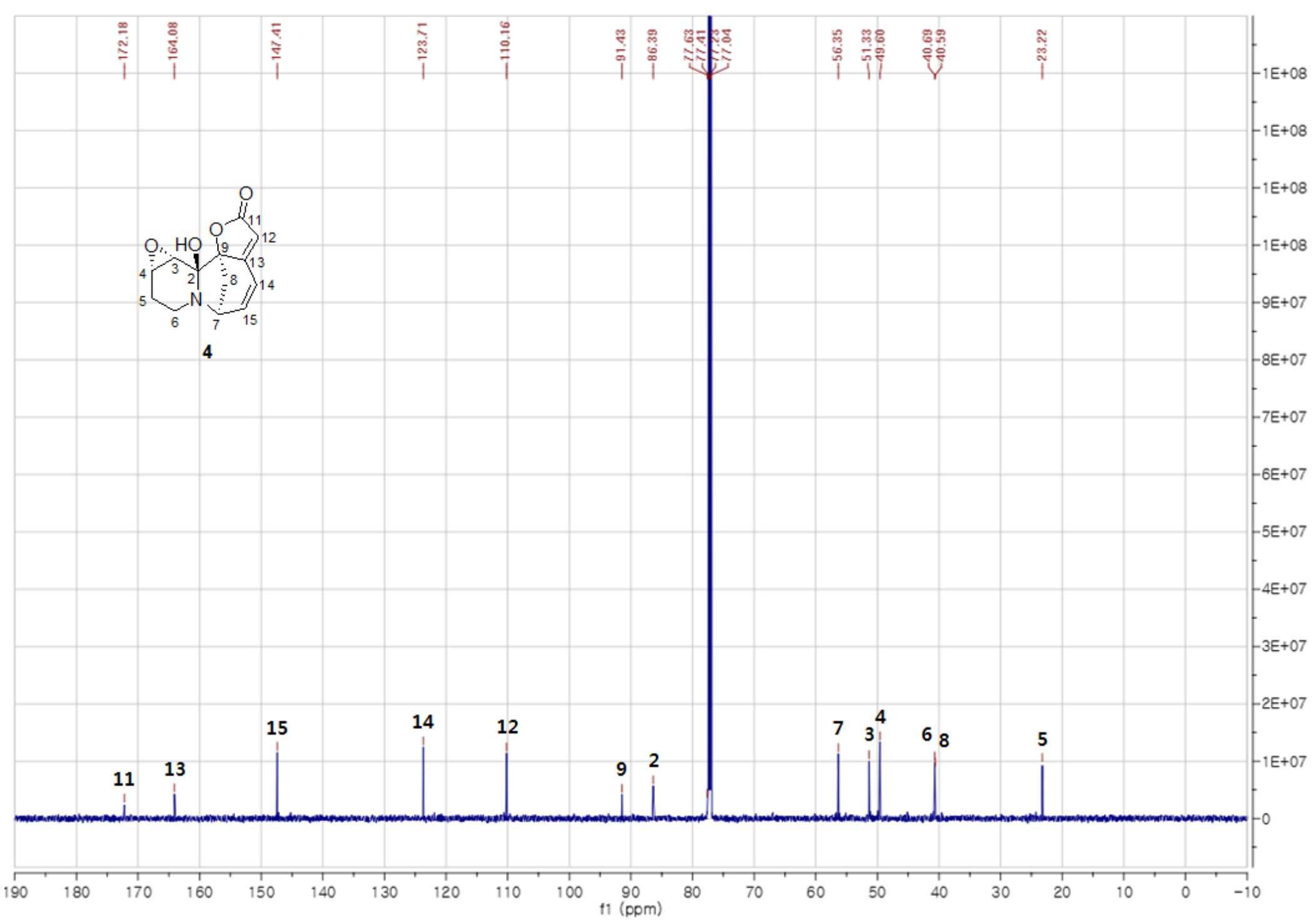


Figure S27. The COSY spectrum of $\mathbf{4}$ in chloroform- $d$.

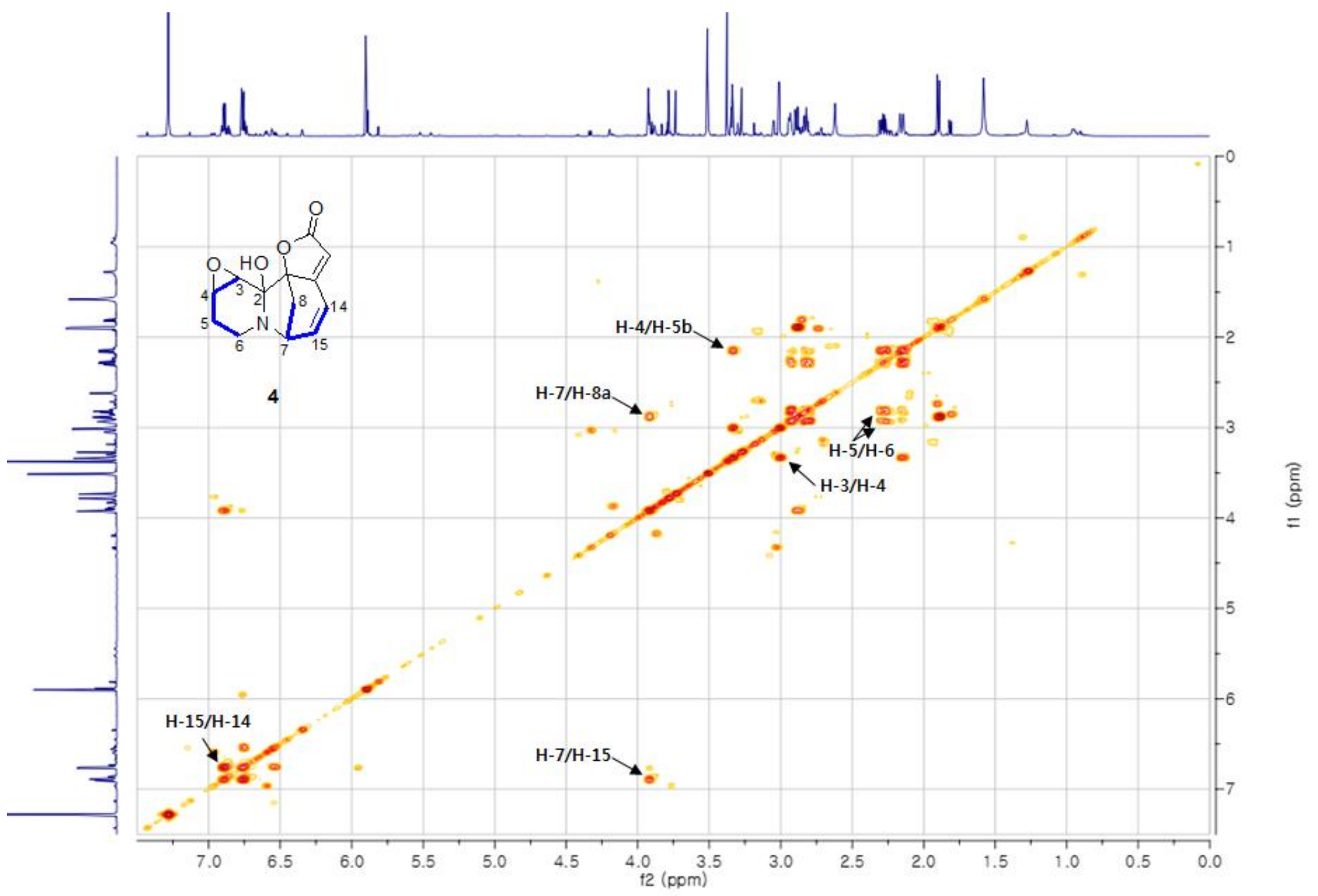


Figure S28. The HSQC spectrum of $\mathbf{4}$ in chloroform- $d$.

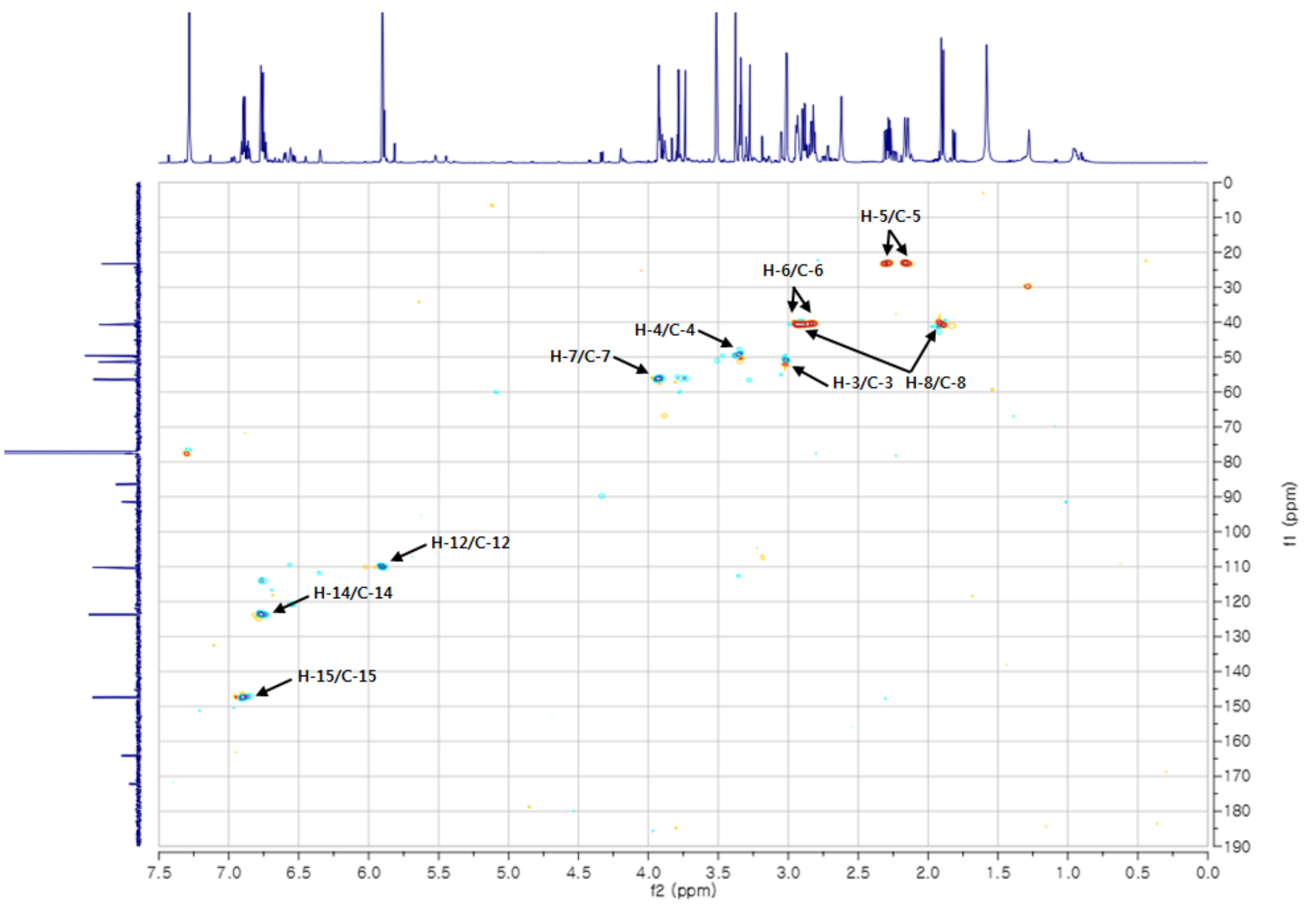


Figure S29. The HMBC spectrum of $\mathbf{4}$ in chloroform- $d$.

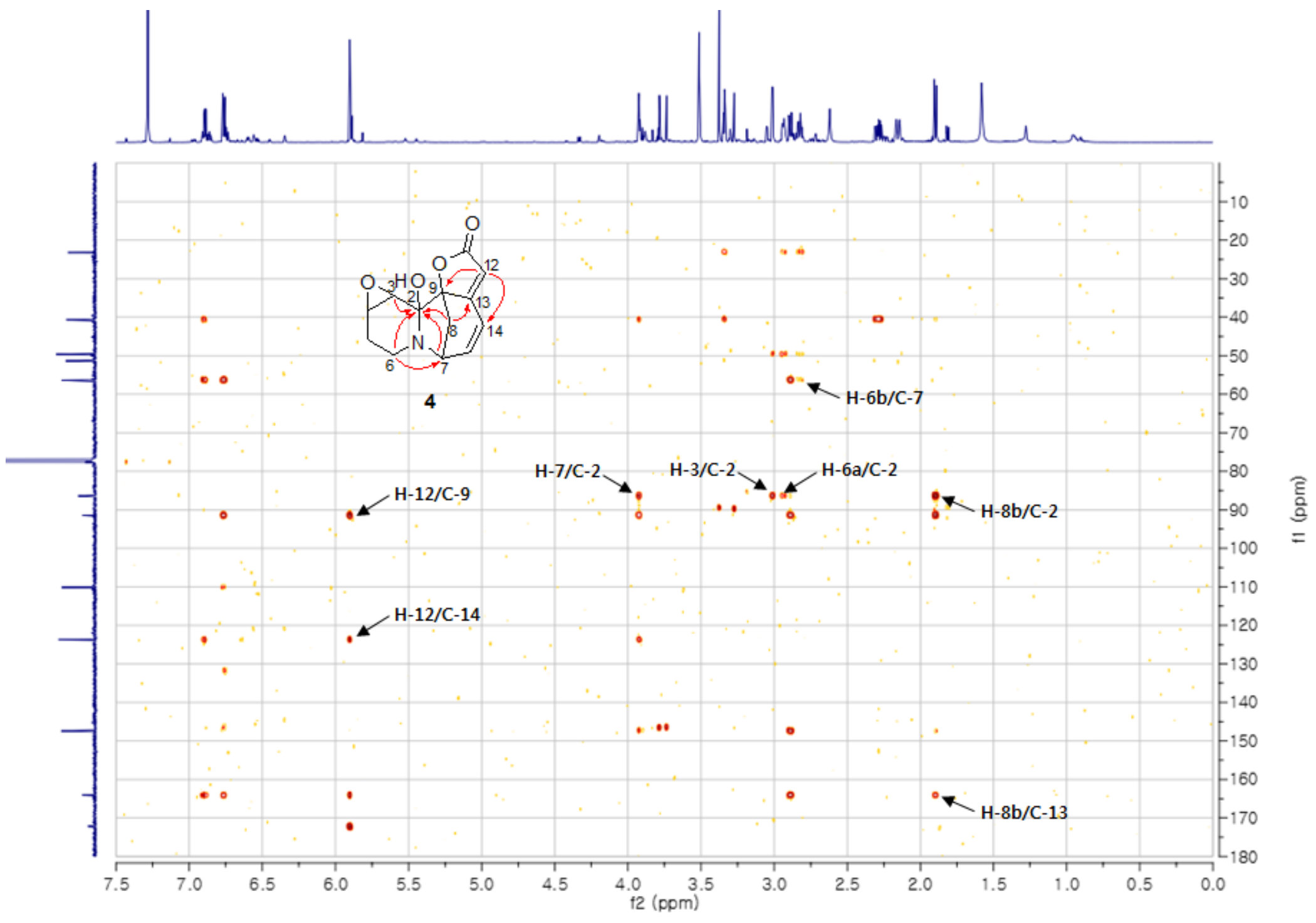


Figure S30. The ${ }^{1} \mathrm{H}$ NMR spectrum of 4 in DMSO- $d_{6}$.

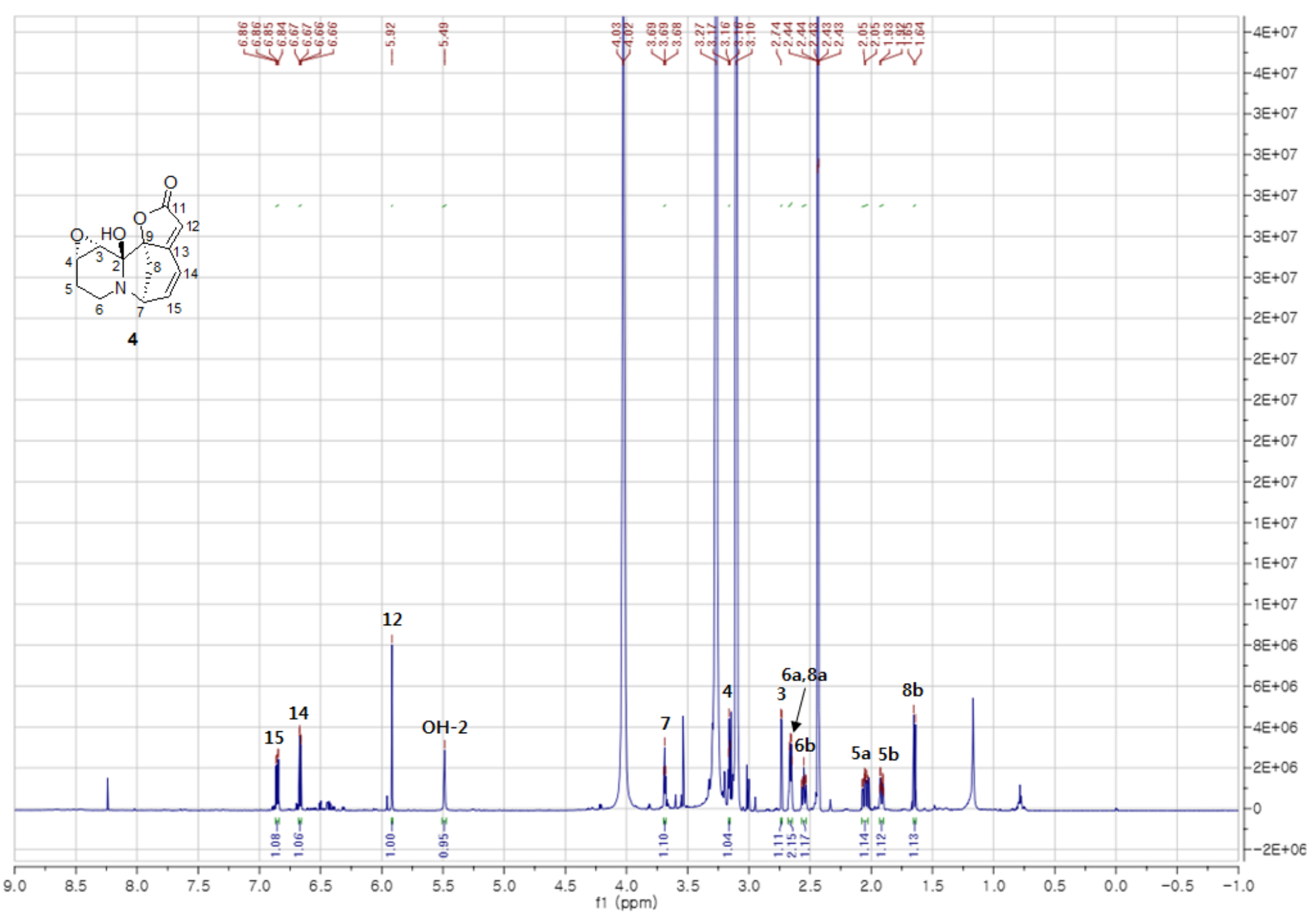


Figure S31. The NOESY spectrum of $\mathbf{4}$ in DMSO- $d_{6}$.

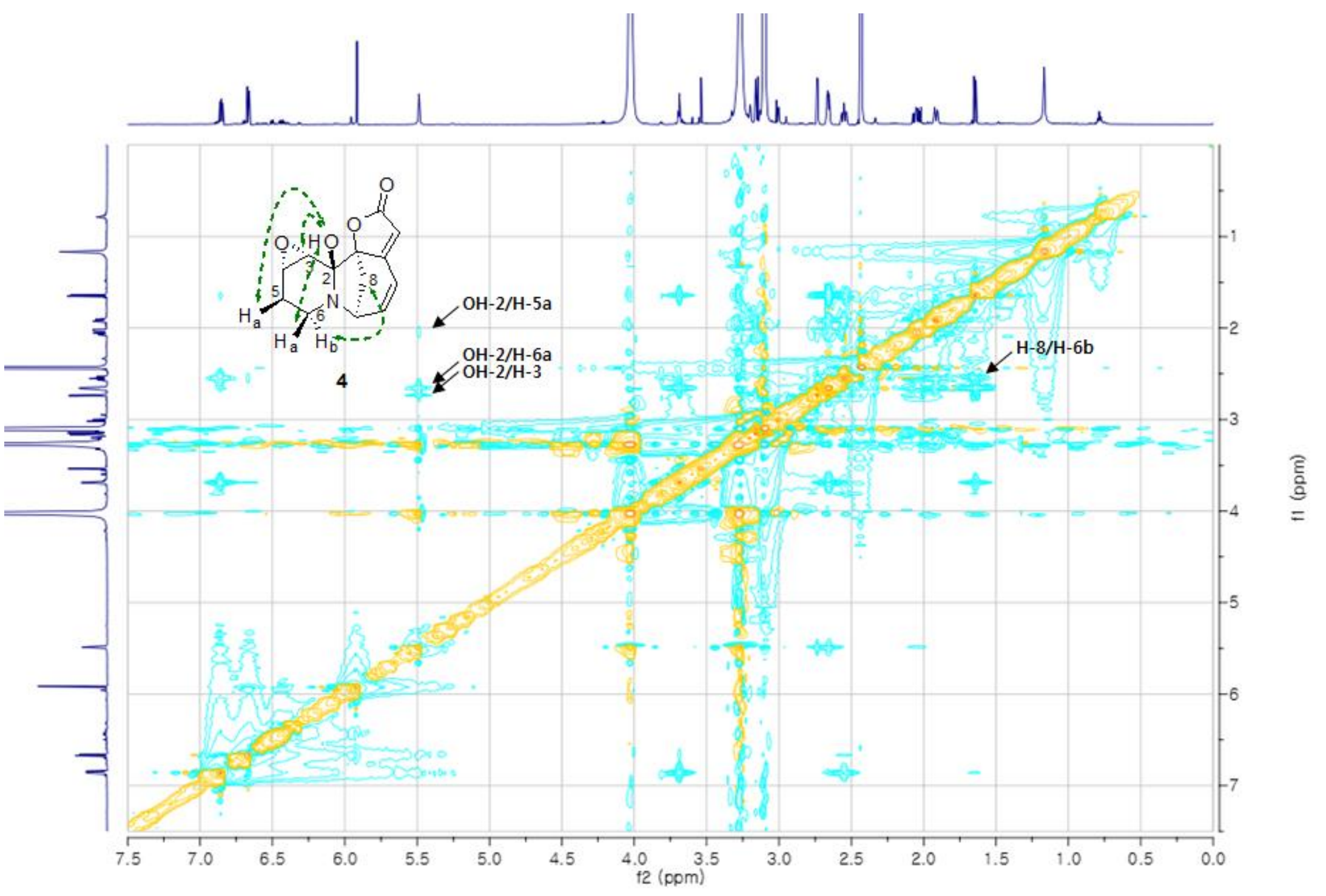


Figure S32. The HRESIMS spectrum of 5.

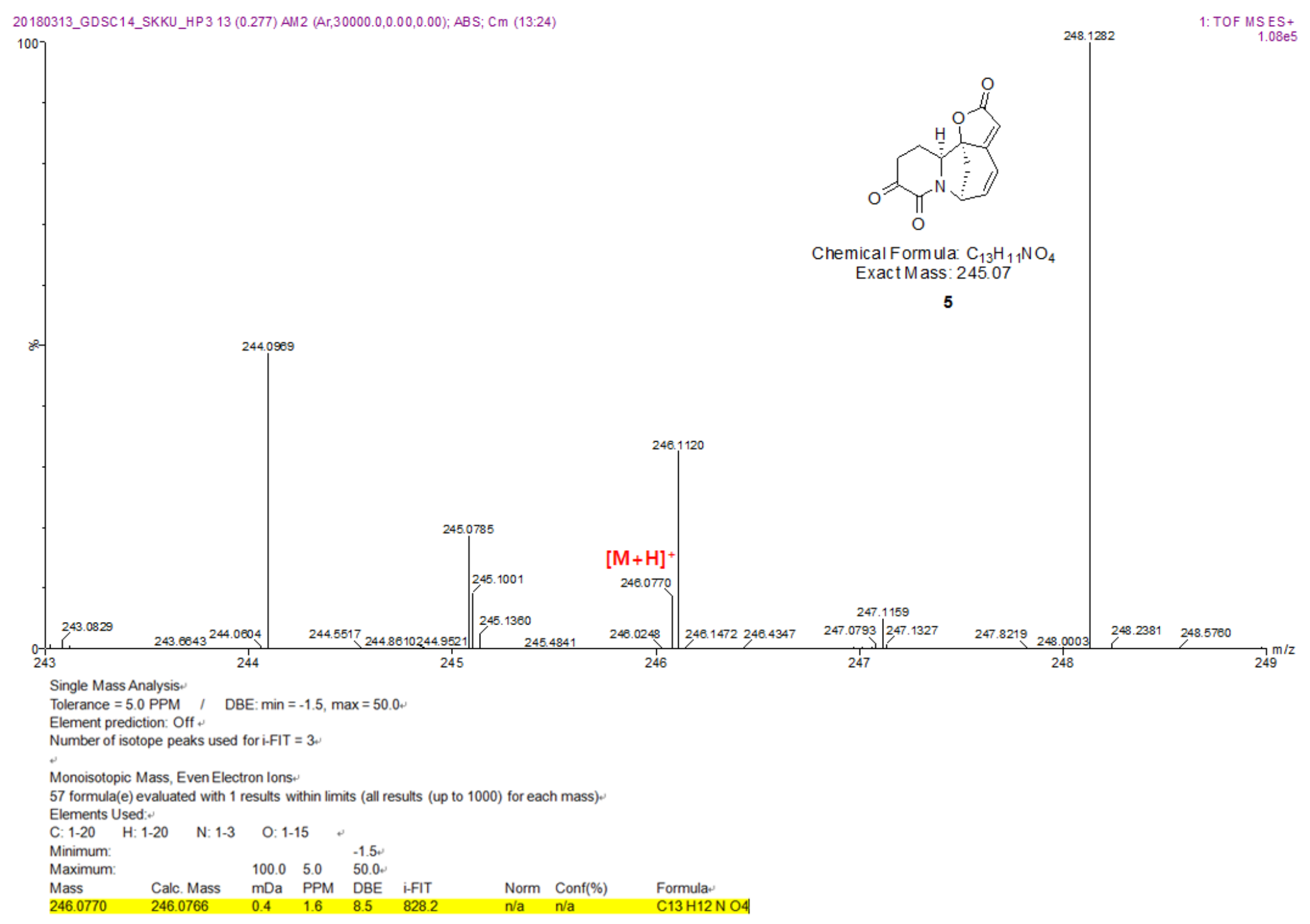


Figure S33. The ${ }^{1} \mathrm{H}$ NMR spectrum of 5 in chloroform- $d$.

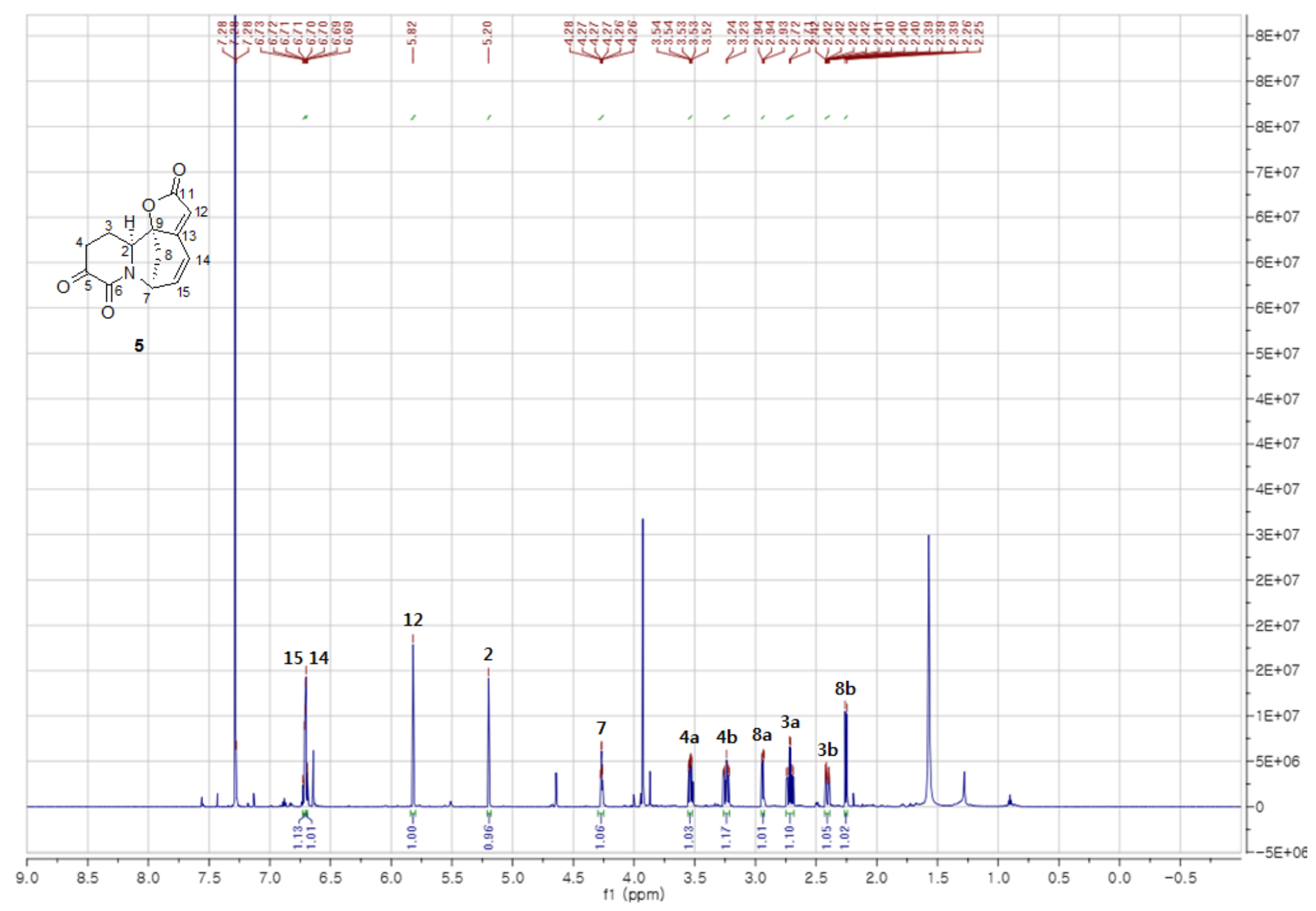


Figure S34. The ${ }^{13} \mathrm{C}$ NMR spectrum of 5 in chloroform- $d$.

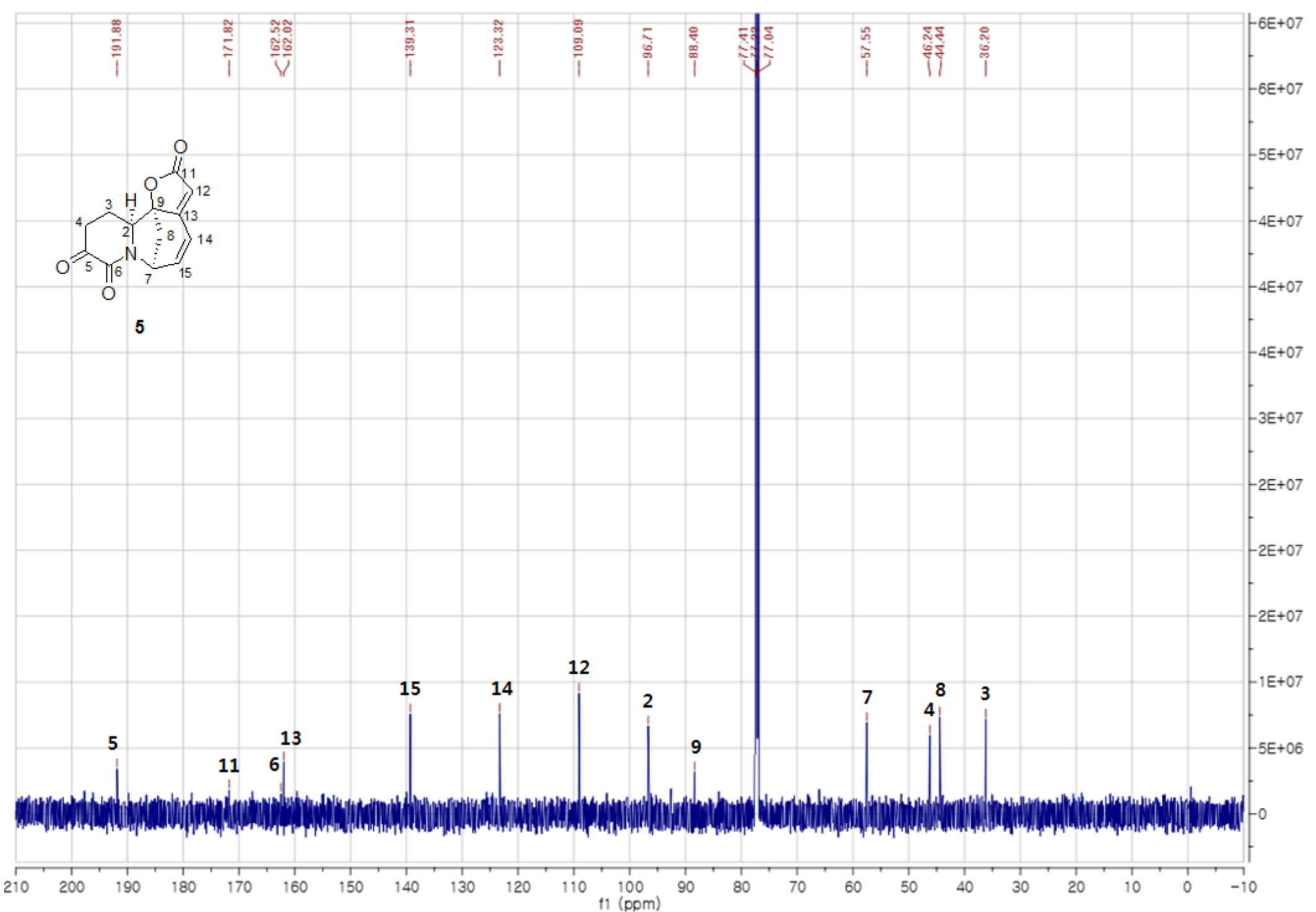


Figure S35. The COSY spectrum of $\mathbf{5}$ in chloroform- $d$.

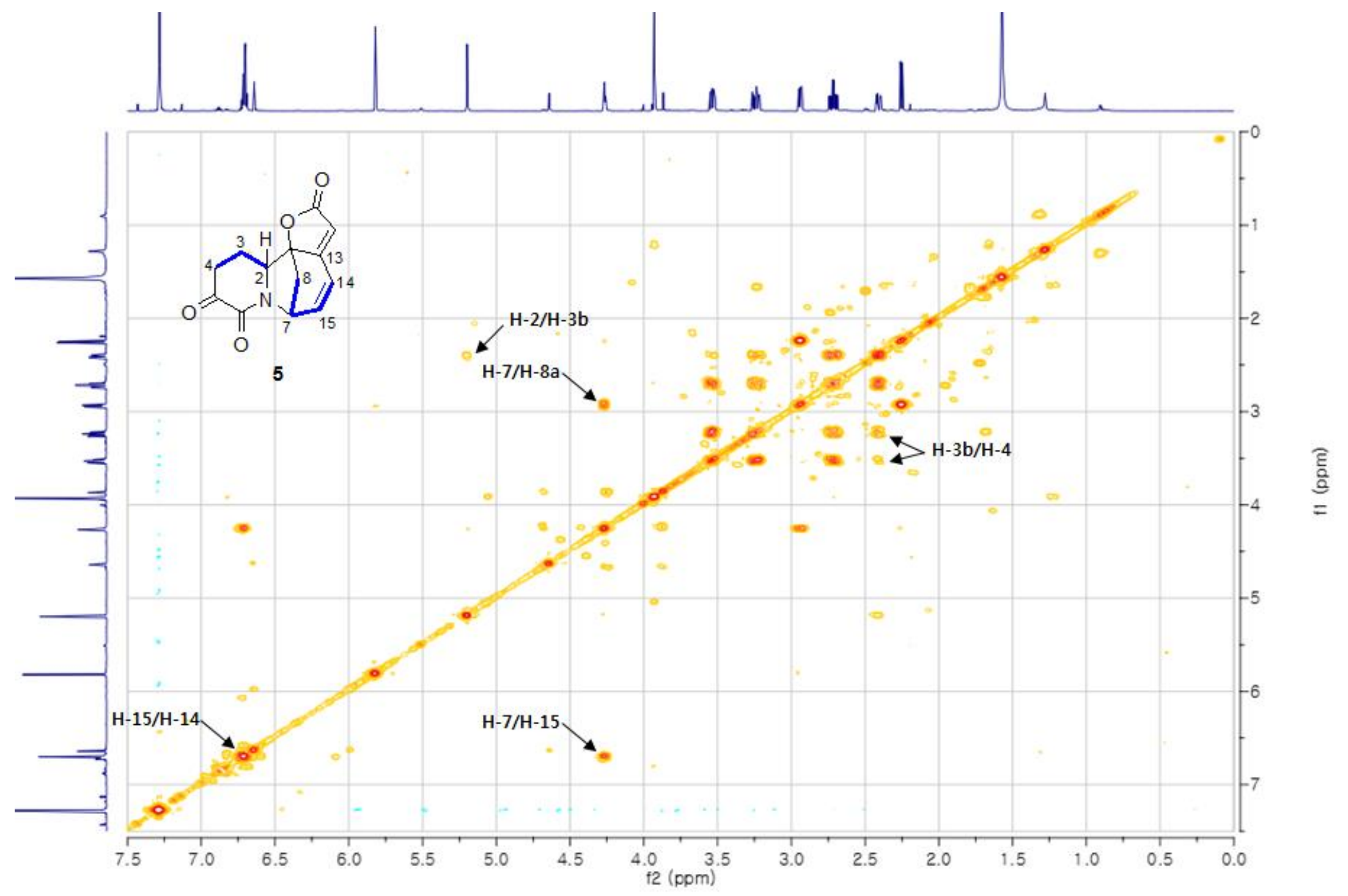


Figure S36. The HSQC spectrum of $\mathbf{5}$ in chloroform- $d$.

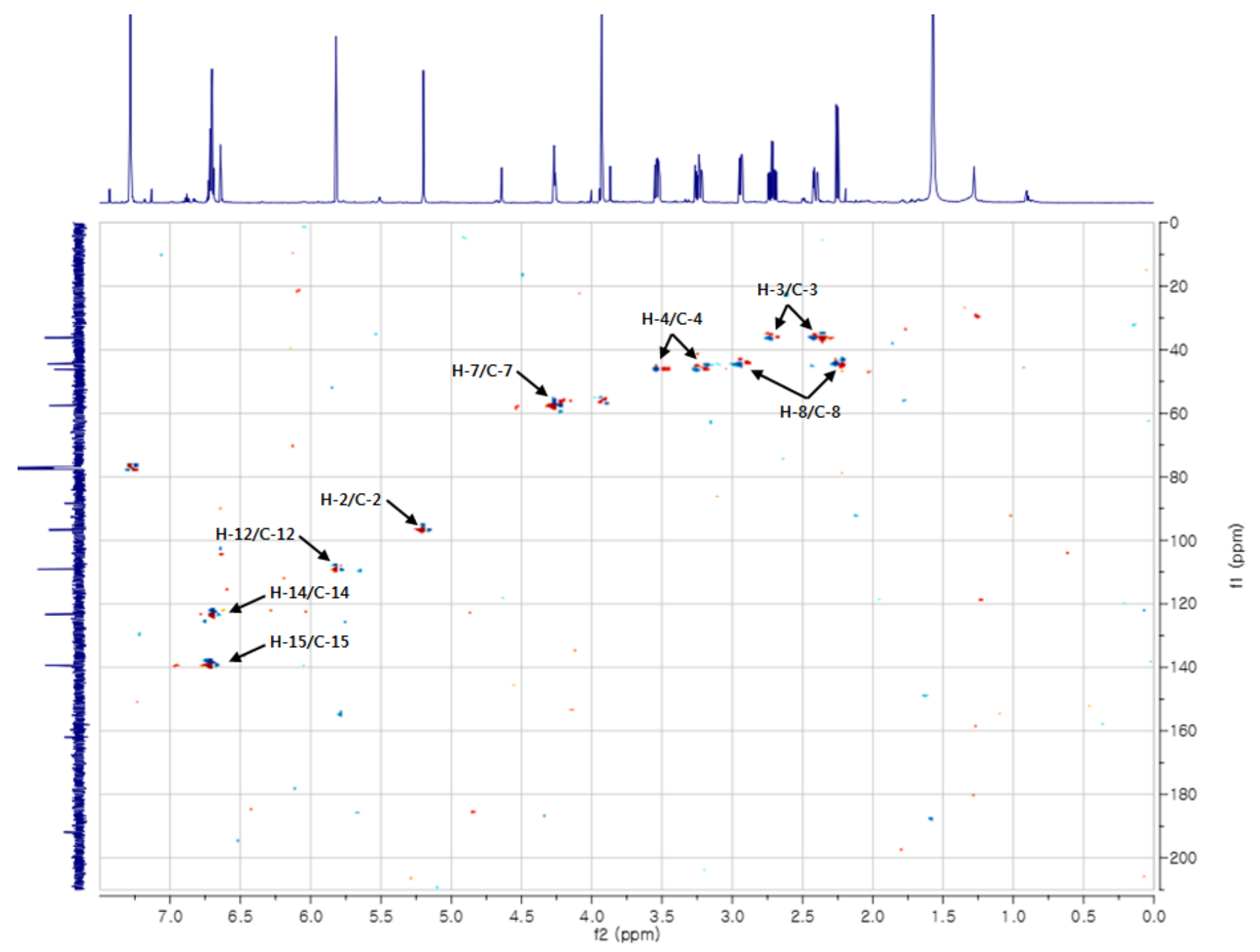


Figure S37. The HMBC spectrum of $\mathbf{5}$ in chloroform- $d$.

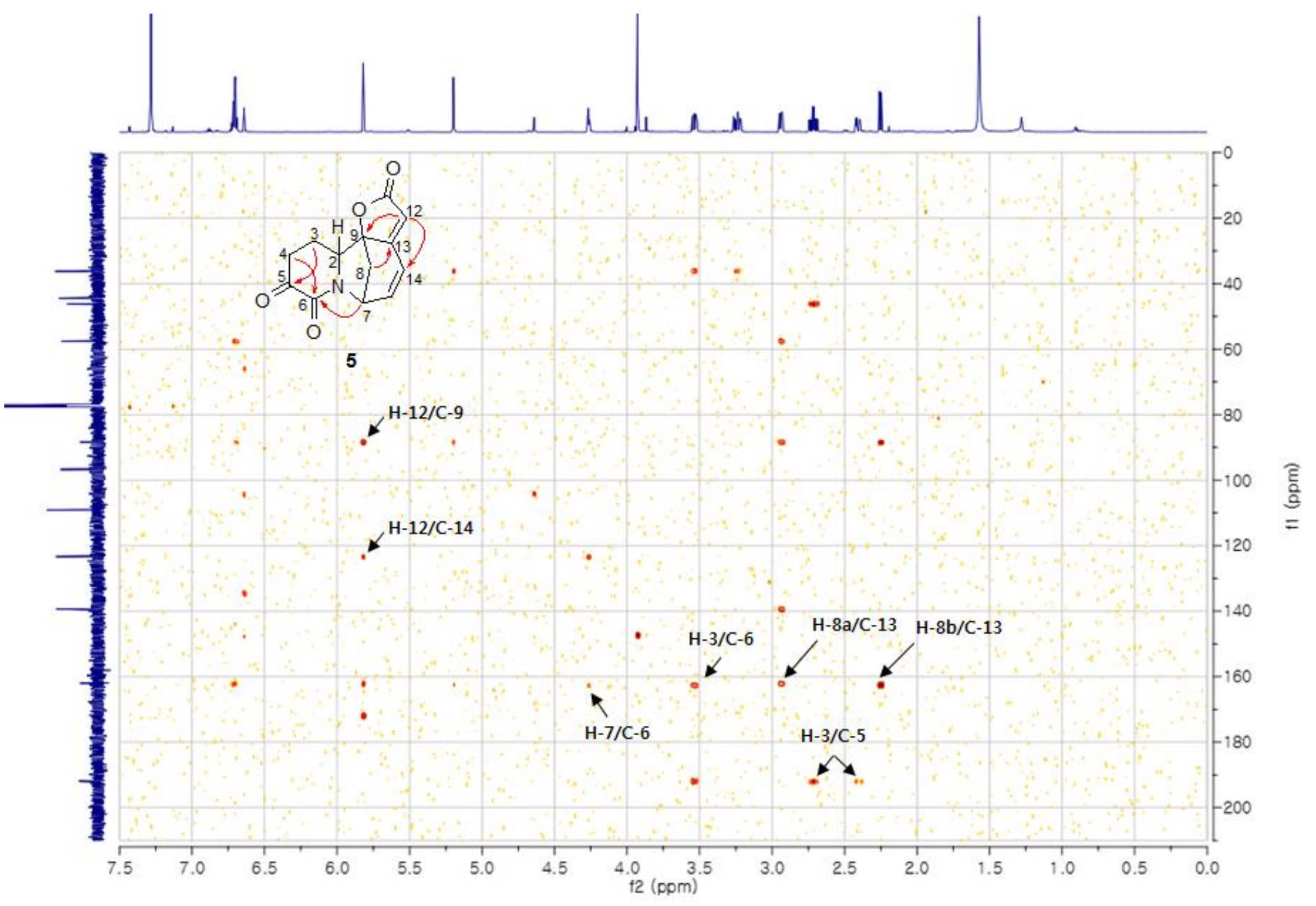


Figure S38. The NOESY spectrum of $\mathbf{5}$ in chloroform- $d$.

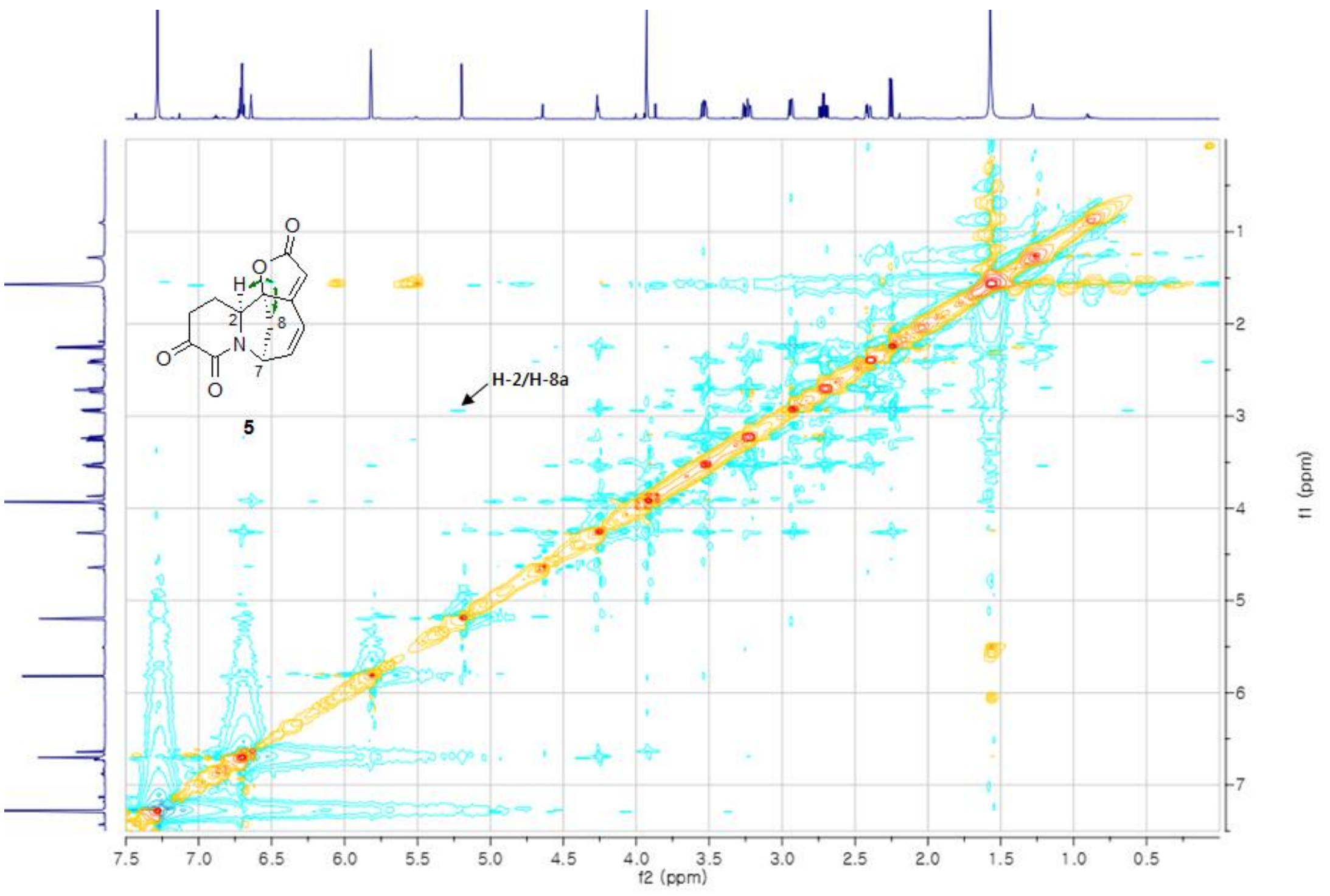


Figure S39. The HRESIMS spectrum of $\mathbf{6}$.

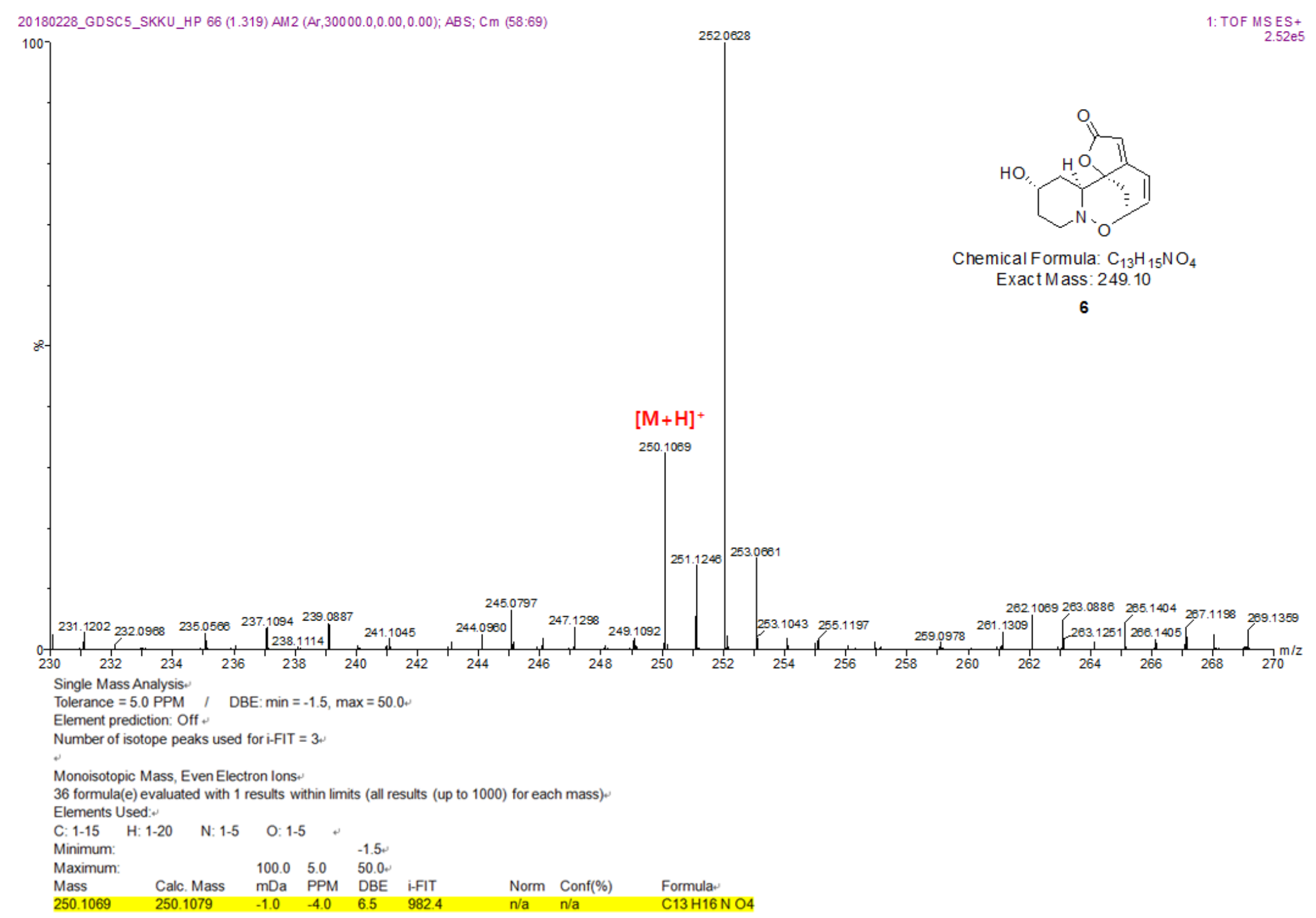


Figure S40. The ${ }^{1} \mathrm{H}$ NMR spectrum of 6 in chloroform- $d$.

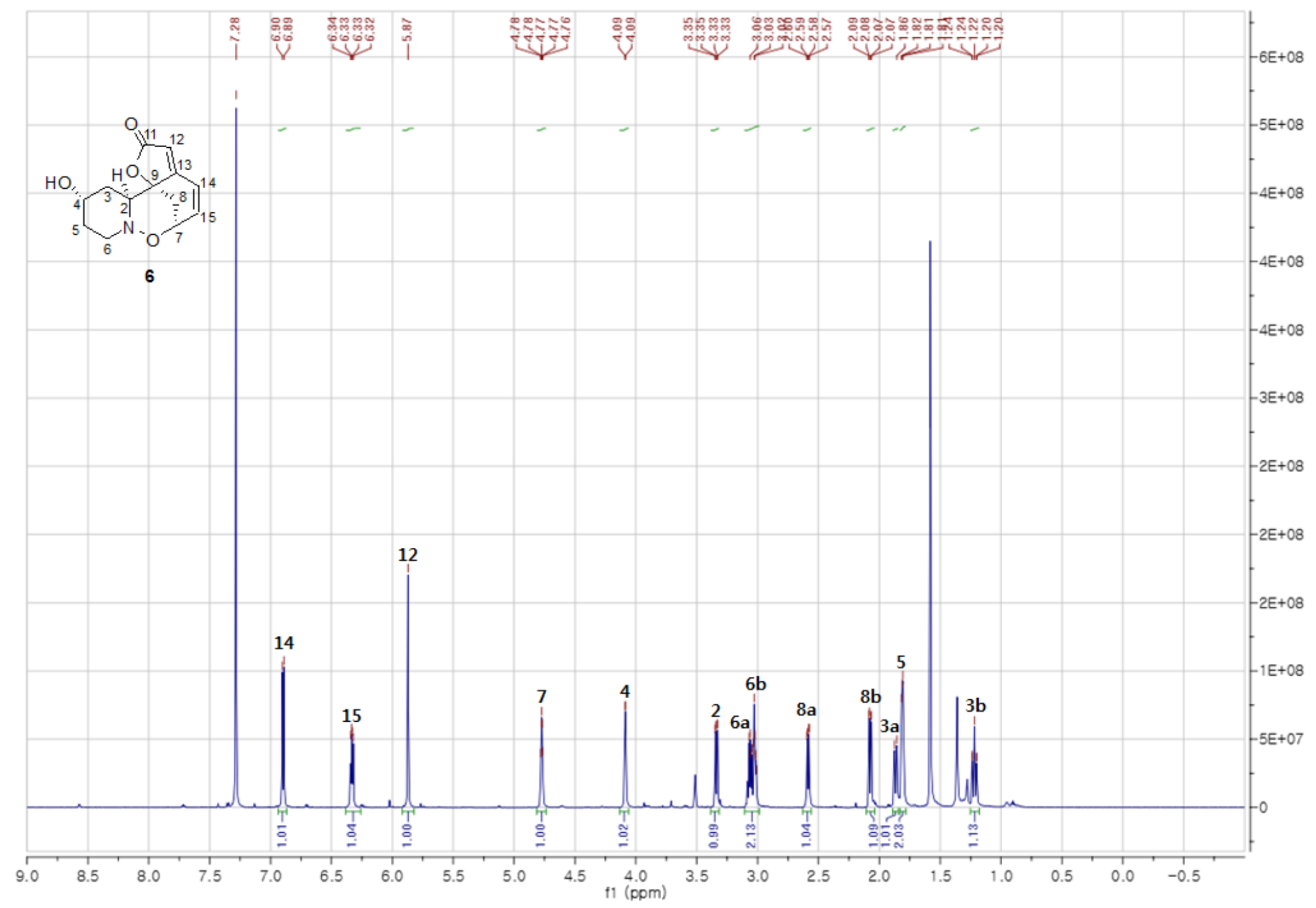


Figure S41. The ${ }^{13} \mathrm{C}$ NMR spectrum of 6 in chloroform- $d$.

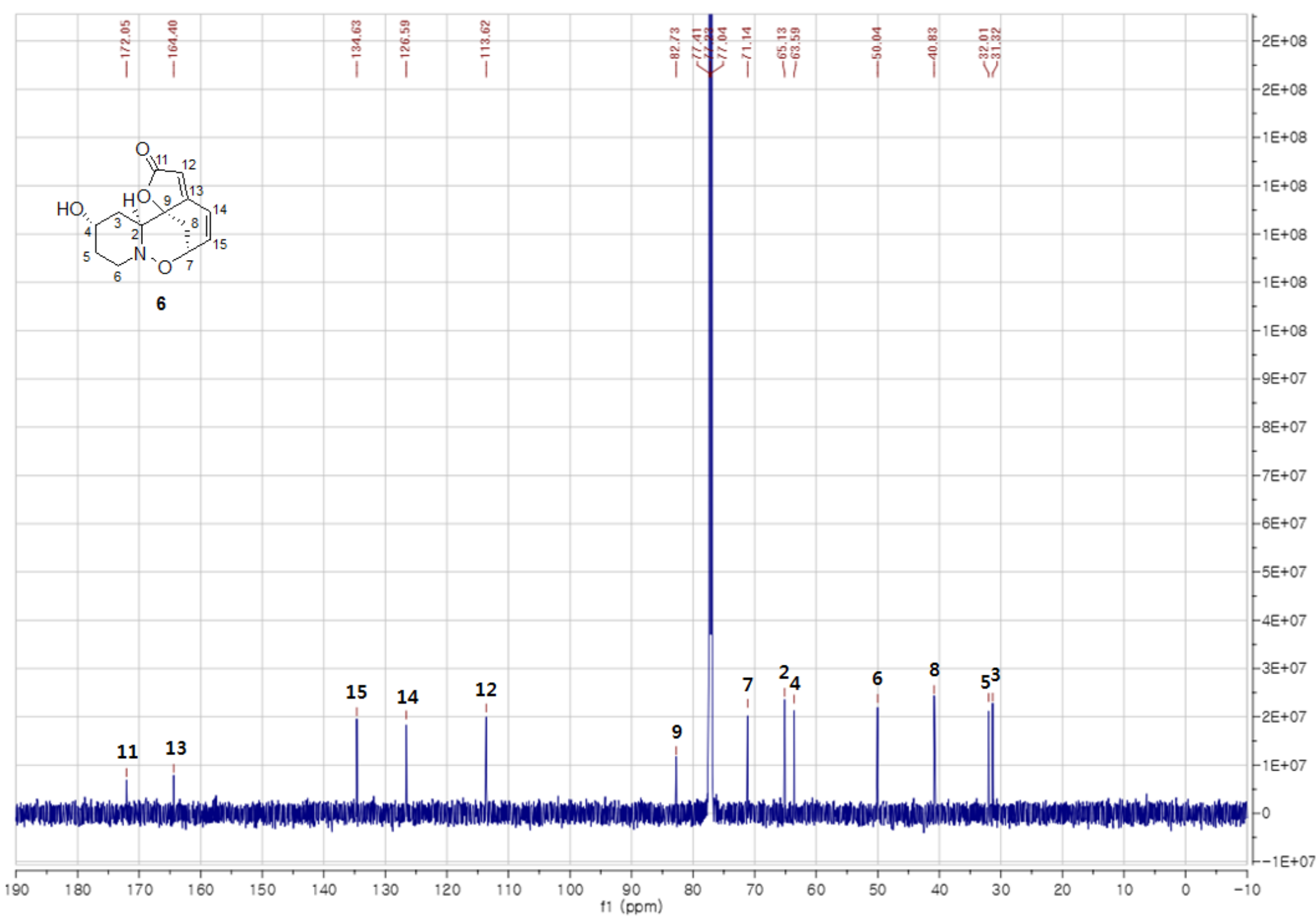


Figure S42. The COSY spectrum of $\mathbf{6}$ in chloroform- $d$.

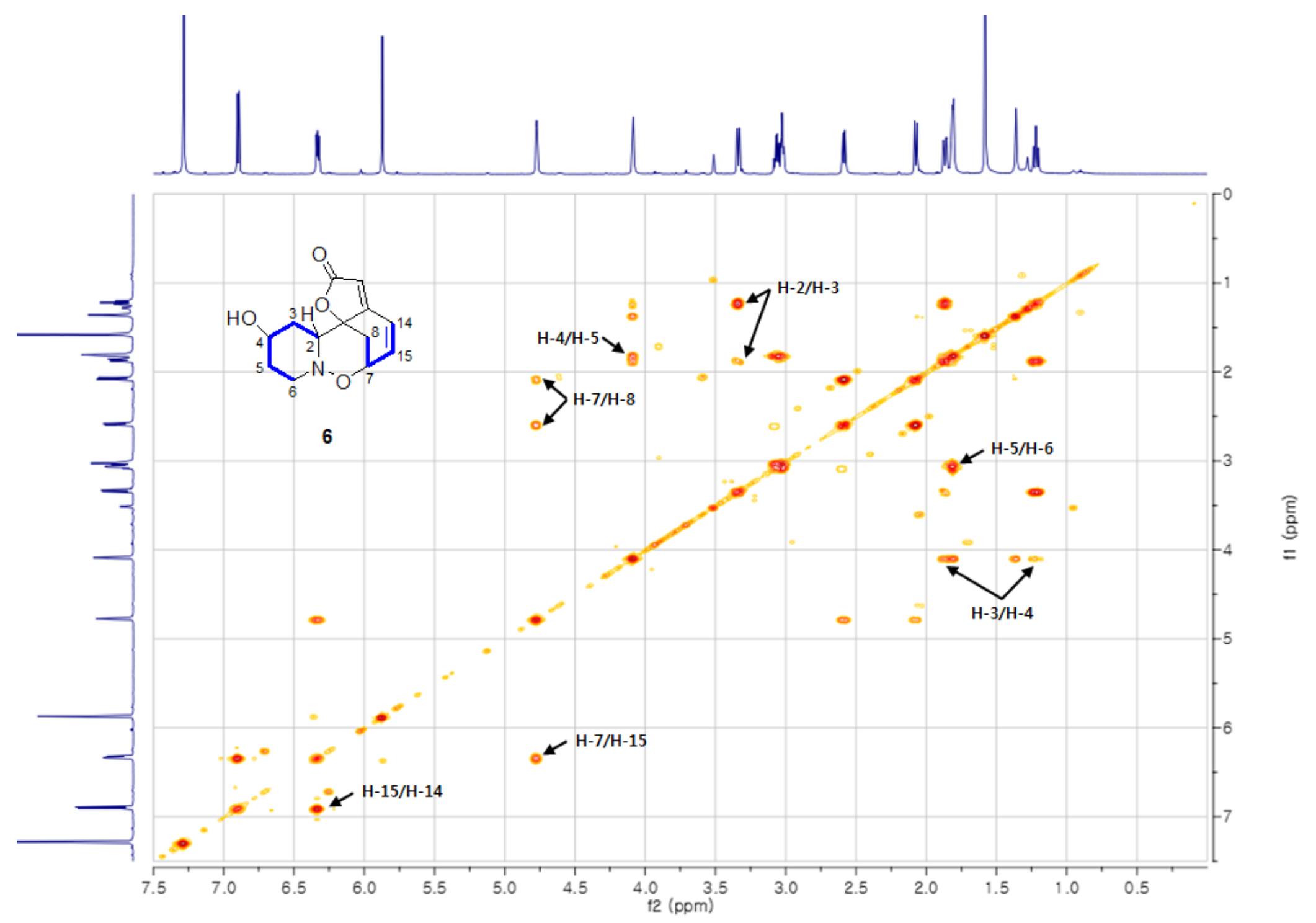


Figure S43. The HSQC spectrum of $\mathbf{6}$ in chloroform- $d$.

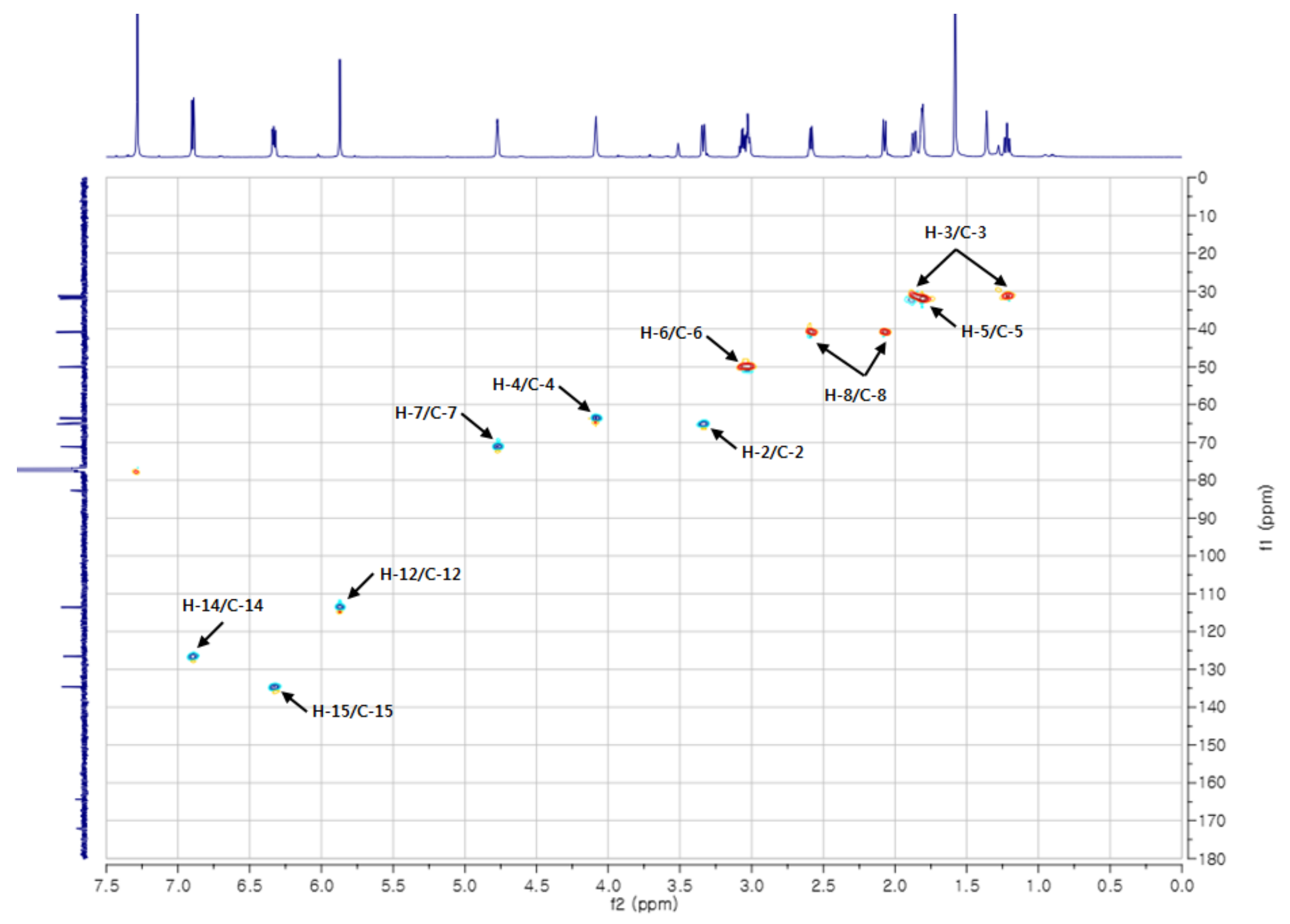


Figure S44. The HMBC spectrum of 6 in chloroform- $d$.

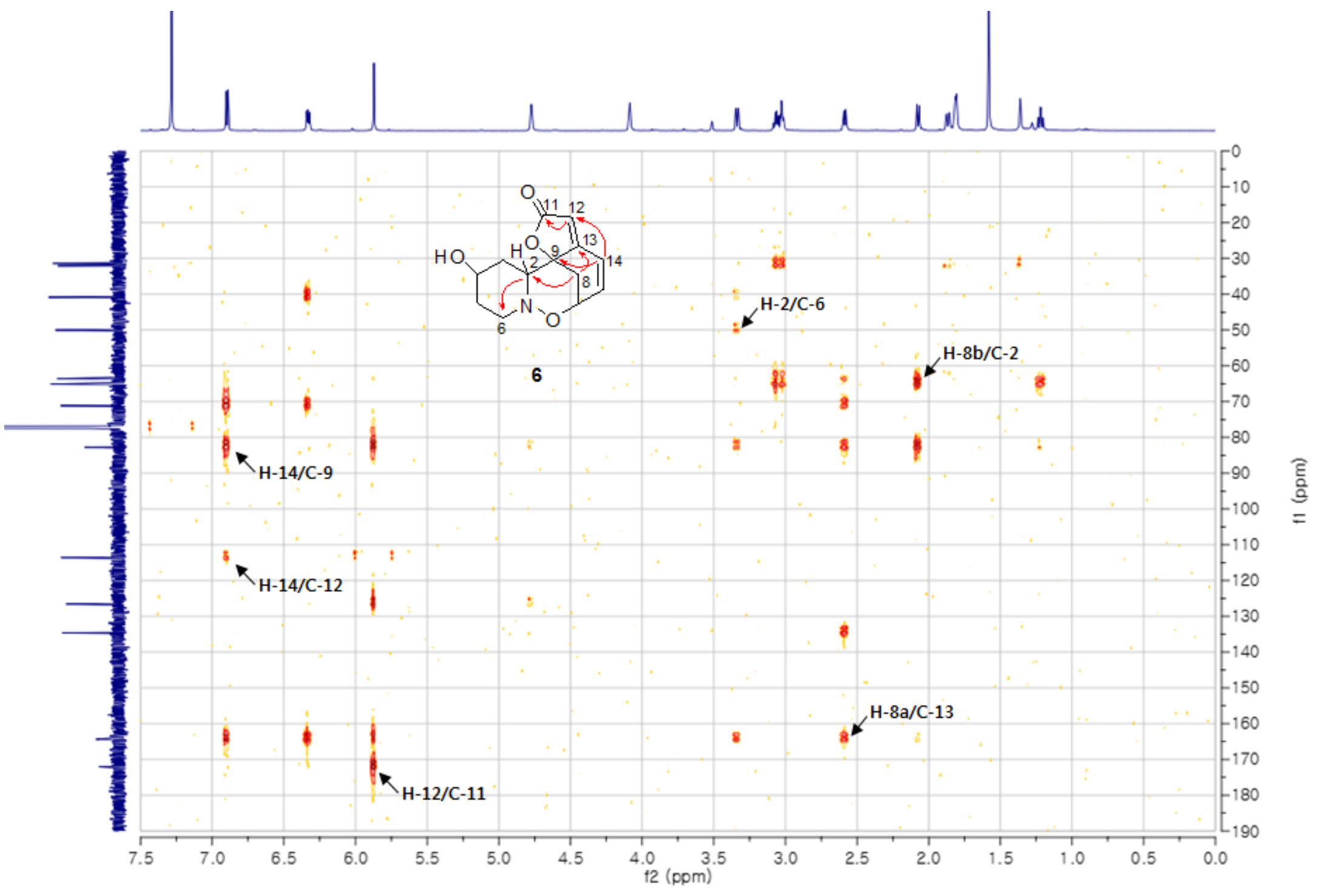


Figure S45. The NOESY spectrum of 6 in chloroform- $d$.

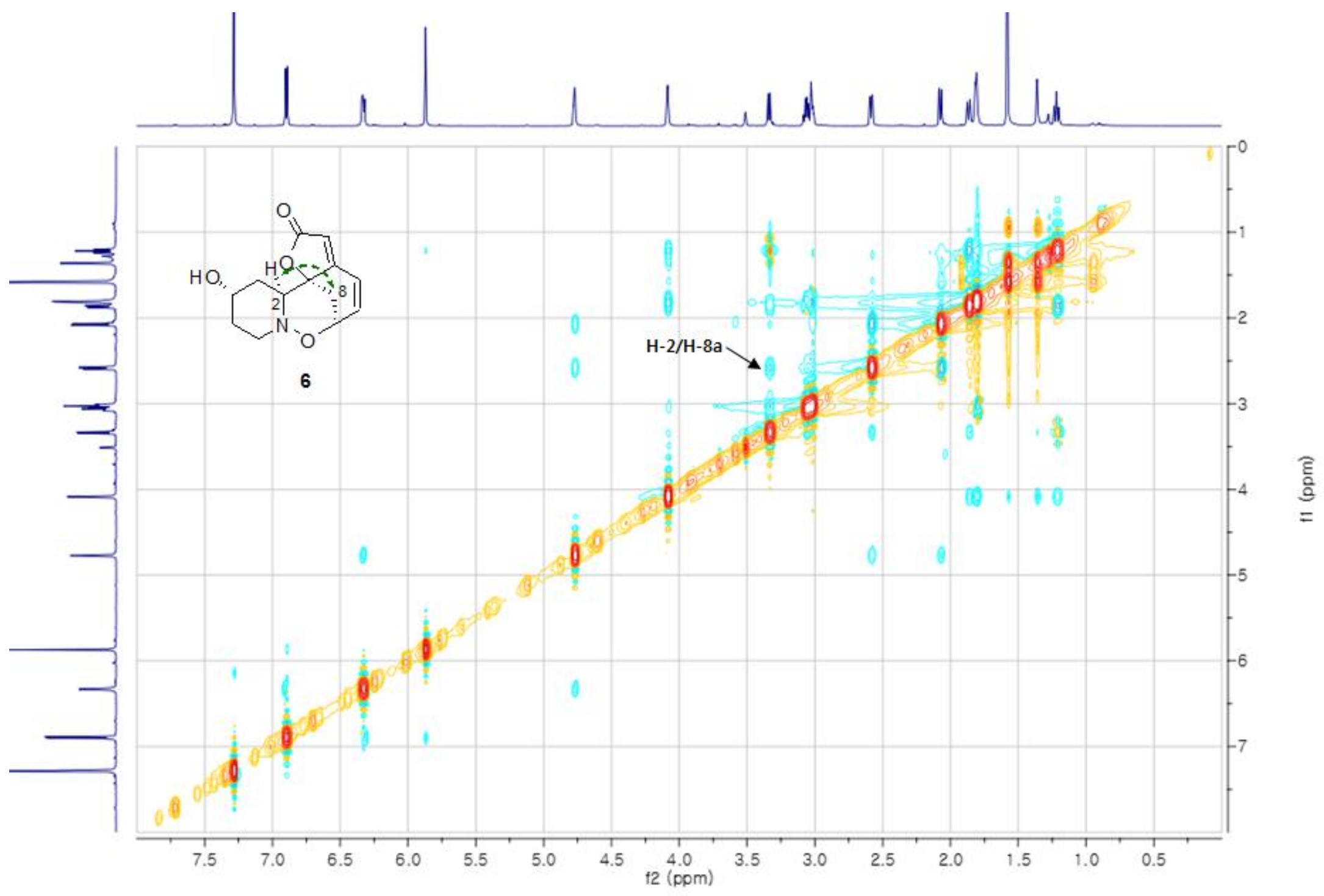


Figure S46. The experimental ECD spectrum of 6.
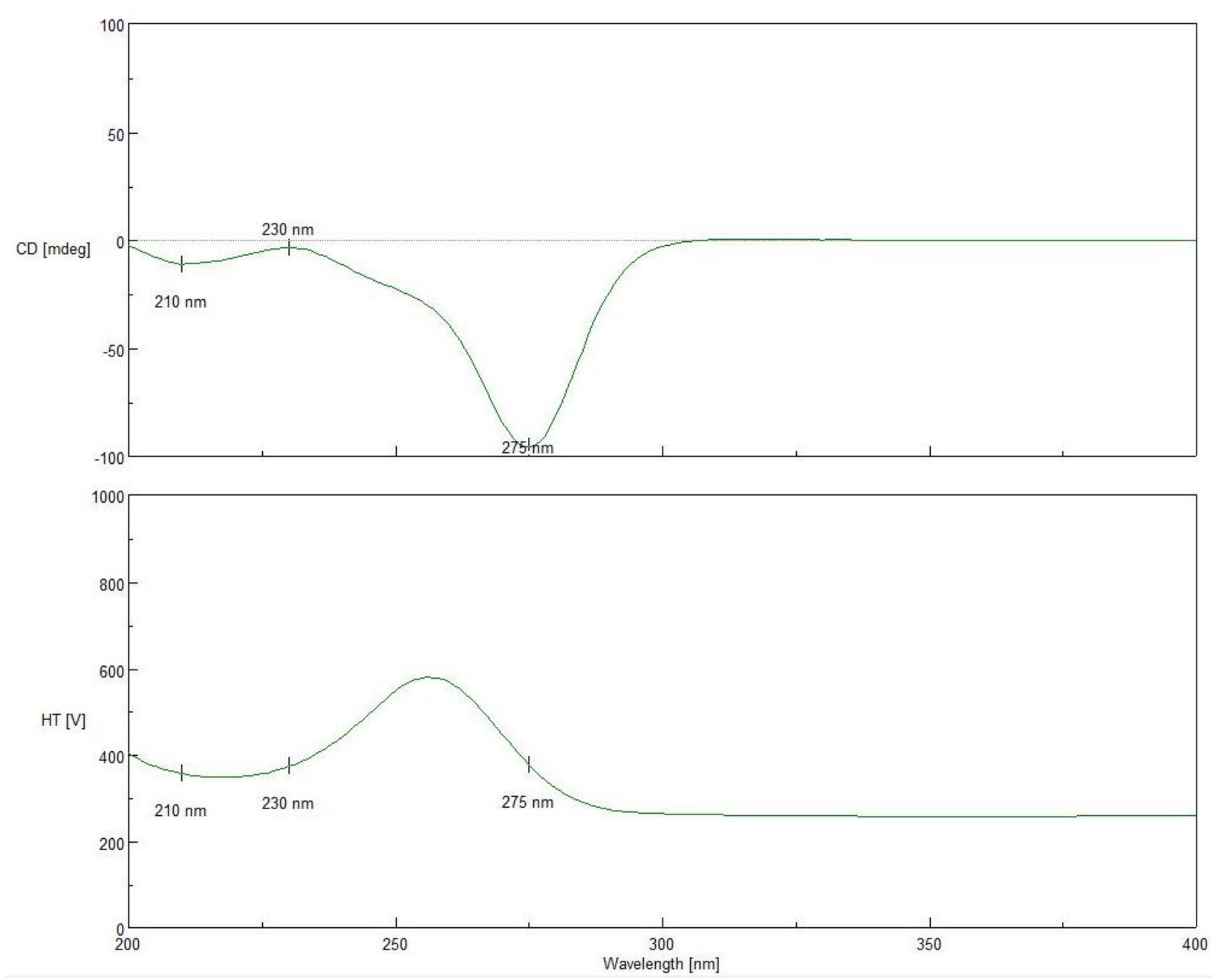
Figure S47. The HRESIMS spectrum of 7.

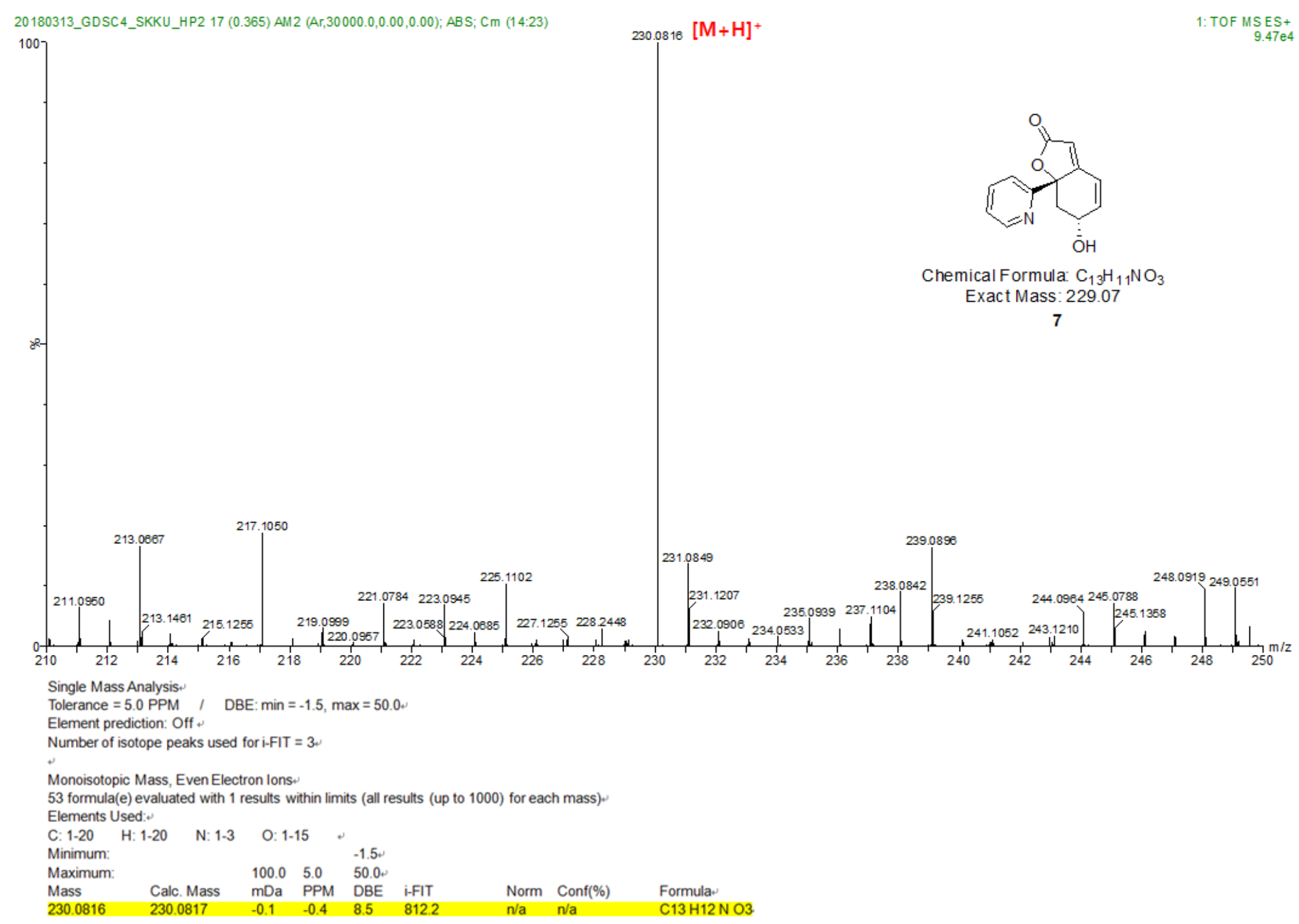


Figure S48. The ${ }^{1} \mathrm{H}$ NMR spectrum of 7 in chloroform- $d$.

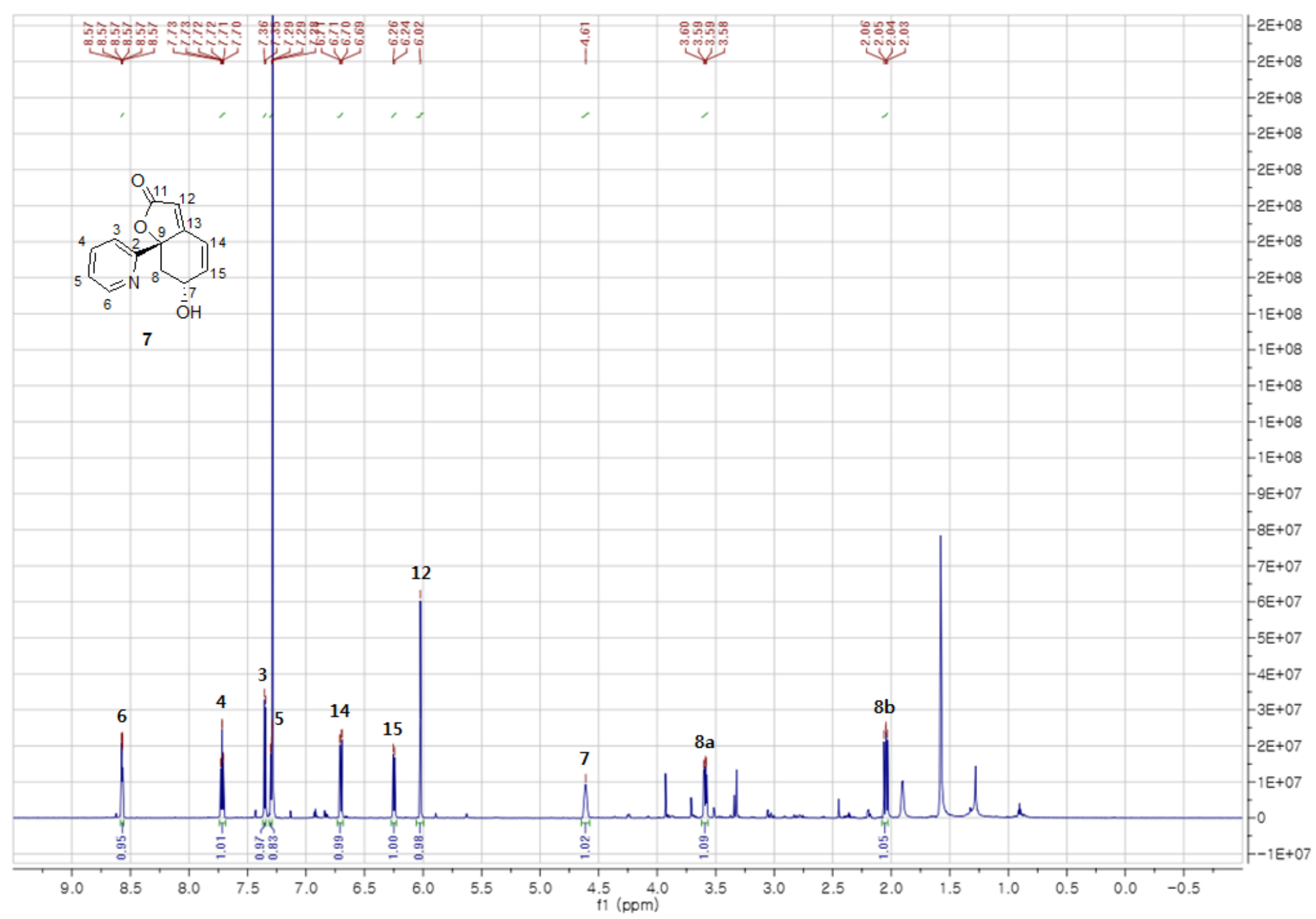


Figure S49. The ${ }^{13} \mathrm{C}$ NMR spectrum of 7 in chloroform- $d$.

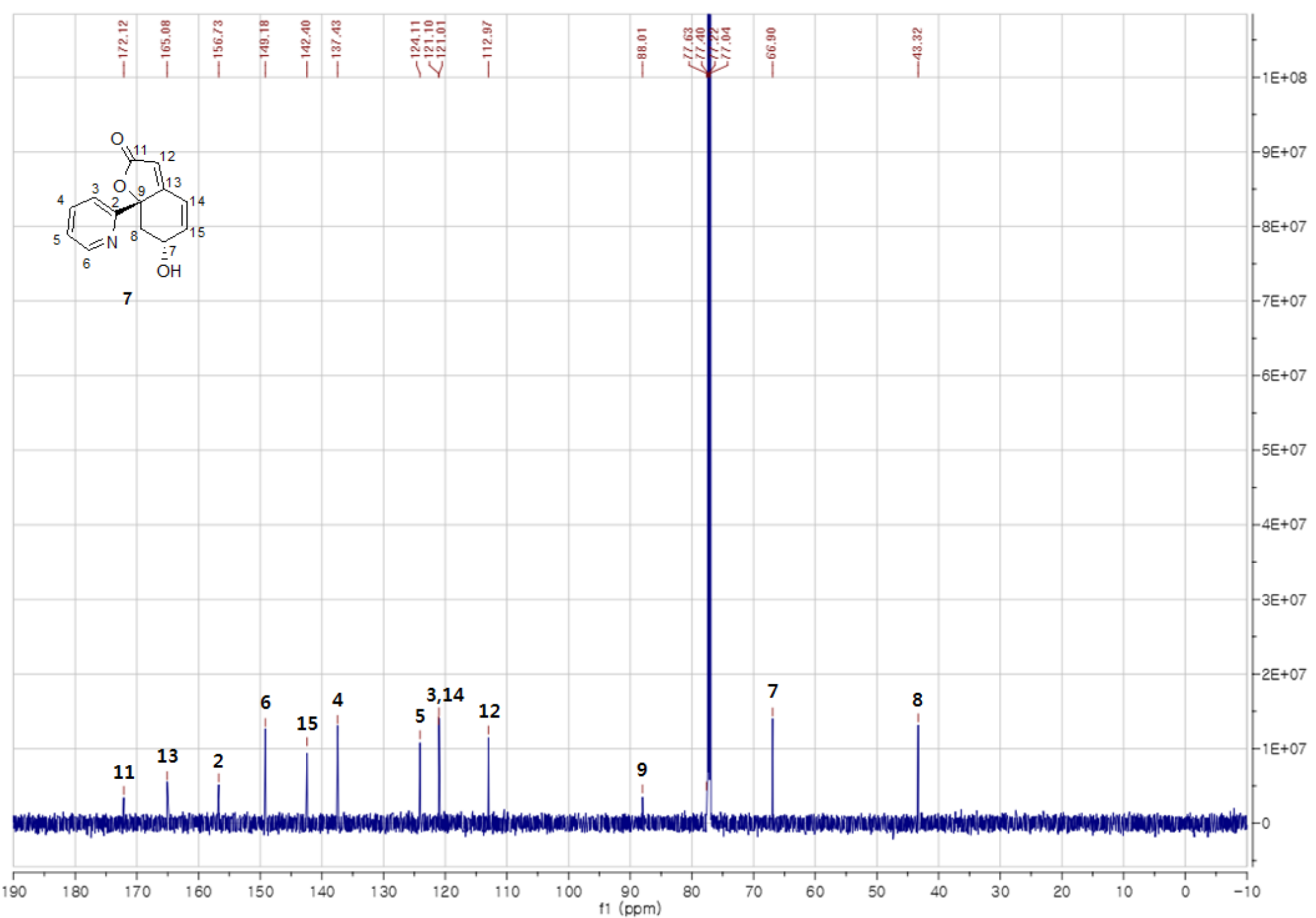


Figure S50. The COSY spectrum of 7 in chloroform- $d$.

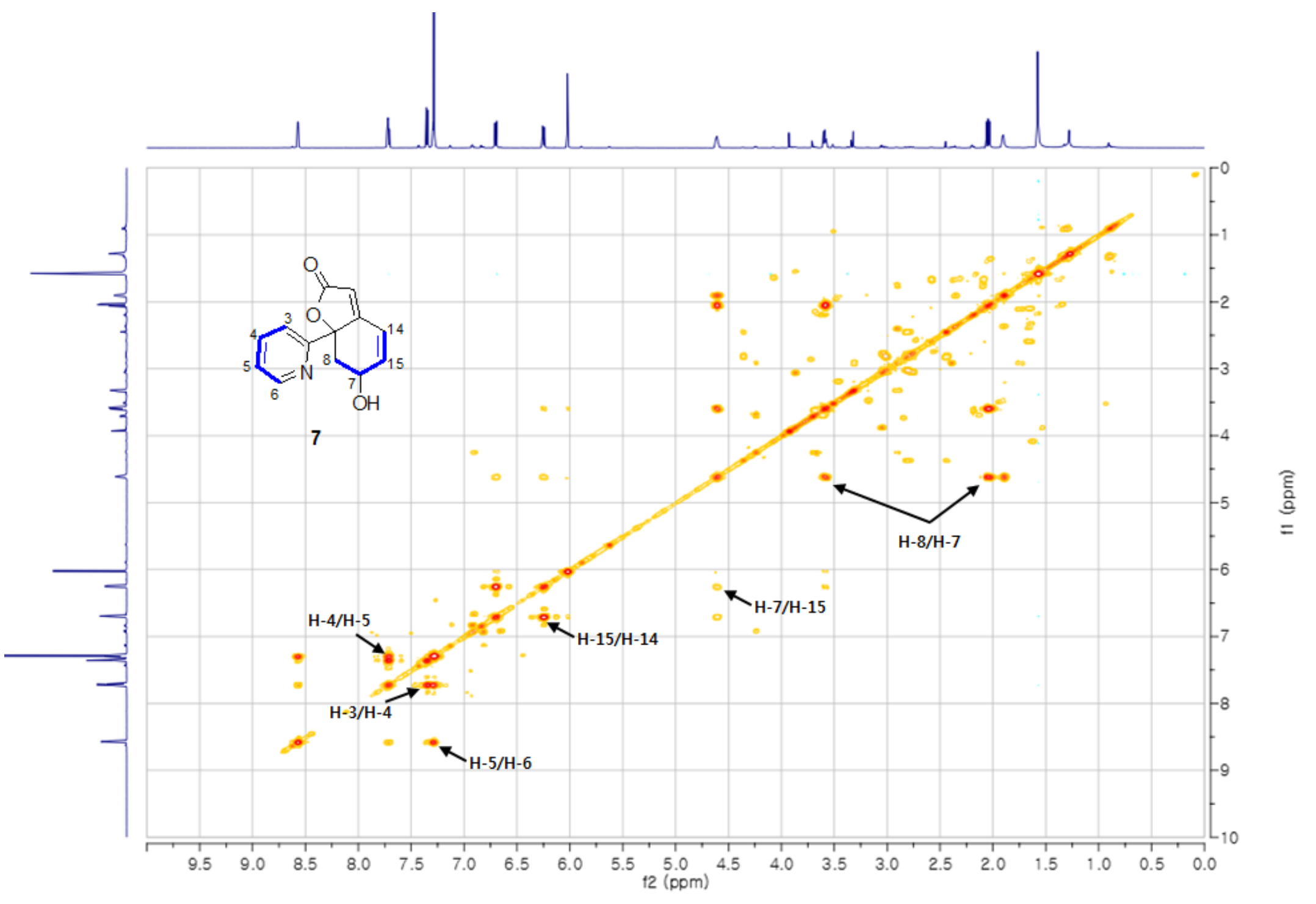


Figure S51. The HSQC spectrum of 7 in chloroform- $d$.

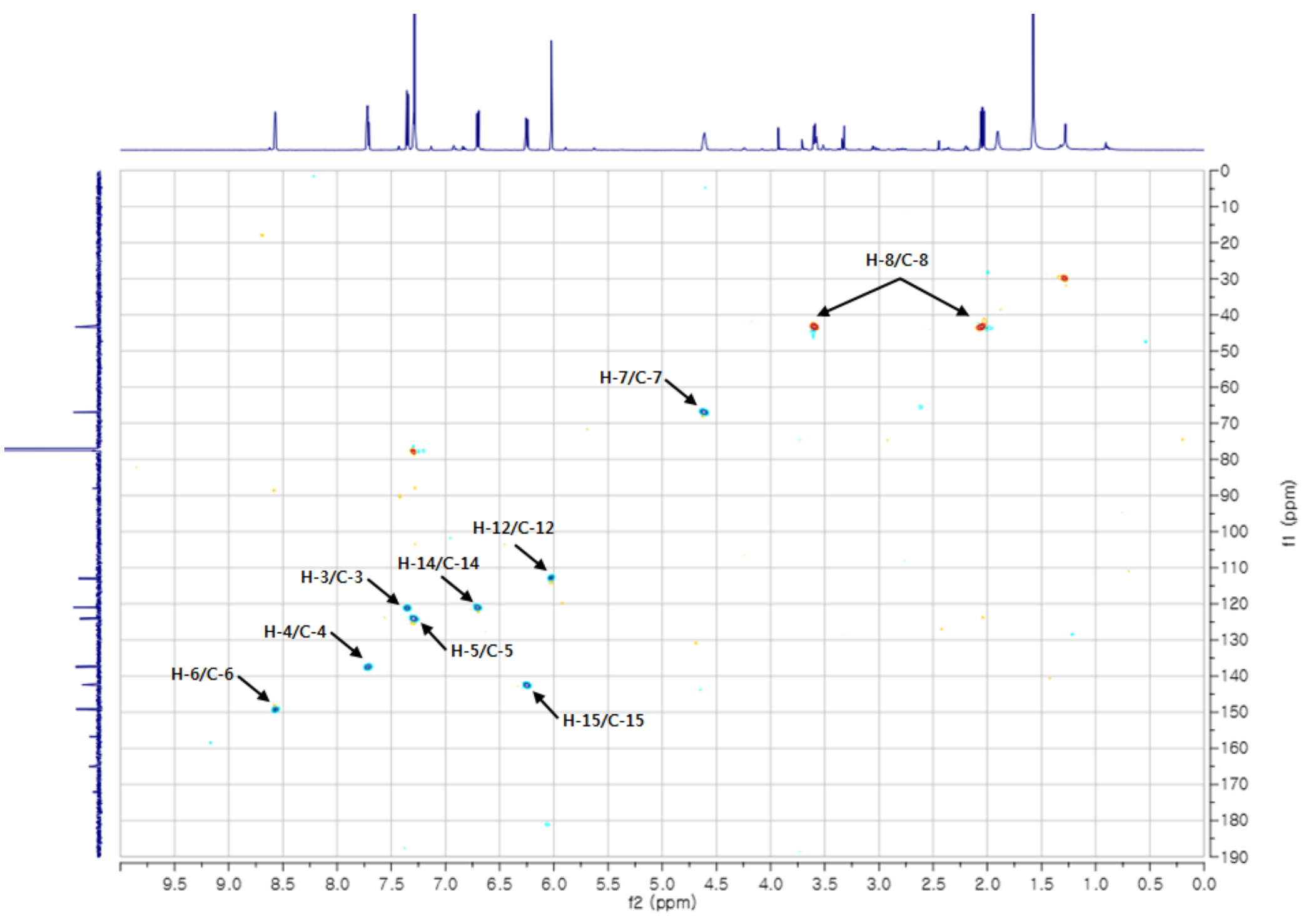


Figure S52. The HMBC spectrum of 7 in chloroform- $d$.

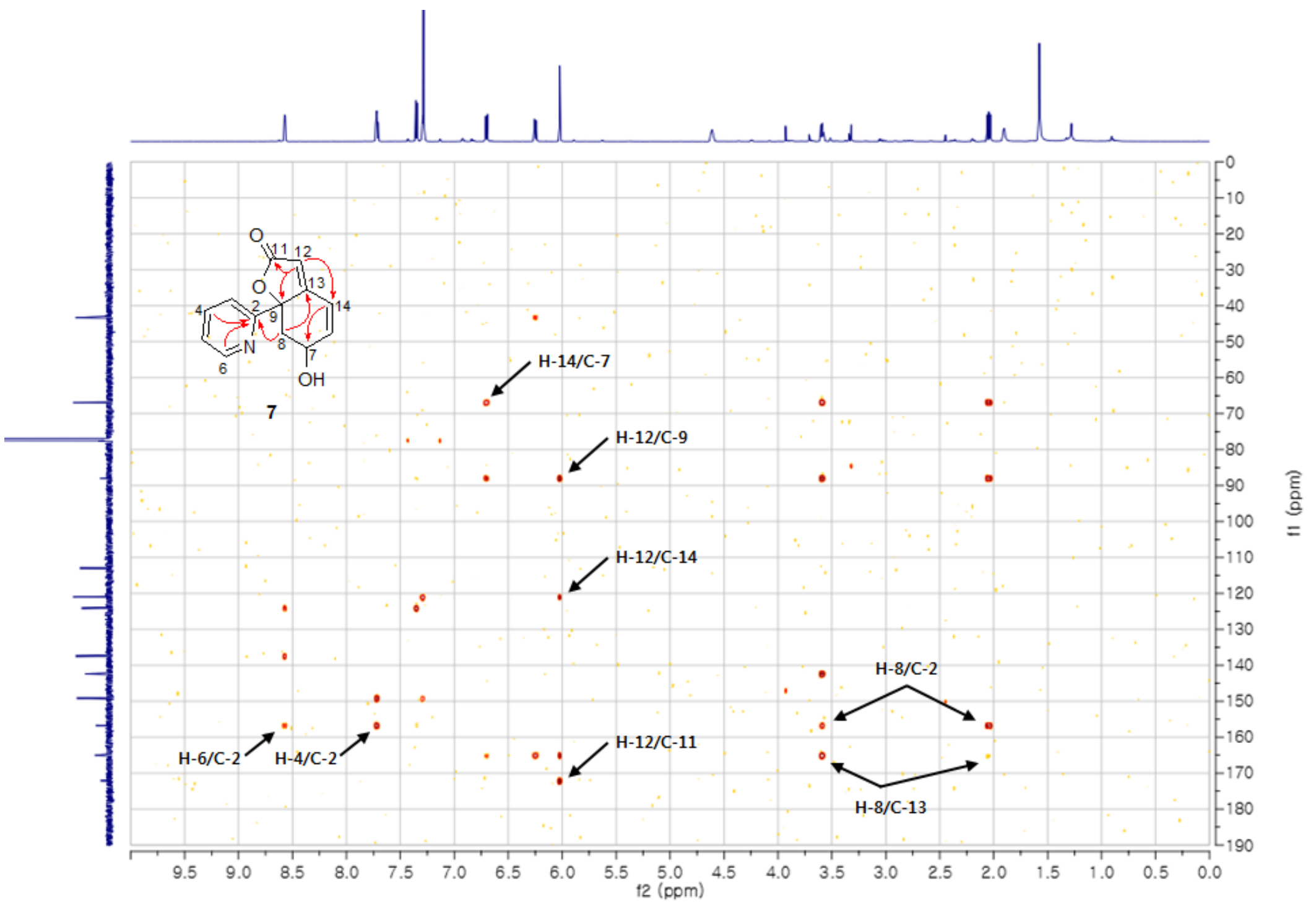


Figure S53. The ${ }^{1} \mathrm{H}$ NMR spectrum of 8 in chloroform- $d$.

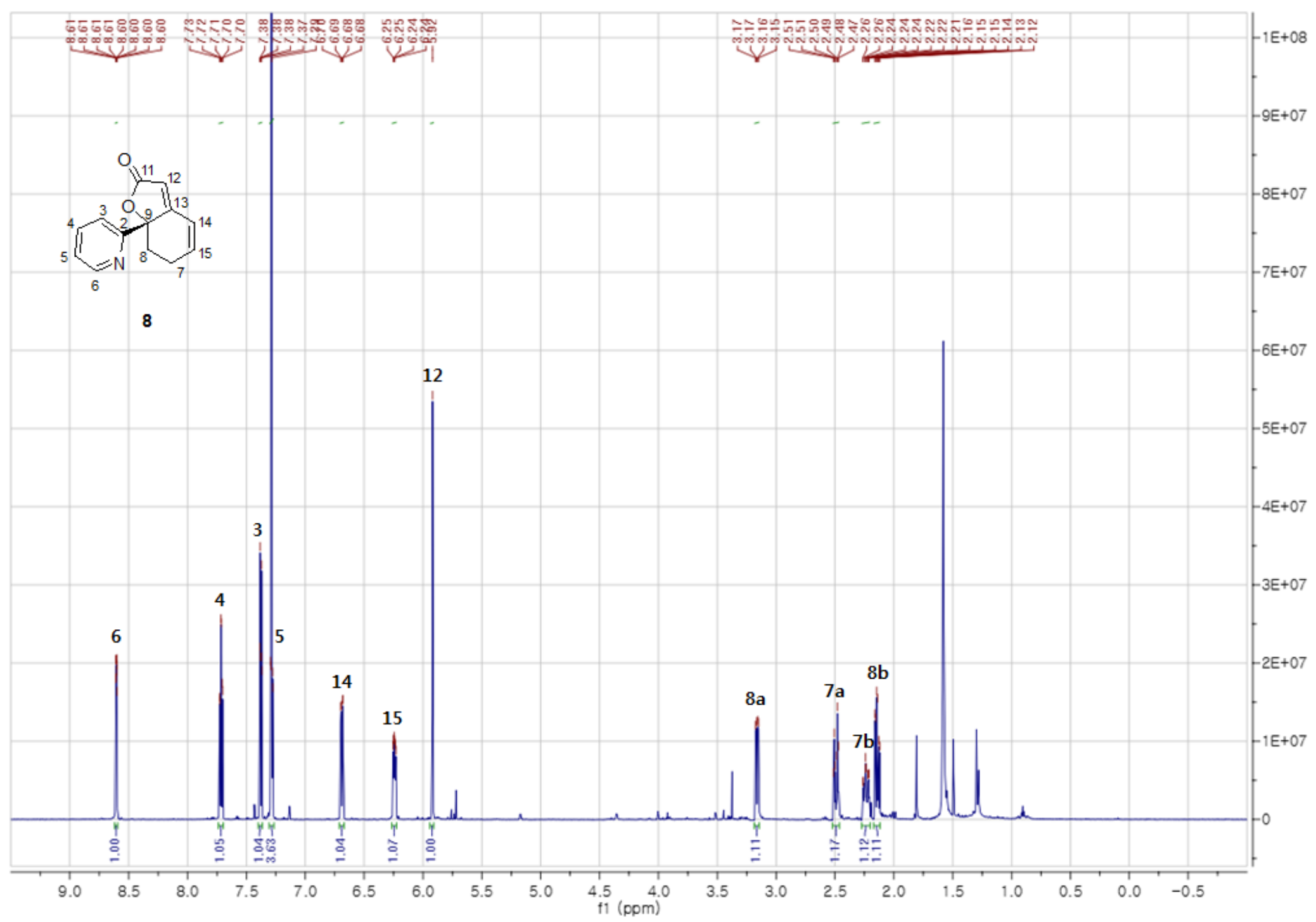


Figure S54. The ${ }^{13} \mathrm{C}$ NMR spectrum of 8 in chloroform- $d$.

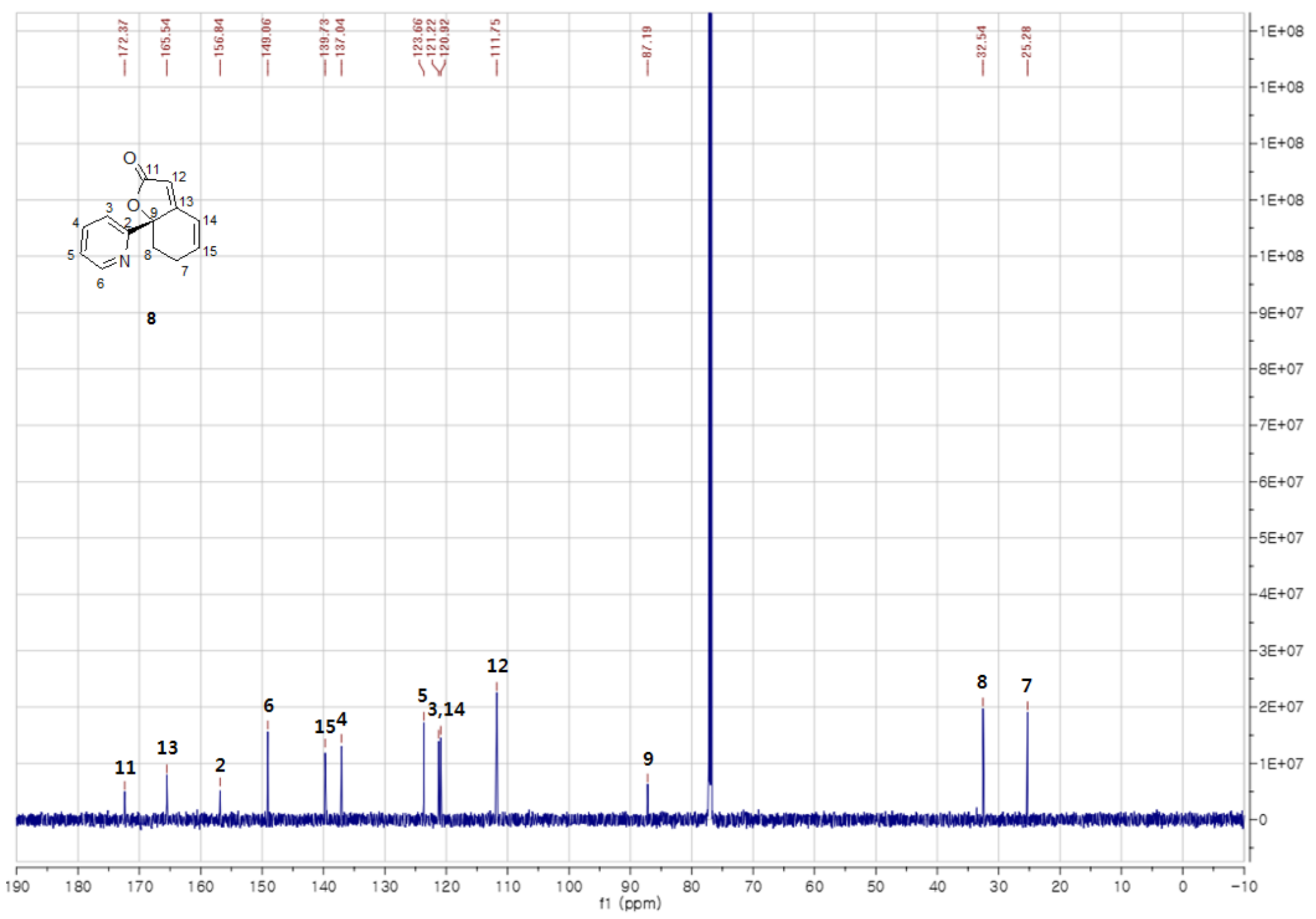


Figure S55. The COSY spectrum of $\mathbf{8}$ in chloroform- $d$.

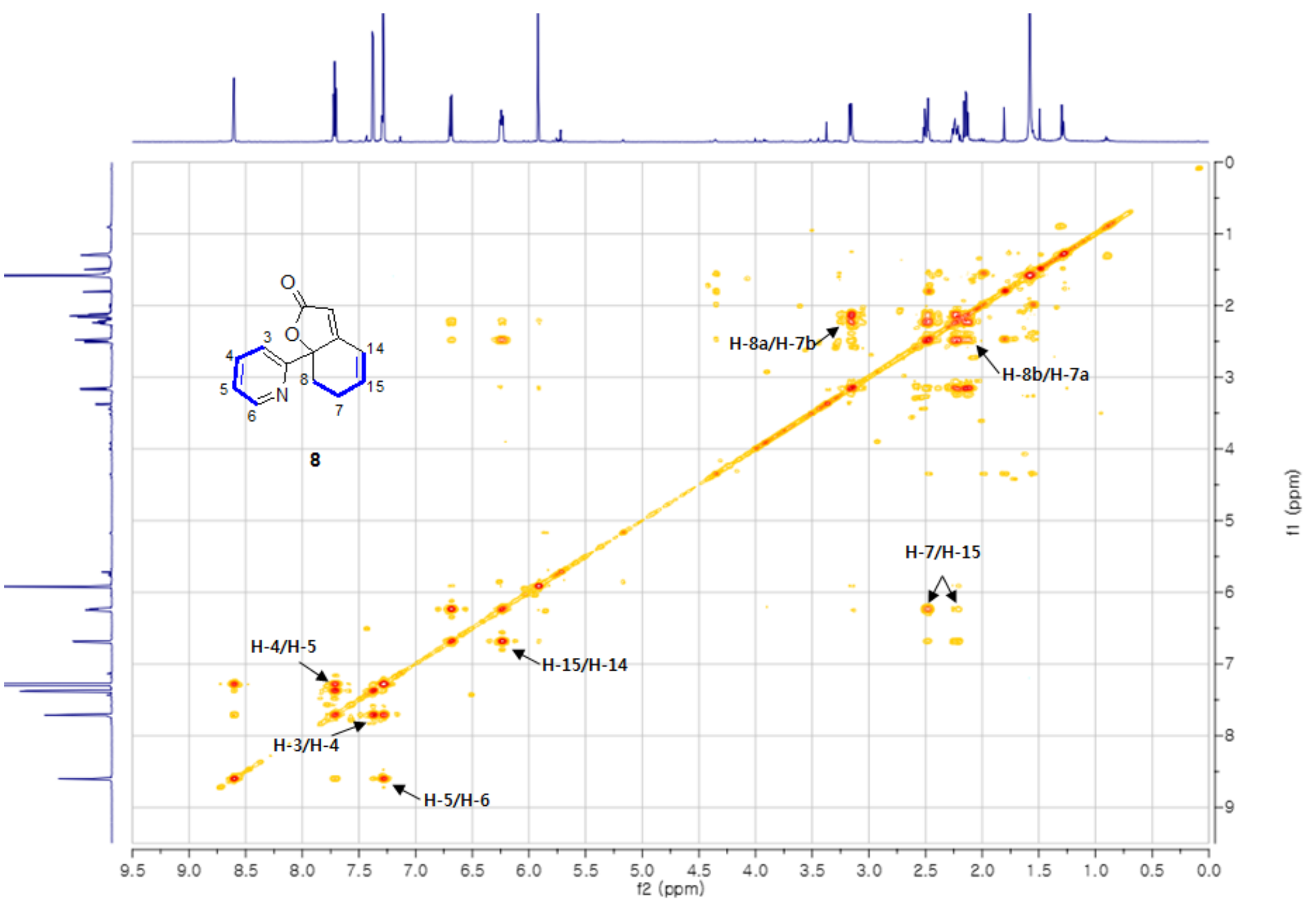


Figure S56. The HSQC spectrum of $\mathbf{8}$ in chloroform- $d$.

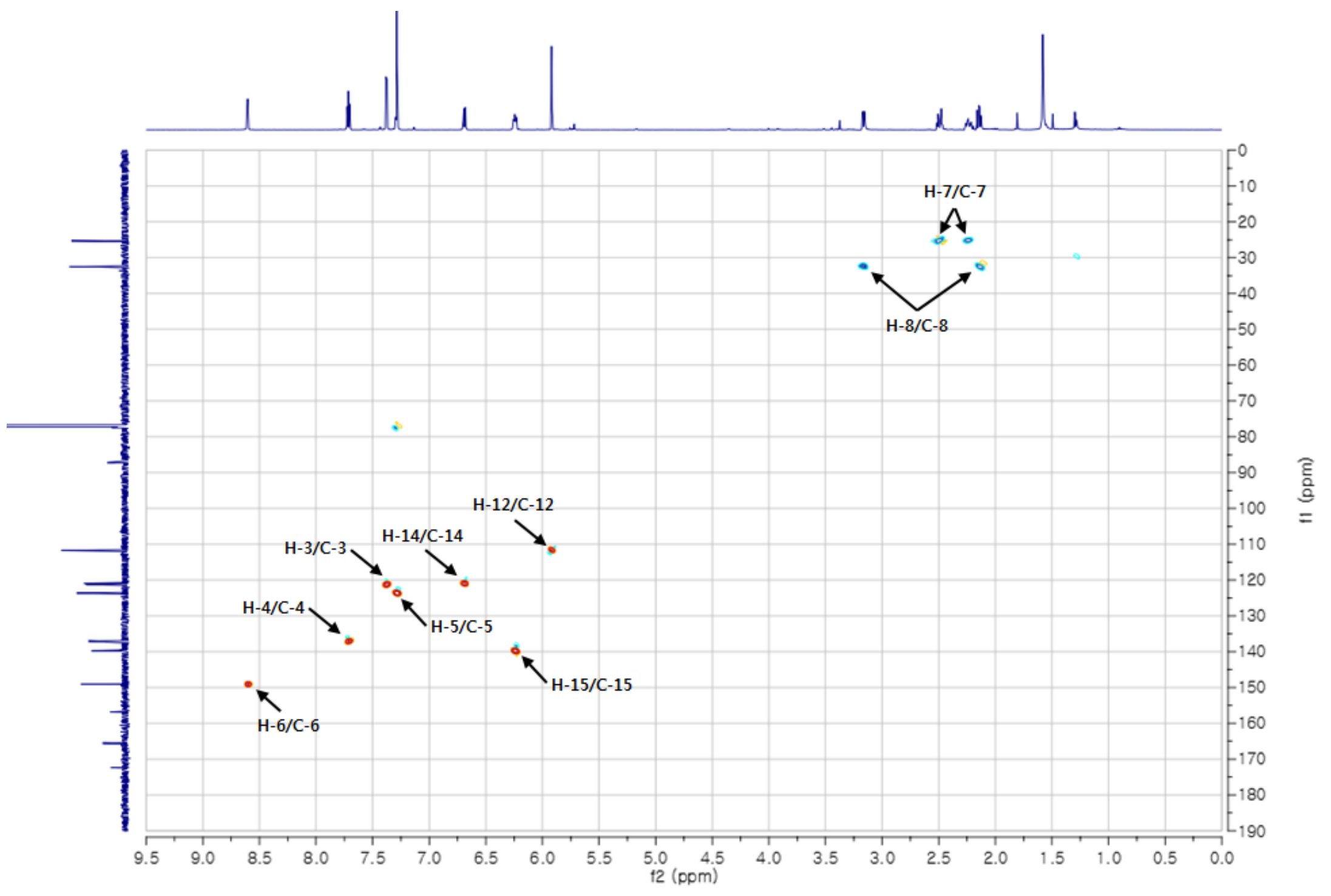




$$
=5
$$


Figure S58. Experimental and calculated ECD spectra of $\mathbf{8}$.

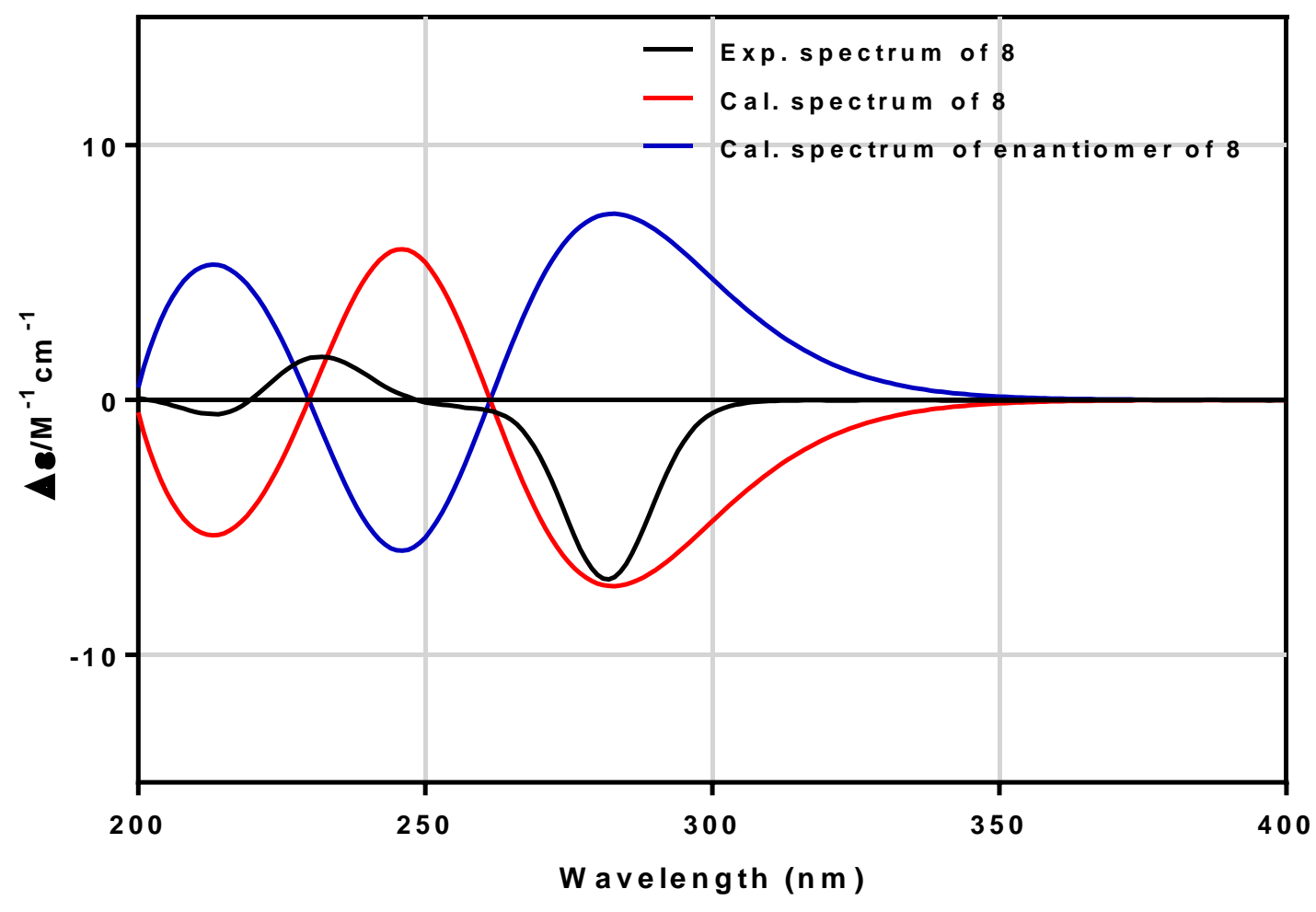


Figure S59. The chemical structures of 1a-1d.

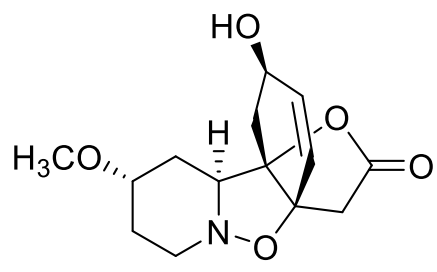

$1 a$

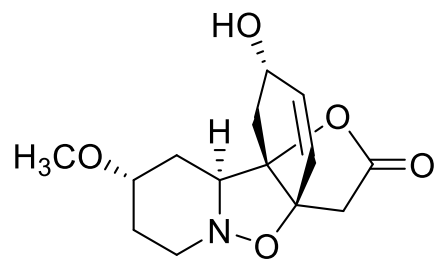

1c

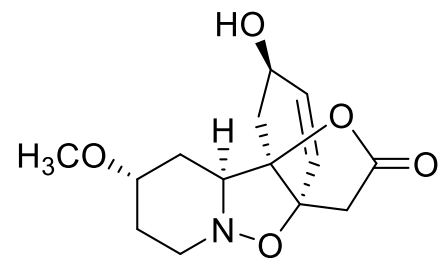

1b

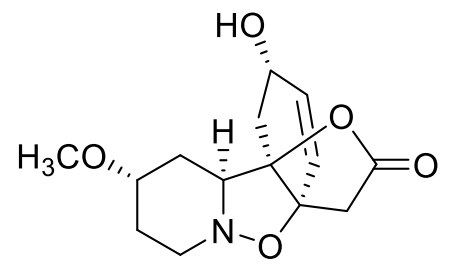

1d 
Figure S60. The 3D structures of the conformers of 1a-1d (Boltzmann populations in parenthesis) .

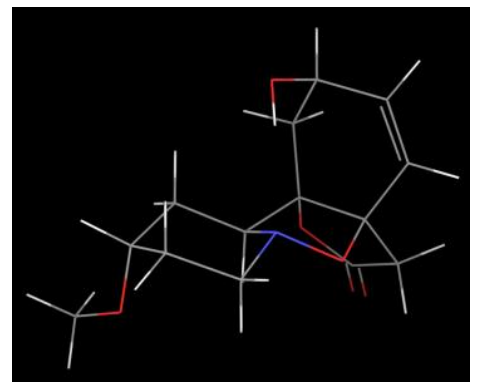

Conformer $1(40.3 \%)$

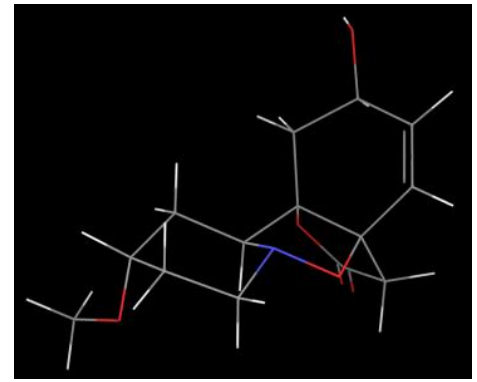

Conformer 4 (7.6\%)

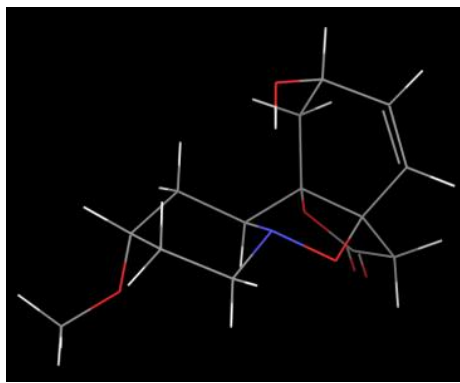

Conformer $2(23.1 \%)$

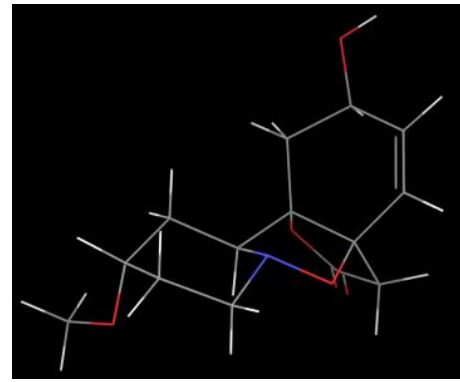

Conformer 5 (6.0\%)

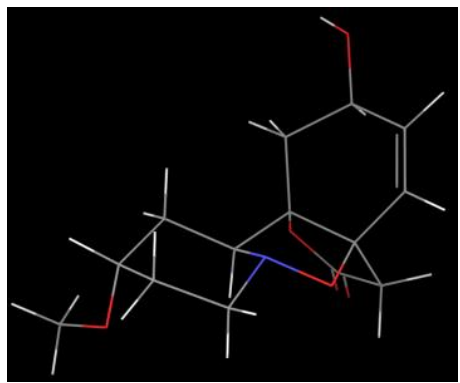

Conformer 3 (8.2\%)

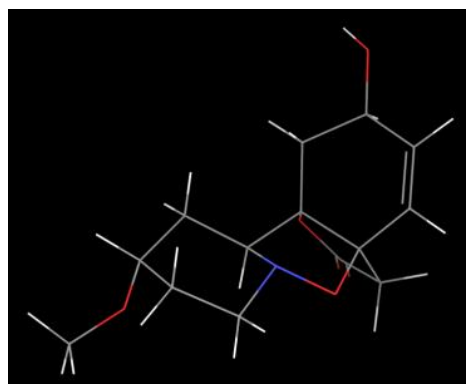

Conformer 7 (5.8\%)

1a

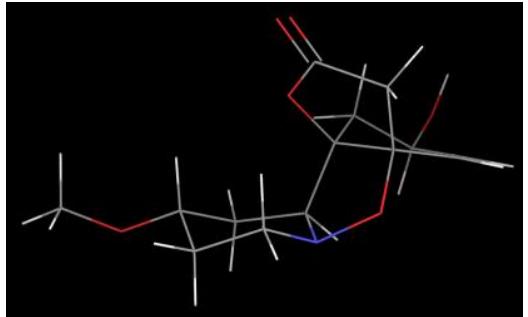

Conformer $1(25.8 \%)$

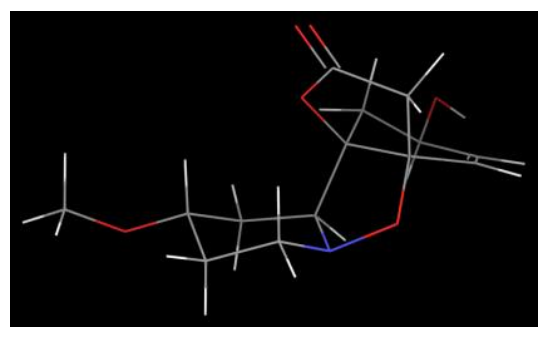

Conformer 4 (15.3\%)

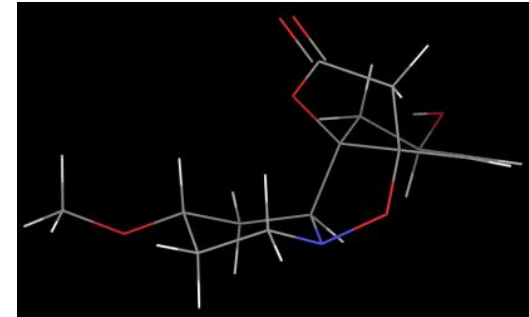

Conformer 2 (20.1\%)

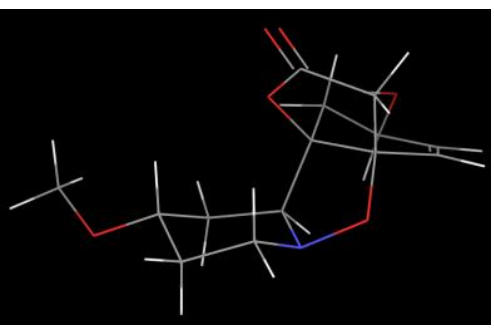

Conformer 5 (11.4\%)

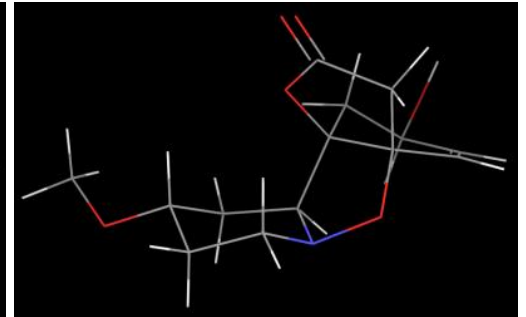

Conformer 3 (17.3\%)

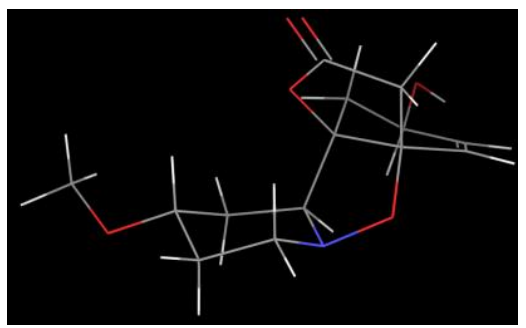

Conformer 7 (10.1\%) 
Figure S60. The 3D structures of the conformers of $\mathbf{1 a}-\mathbf{1 d}$ (continued) .

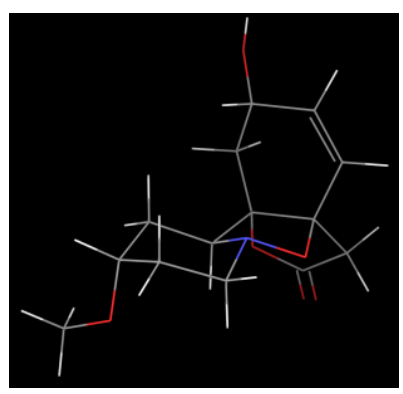

Conformer $1(25.4 \%)$

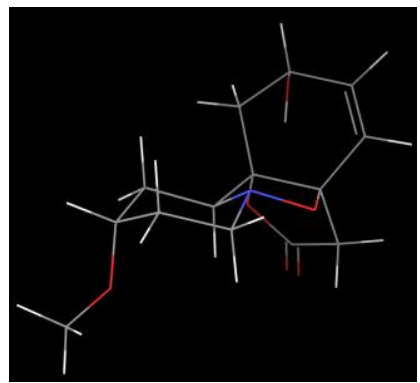

Conformer $4(11.7 \%)$

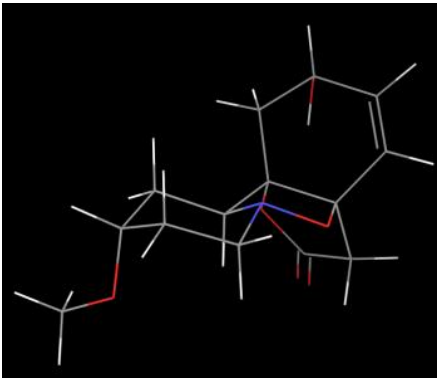

Conformer 2 (19.1\%)

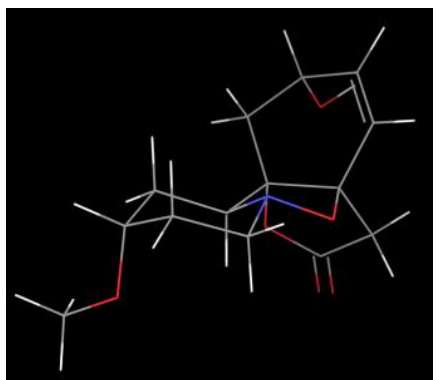

Conformer 5 (9.1\%)

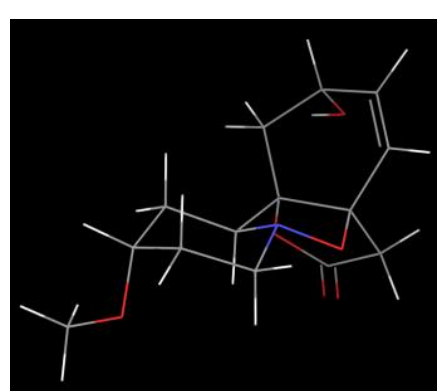

Conformer $3(15.4 \%)$

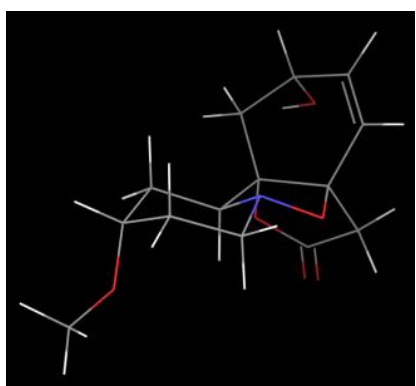

Conformer 7 (8.4\%)

1c

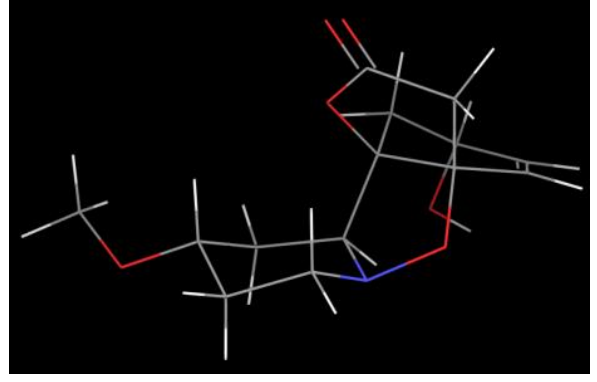

Conformer $1(41.8 \%)$

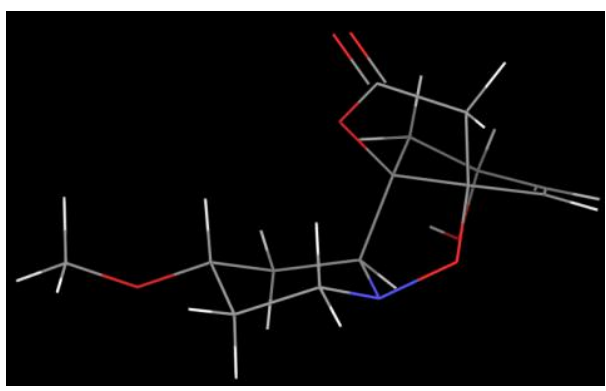

Conformer $3(13.3 \%)$

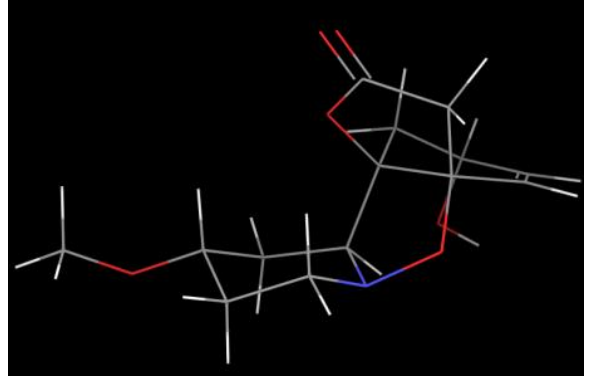

Conformer 2 (34.5\%)

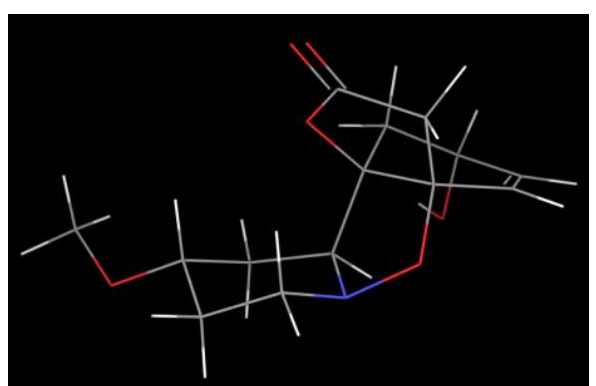

Conformer 4 (10.3\%) 
Table S1. Experimental (Exp.) and calculated (Cal.) ${ }^{1} \mathrm{H}$ and ${ }^{13} \mathrm{C}$ chemical shift values of 1 and its possible isomers 1a-1d used for DP4+ analysis.

\begin{tabular}{|c|c|c|c|c|c|c|c|c|c|c|c|}
\hline \multirow{2}{*}{ Carbon } & \multirow{2}{*}{$\frac{\text { Exp. }}{1}$} & \multicolumn{4}{|c|}{ Cal. } & \multirow{2}{*}{ Proton } & \multirow{2}{*}{$\frac{\text { Exp. }}{1}$} & \multicolumn{4}{|c|}{ Cal. } \\
\hline & & 1a & $1 b$ & 1c & $1 d$ & & & $1 \mathbf{a}$ & $1 \mathrm{~b}$ & 1c & 1d \\
\hline 2 & 67.1 & 73.0 & 66.2 & 72.9 & 67.6 & 2 & 2.51 & 2.82 & 3.47 & 2.83 & 4.42 \\
\hline 3 & 28.9 & 30.4 & 33.0 & 30.4 & 31.7 & $3 a$ & 2.12 & 2.21 & 2.36 & 2.38 & 2.49 \\
\hline 4 & 72.2 & 76.0 & 76.0 & 76.1 & 76.2 & $3 b$ & 1.77 & 1.96 & 1.80 & 1.33 & 1.78 \\
\hline 5 & 28.1 & 32.6 & 32.5 & 33.7 & 33.2 & 4 & 3.59 & 3.44 & 3.63 & 3.43 & 3.64 \\
\hline 6 & 49.5 & 52.5 & 55.6 & 53.0 & 55.9 & $5 a$ & 2.07 & 1.99 & 2.04 & 1.94 & 1.98 \\
\hline 7 & 64.2 & 66.8 & 69.6 & 67.8 & 67.7 & $5 b$ & 1.73 & 1.73 & 1.46 & 1.70 & 1.49 \\
\hline 8 & 37.6 & 38.7 & 41.2 & 37.4 & 37.6 & $6 a$ & 3.22 & 3.12 & 2.81 & 3.12 & 2.86 \\
\hline 9 & 93.5 & 96.0 & 98.4 & 96.4 & 98.0 & $6 b$ & 2.75 & 2.93 & 3.27 & 2.89 & 3.29 \\
\hline 11 & 174.6 & 171.9 & 172.3 & 172.1 & 172.6 & 7 & 4.43 & 4.21 & 4.34 & 4.53 & 4.53 \\
\hline 12 & 42.2 & 45.7 & 47.0 & 46.7 & 46.0 & $8 a$ & 2.42 & 2.21 & 2.73 & 2.12 & 2.62 \\
\hline 13 & 80.9 & 83.7 & 88.7 & 84.1 & 88.4 & $8 b$ & 1.88 & 1.86 & 1.48 & 1.98 & 1.81 \\
\hline 14 & 126.9 & 128.3 & 127.0 & 131.2 & 130.3 & $12 \mathrm{a}$ & 3.06 & 2.97 & 2.92 & 2.95 & 2.89 \\
\hline 15 & 134.6 & 133.0 & 129.3 & 131.1 & 124.8 & $12 b$ & 2.76 & 2.58 & 2.80 & 2.66 & 2.77 \\
\hline $\mathrm{OCH}_{3}-4$ & 56.0 & 56.5 & 56.8 & 56.4 & 56.7 & 14 & 5.93 & 6.14 & 6.02 & 6.31 & 6.18 \\
\hline & & & & & & 15 & 6.11 & 6.54 & 6.14 & 6.45 & 6.05 \\
\hline & & & & & & $\mathrm{OCH}_{3}-4$ & 3.34 & 3.45 & 3.47 & 3.45 & 3.50 \\
\hline
\end{tabular}


Figure S61. Results of DP4+ analysis of 1.

\begin{tabular}{|c|c|c|c|c|c|c|c|}
\hline \multicolumn{2}{|c|}{ Functional } & \multicolumn{2}{|c|}{ Solvent? } & \multicolumn{2}{|c|}{ Basis Set } & \multicolumn{2}{|c|}{ Type of Data } \\
\hline \multicolumn{2}{|c|}{ B3LYP } & \multicolumn{2}{|c|}{ PCM } & \multicolumn{2}{|c|}{$6-31+G(d, p)$} & \multicolumn{2}{|c|}{ Unscaled Shifts } \\
\hline & & DP4+ & $100.00 \%$ & $0.00 \%$ & $0.00 \%$ & Nn $0.00 \%$ & - \\
\hline Nuclei & $\mathrm{sp2?}$ & Experimental & Isomer 1 & Isomer 2 & Isomer 3 & Isomer 4 & Isomer 5 \\
\hline C & & 67.1 & 73.0 & 66.19 & 72.9 & 67.64 & \\
\hline $\mathrm{C}$ & & 28.9 & 30.4 & 32.99 & 30.4 & 31.74 & \\
\hline $\mathrm{C}$ & & 72.2 & 76.0 & 75.98 & 76.1 & 76.16 & \\
\hline $\mathrm{C}$ & & 28.1 & 32.6 & 32.47 & 33.7 & 33.24 & \\
\hline $\mathrm{C}$ & & 49.5 & 52.5 & 55.62 & 53.0 & 55.88 & \\
\hline $\mathrm{C}$ & & 64.2 & 66.8 & 69.55 & 67.8 & 67.65 & \\
\hline $\mathrm{C}$ & & 37.6 & 38.7 & 41.21 & 37.4 & 37.63 & \\
\hline $\mathrm{C}$ & & 93.5 & 96.0 & 98.39 & 96.4 & 97.99 & \\
\hline $\mathrm{C}$ & $x$ & 174.6 & 171.9 & 172.26 & 172.1 & 172.57 & \\
\hline $\mathrm{C}$ & & 42.2 & 45.7 & 46.98 & 46.7 & 46 & \\
\hline $\mathrm{C}$ & & 80.9 & 83.7 & 88.7 & 84.1 & 88.44 & \\
\hline $\mathrm{C}$ & $x$ & 126.9 & 128.26 & 126.95 & 131.17 & 130.34 & \\
\hline $\mathrm{C}$ & $x$ & 134.6 & 132.98 & 129.31 & 131.08 & 124.77 & \\
\hline $\mathrm{C}$ & & 56 & 56.51 & 56.79 & 56.44 & 56.68 & \\
\hline $\mathrm{H}$ & & 2.51 & 2.82 & 3.47 & 2.83 & 4.42 & \\
\hline $\mathrm{H}$ & & 2.12 & 2.21 & 2.36 & 2.38 & 2.49 & \\
\hline $\mathrm{H}$ & & 1.77 & 1.96 & 1.8 & 1.33 & 1.78 & \\
\hline $\mathrm{H}$ & & 3.59 & 3.44 & 3.63 & 3.43 & 3.64 & \\
\hline $\mathrm{H}$ & & 2.07 & 1.99 & 2.04 & 1.94 & 1.98 & \\
\hline $\mathrm{H}$ & & 1.73 & 1.73 & 1.46 & 1.70 & 1.49 & \\
\hline $\mathrm{H}$ & & 3.22 & 3.12 & 3.27 & 3.12 & 3.29 & \\
\hline $\mathrm{H}$ & & 2.75 & 2.93 & 2.81 & 2.89 & 2.86 & \\
\hline $\mathrm{H}$ & & 4.43 & 4.21 & 4.34 & 4.53 & 4.53 & \\
\hline $\mathrm{H}$ & & 2.42 & 2.21 & 2.73 & 2.12 & 2.62 & \\
\hline $\mathrm{H}$ & & 1.88 & 1.86 & 1.48 & 1.98 & 1.81 & \\
\hline $\mathrm{H}$ & & 3.06 & 2.97 & 2.92 & 2.95 & 2.89 & \\
\hline $\mathrm{H}$ & & 2.76 & 2.58 & 2.8 & 2.66 & 2.77 & \\
\hline $\mathrm{H}$ & $x$ & 5.93 & 6.14 & 6.02 & 6.31 & 6.18 & \\
\hline $\mathrm{H}$ & $x$ & 6.11 & 6.54 & 6.14 & 6.45 & 6.05 & \\
\hline $\mathrm{H}$ & & 3.34 & 3.45 & 3.47 & 3.45 & 3.5 & \\
\hline
\end{tabular}


Table S2. Experimental (Exp.) and calculated (Cal.) ${ }^{1} \mathrm{H}$ and ${ }^{13} \mathrm{C}$ chemical shift values of 7 and its possible isomers $7 \mathbf{a}$ and $\mathbf{7 b}$ used for DP4+ analysis.

\begin{tabular}{|c|c|c|c|c|c|c|c|}
\hline \multirow{2}{*}{ Carbon } & \multirow{2}{*}{$\frac{\text { Exp. }}{7}$} & \multicolumn{2}{|c|}{ Cal. } & \multirow{2}{*}{ Proton } & \multirow{2}{*}{$\frac{\text { Exp. }}{7}$} & \multicolumn{2}{|c|}{ Cal. } \\
\hline & & $7 \mathbf{a}$ & $7 b$ & & & $7 a$ & $7 b$ \\
\hline 2 & 156.7 & 159.1 & 160.0 & 3 & 7.35 & 7.72 & 7.85 \\
\hline 3 & 121.1 & 118.3 & 117.7 & 4 & 7.72 & 8.00 & 8.02 \\
\hline 4 & 137.4 & 134.6 & 134.9 & 5 & 7.30 & 7.48 & 7.48 \\
\hline 5 & 124.1 & 120.6 & 120.5 & 6 & 8.57 & 8.76 & 8.77 \\
\hline 6 & 149.1 & 146.1 & 146.2 & 7 & 4.61 & 5.83 & 5.66 \\
\hline 7 & 66.9 & 71.7 & 72.2 & $8 a$ & 3.59 & 3.08 & 2.99 \\
\hline 8 & 43.3 & 47.9 & 49.0 & $8 b$ & 2.05 & 1.91 & 1.68 \\
\hline 9 & 88.0 & 90.3 & 90.3 & 12 & 6.02 & 5.77 & 5.72 \\
\hline 11 & 172.1 & 169.9 & 169.6 & 14 & 6.70 & 6.83 & 6.86 \\
\hline 12 & 112.9 & 107.7 & 107.5 & 15 & 6.25 & 6.80 & 6.90 \\
\hline 13 & 165.0 & 168.5 & 168.4 & & & & \\
\hline 14 & 121.0 & 118.4 & 118.6 & & & & \\
\hline 15 & 142.4 & 145.8 & 146.8 & & & & \\
\hline
\end{tabular}


Figure S62. Results of DP4+ analysis of 7.

\begin{tabular}{|c|c|c|c|c|c|c|c|}
\hline \multirow{2}{*}{\multicolumn{2}{|c|}{$\begin{array}{c}\text { Functional } \\
\text { B3LYP }\end{array}$}} & \multicolumn{2}{|c|}{ Solvent? } & \multicolumn{2}{|c|}{ Basis Set } & \multicolumn{2}{|c|}{ Type of Data } \\
\hline & & \multicolumn{2}{|c|}{ PCM } & \multicolumn{2}{|c|}{$6-31+G(d, p)$} & \multicolumn{2}{|c|}{ Unscaled Shifts } \\
\hline & & DP4+ & $100.00 \%$ & $0.00 \%$ & - & - & - \\
\hline Nuclei & sp2? & Experimental & Isomer 1 & Isomer 2 & Isomer 3 & Isomer 4 & Isomer 5 \\
\hline $\mathrm{C}$ & $x$ & 156.7 & 159.07 & 159.95 & & & \\
\hline C & $x$ & 121.1 & 118.31 & 117.65 & & & \\
\hline C & $x$ & 137.4 & 134.64 & 134.88 & & & \\
\hline C & $x$ & 124.1 & 120.64 & 120.45 & & & \\
\hline C & $\mathrm{x}$ & 149.1 & 146.08 & 146.18 & & & \\
\hline C & & 66.9 & 71.72 & 72.15 & & & \\
\hline C & & 43.3 & 47.92 & 48.99 & & & \\
\hline C & & 88 & 90.25 & 90.31 & & & \\
\hline C & $x$ & 172.1 & 169.86 & 169.63 & & & \\
\hline C & $x$ & 112.9 & 107.68 & 107.49 & & & \\
\hline C & $\mathrm{x}$ & 165 & 168.45 & 168.43 & & & \\
\hline C & $x$ & 121 & 118.44 & 118.6 & & & \\
\hline C & $\mathrm{x}$ & 142.4 & 145.76 & 146.76 & & & \\
\hline $\mathrm{H}$ & $\mathrm{x}$ & 7.35 & 7.72 & 7.85 & & & \\
\hline H & $\mathrm{x}$ & 7.72 & 8 & 8.02 & & & \\
\hline $\mathrm{H}$ & $\mathrm{x}$ & 7.3 & 7.48 & 7.48 & & & \\
\hline $\mathrm{H}$ & $x$ & 8.57 & 8.76 & 8.77 & & & \\
\hline $\mathrm{H}$ & & 4.61 & 5.83 & 5.66 & & & \\
\hline $\mathrm{H}$ & & 3.59 & 3.08 & 2.99 & & & \\
\hline $\mathrm{H}$ & & 2.05 & 1.91 & 1.68 & & & \\
\hline $\mathrm{H}$ & $x$ & 6.02 & 5.77 & 5.72 & & & \\
\hline $\mathrm{H}$ & $x$ & 6.7 & 6.83 & 6.86 & & & \\
\hline $\mathrm{H}$ & $x$ & 6.25 & 6.8 & 6.9 & & & \\
\hline
\end{tabular}


Table S3. Boltzmann populations of the identified conformers of $\mathbf{7 a}$ and $\mathbf{7 b} .^{a}$

\begin{tabular}{cccc}
\hline Conformer & Boltzmann population & Conformer & Boltzmann population \\
\hline 7a_1 & $31.9 \%$ & 7b_1 & $100.0 \%$ \\
7a_2 & $26.4 \%$ & & \\
7a_3 & $25.3 \%$ & & \\
7a_4 & $16.4 \%$ & & \\
\hline
\end{tabular}

${ }^{a}$ Conformers with population less than $5 \%$ were ignored for chemical shifts calculation. 